\title{
CELINA WIERZBICKA NEW FRACTIONATION TOOLS TARGETING ELUSIVE POST-TRANSLATIONAL MODIFICATIONS
}
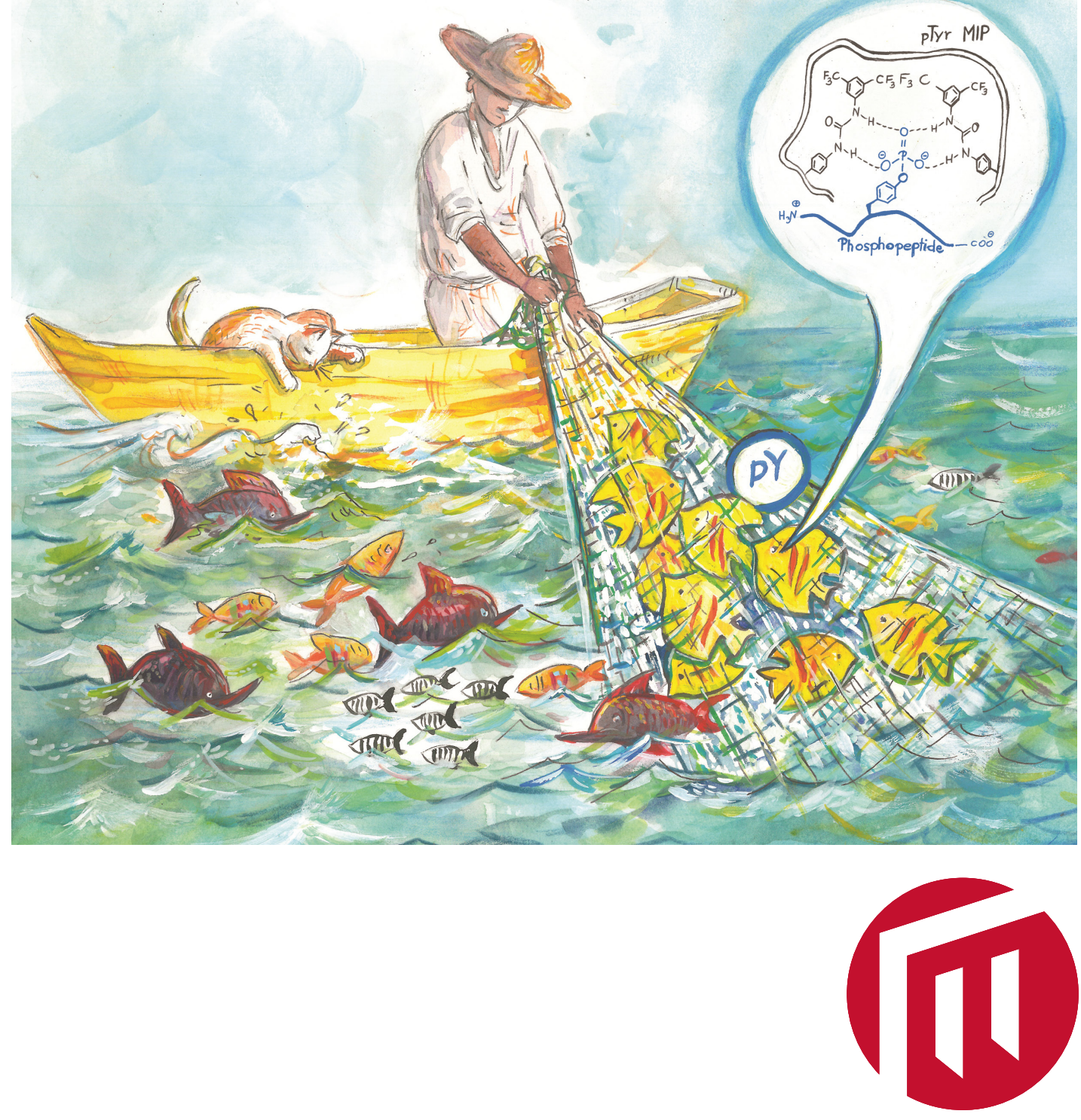

NEW FRACTIONATION TOOLS TARGETING ELUSIVE

POST-TRANSLATIONAL MODIFICATIONS 


\section{Malmö University}

Health and Society, Doctoral Dissertation 2017:3

(C) Copyright Celina Wierzbicka 2017

Front illustration: Fishing the phosphotyrosine peptides out of a peptide mixture by Katarzyna Czyżyńska-Gołos

ISBN 978-91-7104-728-1 (print)

ISBN 978-91-7104-729-8 (pdf)

ISSN 1653-5383

Holmbergs, Malmö 2017 


\section{CELINA WIERZBICKA}

NEW FRACTIONATION

TOOLS TARGETING ELUSIVE POST-TRANSLATIONAL MODIFICATIONS

Malmö University, 2017

Faculty of Health and Society Department of Biomedical Science 



\section{CONTENTS}

ABBREVIATIONS .................................................... 7

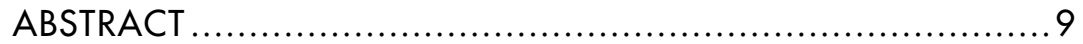

POPULÄRVETENSKAPLIG SAMMANFATTNING ................... 11

LIST OF PUBLICATIONS ......................................... 13

INTRODUCTION ..................................................... 15

Protein post-translational modifications ....................................... 15

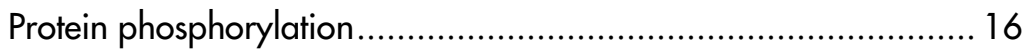

Protein histidine phosphorylation - an elusive PTM ..................... 17

The role of phosphorylation in disease pathogenesis.................... 19

Limitations in phosphoproteomic studies .................................... 20

Enrichment strategies for phosphoproteomics ............................. 21

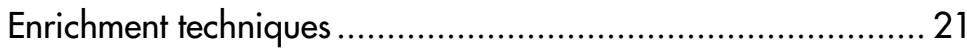

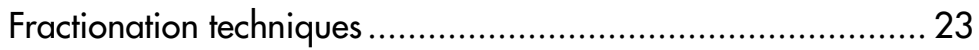

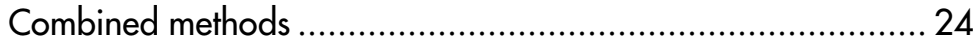

Molecularly imprinted polymers ............................................... 25

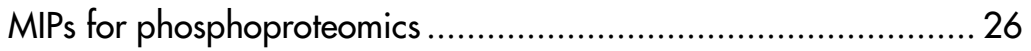

Urea-based functional monomers............................................... 28

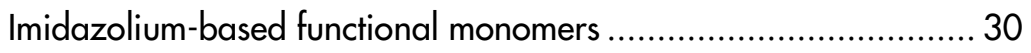

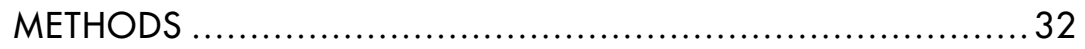

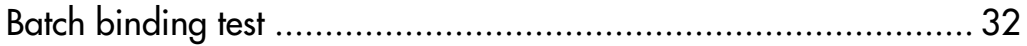

Molecularly imprinted solid phase extraction ................................ 35

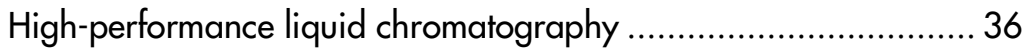

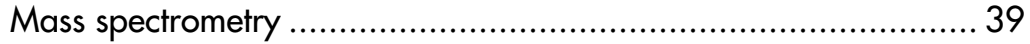

Nuclear magnetic resonance ................................................ 40

Thermogravimetric analysis ................................................... 43 
RESULTS AND DISCUSSION .................................. 44

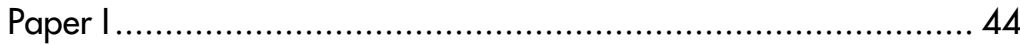

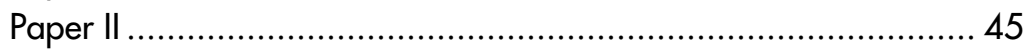

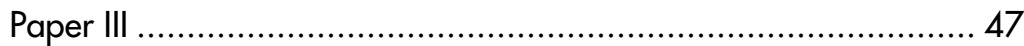

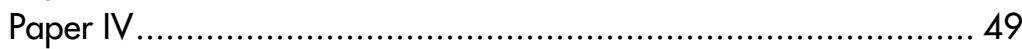

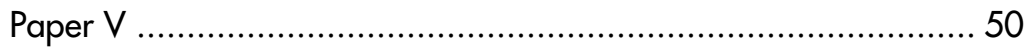

CONCLUDING REMARKS AND FUTURE OUTLOOK.............. 52

ACKNOWLEDGEMENTS ......................................... 54

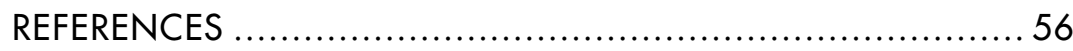

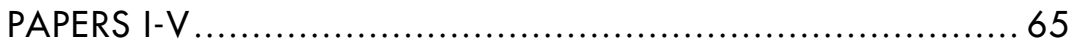




\section{ABBREVIATIONS}

$\begin{array}{ll}\text { ACN } & \text { Acetonitrile } \\ \text { BSA } & \text { Bovine serum albumin } \\ \text { Da } & \text { Dalton } \\ \text { ESI } & \text { Electrospray ionization } \\ \text { EDMA } & \text { Ethylene glycol dimethacrylate } \\ \text { HPLC } & \text { High-performance liquid chromatography } \\ \text { His } & \text { Histidine } \\ \text { IMAC } & \text { Immobilized metal affinity chromatography } \\ \text { LC-MS } & \text { Liquid chromatography-mass spectrometry } \\ \text { MeOH } & \text { Methanol } \\ \text { MS } & \text { Mass spectrometry } \\ \text { MALDI } & \text { Matrix assisted laser desorption/ionization } \\ \text { MOAC } & \text { Metal oxide affinity chromatography } \\ \text { MIP } & \text { Molecularly imprinted polymer } \\ \text { Fmoc } & \text { N-(9-fluorenylmethoxy)carbonyl } \\ \text { NIP } & \text { Non-imprinted polymer } \\ \text { PAC } & \text { Phosphoramidate chemistry } \\ \text { PETA } & \text { Pentaerythritol triacrylate } \\ \text { pHis } & \text { Phosphohistidine } \\ \text { pSer } & \text { Phosphoserine } \\ \text { pThr } & \text { Phosphothreonine } \\ \text { pTza } & \text { Phosphonotriazolylalanine } \\ \text { pTyr } & \text { Phosphotyrosine } \\ \text { PTM } & \text { Post-translational modification } \\ \text { SAX } & \text { Strong anion exchange } \\ \text { SCX } & \text { Strong cation exchange } \\ \text { Ser } & \text { Serine } \\ \text { Thr } & \text { Threonine } \\ \text { TEA } & \text { Triethylamine } \\ \text { TFA } & \text { Trifluoroacetic acid } \\ \text { Tyr } & \text { Tyrosine } \\ & \end{array}$





\section{ABSTRACT}

Protein phosphorylation is a reversible post-translational modification (PTM) playing a central role in numerous biological events including disease pathogenesis. Thus, the analysis of phosphoproteome is crucial for understanding cellular regulation processes and can facilitate the development of new diagnostic and therapeutic tools.

Phosphoproteins are typically analyzed using liquid chromatography coupled with mass spectrometry (LC-MS) after proteolytic processing. However, phosphopeptides are notoriously difficult to analyze by LC-MS due their low abundance and transient nature. This creates a need for effective enrichment tools for phosphorylated proteins and peptides prior to mass spectrometry analysis.

The work presented in this thesis is focused on development and validation of methods and tools for enrichment of phosphopeptides with the use of molecular imprinting technology. In particular, the targeted PTMs include phosphorylation on tyrosine (pTyr) and histidine (pHis).

The key recognition element employed in developed synthetic receptors was 1,3-diaryl urea functional monomer FM1. This monomer is a potent hydrogen bond donor forming strong cyclic hydrogen bonds with oxyanions such as phosphates. The bias of the imprinted urea-based receptor towards different phosphorylated residues can be programmed by selection of the template. Thus, the N, C-protected phosphotyrosine and phosphonotriazolylalanine were used as templates to generate phosphotyrosine (pTyr MIP) and phosphohistidine ( $\mathrm{pHis}$ MIP) selective molecularly imprinted polymers, respectively.

The application of previously reported pTyr MIP for phosphoproteomic studies was validated on complex biological samples of the mouse brain lysate digest spiked with standard peptides and HeLa cells digested proteins. Furthermore, the pTyr MIP was developed in the format of microspherical porous 
beads characterized by uniformly sized and shaped particles with increased surface area and pore size as well as improved binding affinity and selectivity for larger pTyr peptides $(2-3 \mathrm{kDa})$. This opens the way to generation of capture materials suitable for middle-down phosphoproteomics.

In response to the lack of adequate tools and methods for enrichment of acid-labile phosphohistidine peptides a $\mathrm{pHis}$ MIP-based approach is proposed as a solution. The method involving selective dephosphorylation of phosphoserine (pSer) peptide by alkali treatment of the sample, followed by extraction of base-stable pHis peptides with MIP was demonstrated on the sample of bovine serum albumin digest spiked with standard pSer and $\mathrm{pHis}$ peptides.

The last part of this thesis is focused on improving the recognition of phosphopeptides in aqueous media - the natural environment of biological samples. Guided by the principles of supramolecular chemistry, novel cationic host monomers were introduced for binding phosphates by ionic hydrogen bonds. These were used to synthesize MIPs showing enhanced binding of phosphopeptides in aqueous media. 


\section{POPULÄRVETENSKAPLIG SAMMANFATTNING}

Människokroppen är en komplex maskin baserad på tusentals biokemiska reaktioner varje sekund. En avgörande faktor för att säkerställa integriteten hos hela organismen är kommunikationen mellan enskilda celler. En av de metoder som används av levande organismer för detta ändamål är reversibel fosforylering av proteiner. Studien av kommunikationsvägar mellan celler är mycket viktigt för att förstå biologiska processer och sjukdomsförlopp.

Syftet med denna avhandling var att utveckla verktyg och metoder som underlättar studier av fosforylerade proteiner och peptider. Dagens analytiska metoder bygger på att proteinerna $\mathrm{i}$ ett biologiskt prov först bryts ned och att de resulterande peptiderna därefter anrikas följt av kvantitativ eller kvalitativ analys oftast med hjälp av mass spektrometri. Denna avhandling fokuserar på utveckling av syntetiska receptorer som kan diskriminera mellan fosforylerade och icke fosforylerade peptider. Dessa material framställdes med hjälp av molekylär imprinting teknik som gör det möjligt att skapa polymera material med en fördefinierad selektivitet för en speciell mål-molekyl eller molekyl-klass. Avtrycken görs genom polymerisering av syntetiska monomerer I närvaro av en mall (exempelvis en fosforylerad peptid eller dess fragment) vilken avlägsnas då polymeren har bildats. Detta ger upphov till hålrum med minne för mallen med avseende på dess form, storlek och funktionalitet. Likt en biologisk receptor kan polymeren därför känna igen molekyler som innehåller fragment med mallens struktur.

Detta enkla koncept användes för att generera syntetiska receptorer för molekylär igenkänning av peptider innenhållande fosforylerade tyrosin och histidin-rester vilka idag är svåra att analysera. Metoder för anrikning av fosfopeptider under användning av molekylärt präglade polymerer validerades med av- 
seende på existerande standardmetoder och enkla modelsystem samt på komplexa cell prov.

Fördelarna med materialen och metoderna som rapporteras i denna avhandling är först och främst att de i ett fall erbjuder en unik lösning (phosphohistidin) men generellt är fördelarna deras höga selektivitet kombinerat med hög stabilitet, reproducerbarhet, och enkla protokoll. Dessa erbjuder alltså både nya lösningar samt attraktiva alternativ till dagens etablerade anrikningstekniker. 


\section{LIST OF PUBLICATIONS}

I. Chen, J.; Shinde, S.; Subedi, P.; Wierzbicka, C.; Sellergren, B.; Helling, S.; Marcus, K. Validation of molecularly imprinted polymers for side chain selective phosphopeptide enrichment. Journal of Chromatography A, 1471 (2016) 45-50.

II. Bllaci, L.; Torsetnes, S. B.; Wierzbicka, C.; Shinde, S.; Sellergren, B.; Rogowska-Wrzesinska, A.; Jensen, O. N. Phosphotyrosine biased enrichment of tryptic peptides from cancer cells exploiting combined $\mathrm{pY}$ MIP and $\mathrm{TiO}_{2}$ affinity. Manuscript.

III. Wierzbicka, C.; Torsetnes, S. B.; Jensen, O. N.; Shinde, S.; Sellergren, B. Hierarchically templated beads with tailored pore structure for phosphopeptide capture and phosphoproteomics. RSC Advances, Accepted (2017).

IV. Wierzbicka, C.; Gajoch, K.; Jensen, O. N.; Sellergren, B. Selective enrichment of histidine phosphorylated peptides combining $\beta$-elimination and MIP-based pHis capture. Submitted for publication.

V. Wierzbicka, C.; Liu, M.; Irgum, K.; Sellergren, B. Cationic pTyr/pSer imprinted polymers based on a bis-imidazolium host monomer: Phosphopeptide recognition in aqueous buffers demonstrated by $\mu$ liquid chromatography and monolithic columns. Journal of Materials Chemistry B, 5 (2017) 953-960.

\section{Contribution:}

Paper I. Synthesis of templates, functional monomers and polymers.

Paper II. Synthesis of templates, functional monomers and polymers. Participation in manuscript preparation. 
Paper III. Synthesis of all materials. Performance of experiments and characterizations (except SEM imaging, elemental analysis and nitrogen sorption), evaluation of data and writing the manuscript.

Paper IV. Synthesis of all materials. Performance of all experiments, evaluation of data and writing the manuscript.

Paper V. Synthesis of templates, functional monomers and polymers (except capillary monoliths). Performance of experiments (except characterization of capillary monoliths and micro-liquid chromatography), evaluation of data and writing the draft of the manuscript. 


\section{INTRODUCTION}

\section{Protein post-translational modifications}

Biosynthesis of proteins is a complex multistep process involving transcription of information encoded in DNA to mRNA followed by translation step, where amino acids are assembled to form proteins. Post-translational modifications (PTMs) occur on proteins after the translation is complete and are responsible for change of structure and functions of proteins. These covalent modifications, including phosphorylation, acetylation, methylation, glycosylation and ubiquitination (Table 1) regulate nearly all biological processes in living organisms. $^{1-3}$

Table 1. Common post-translational modifications.

\begin{tabular}{cc}
\hline PTM & Function (examples) \\
\hline Phosphorylation & $\begin{array}{c}\text { Cell proliferation and differentiation, } \\
\text { signal transduction }\end{array}$ \\
Acetylation & Protein stability \\
Methylation & $\begin{array}{c}\text { Regulates protein-protein } \\
\text { and protein-nucleic acid interactions }\end{array}$ \\
Glycosylation & $\begin{array}{c}\text { Protein-ligand interactions, protein folding } \\
\text { and conformation }\end{array}$ \\
\hline Ubiquitination & Protein degradation \\
\hline
\end{tabular}

For example, reversible phosphorylation of proteins acts as a function on/off switch. Acetylation of lysine residues in histone is linked to transcription regulation. ${ }^{4}$ There is also a link between acetylation and cellular metabolism. ${ }^{5,6}$ Protein methylation is known to be involved in cellular stress responses ${ }^{7}$ and 
protein aging and repair. ${ }^{8}$ Glycosylation is an essential modification involved in fundamental processes such as inflammation, immune response, cell growth or protein folding and stability, just to name a few. ${ }^{9,10}$ Proteolytic destruction of proteins, on the other hand, is initiated by protein modification with ubiquitin (ubiquitination). ${ }^{11}$ The analysis of PTMs is therefore essential for understanding fundamental biological functions.

\section{Protein phosphorylation}

Phosphorylation is one of the most widely studied PTMs affecting basic biological processes such as cell growth, proliferation, differentiation, and apoptosis as well as cellular signal transduction. ${ }^{12}$ It can occur on nine amino acids, i.e. serine, threonine, tyrosine, histidine, lysine, arginine, aspartic acid, glutamic acid, and cysteine. However, the phosphorylation of the former three amino acids capture most attention in phosphoproteomics research (Figure 1).<smiles>NC(COP(=O)(O)O)C(=O)O</smiles>

phosphoserine (pSer)<smiles>CC(OP(=O)(O)O)C(N)C(=O)O</smiles>

phosphothreonine (pThr)<smiles>NC(Cc1ccc(OP(=O)(O)O)cc1)C(=O)O</smiles>

phosphotyrosine (pTyr)

Figure 1. Structures of phosphoserine, phosphothreonine and phosphotyrosine.

This reversible modification is tightly regulated by the action of protein kinases and phosphatases being responsible for phosphorylation and dephosphorylation, respectively. Protein kinases catalyze the transfer of the $\gamma$ phosphate from adenosine triphosphate (ATP) to the specific residues in proteins (Figure 2). ${ }^{12}$ Protein phosphatases, on the other hand, remove the phosphate group by enzymatic hydrolysis.

It is estimated that approximately $30 \%$ of proteins in eukaryotic organisms are phosphorylated at any time. ${ }^{13}$ In human, there are about 500 kinases and 100 phosphatases coded by ca. $2 \%$ of human genome. ${ }^{14}$ In eukaryotic organisms phosphorylation occurs predominantly on Ser, Thr and Tyr residues with 
the ratio of 1800:200:1 (pSer:pThr:pTyr). ${ }^{15}$ Nevertheless, phosphorylation on histidine can also occur although it often remains undetected due to its acidlabile nature.

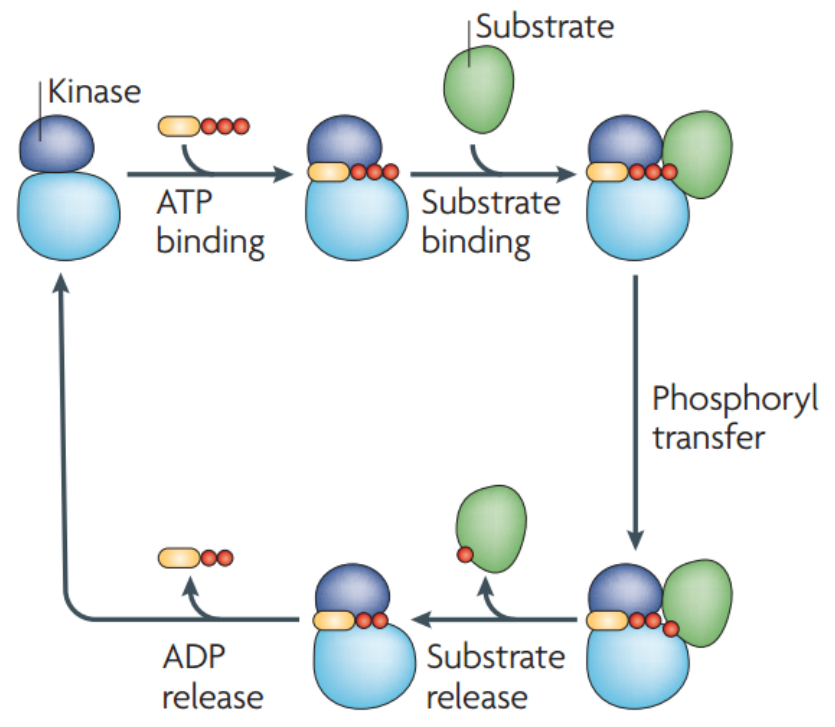

Figure 2. Protein phosphorylation cycle catalyzed by a kinase. Reproduced from Ubersax and Ferrell ${ }^{12}$ with permission from Nature Publishing Group.

In recent years, however, an increasing interest in analysis of this elusive phosphorylation has been observed resulting in development of techniques for enrichment, detection and analysis of pHis peptides. ${ }^{16-20}$

\section{Protein histidine phosphorylation - an elusive PTM}

Phosphorylation of histidine is well known to be involved in two component signaling pathways in prokaryotes and lower eukaryotes ${ }^{21-23}$ and it is now becoming recognized in mammals and implicated in certain human disease states. ${ }^{24-27}$ It has been estimated that histidine phosphorylation in eukaryotes accounts for $6 \%$ of total protein phosphorylation, ${ }^{28}$ thus it is significantly more abundant than pTyr modification. Nonetheless, little is known about the biological role of pHis as compared to phosphoester modifications. This is due to significant technical challenges in enrichment and detection of this PTM.

There are three possible isomers of phosphohistidine (pHis), i.e. $\pi$-pHis, $\tau$-pHis and $\pi, \tau$-pHis (Figure 3 ) of which the former two have been found in 
vivo. ${ }^{16}$ Unlike the phosphoesters (pSer, pThr, pTyr), the phosphoryl group of $\mathrm{pHis}$ is attached to nitrogen atom making it a phosphoramidate. This high energy phosphoramidate bond is susceptible to hydrolysis in acidic environment and it defines unique stability profile of phosphohistidine. ${ }^{29,30}$<smiles>NC(Cc1cncn1P(=O)(O)O)C(=O)O</smiles>

$\pi$-phosphohistidine $(\pi-\mathrm{pHis})$<smiles>NC(Cc1cn(P(=O)(O)O)cn1)C(=O)O</smiles>

$\tau$-phosphohistidine ( $\tau$-pHis)<smiles></smiles>

$\pi, \tau$-diphosphohistidine $(\pi, \tau-\mathrm{pHis})$

Figure 3. Structures of $\pi$-phosphohistidine, $\tau$-phosphohistidine and $\pi, \tau$ diphosphohistidine.

While O-phosphorylated amino acids, pSer and pThr, are stable in acidic media and labile in alkali environment, the phosphoramidates display reversed stability profile, i.e. they are base-stable and acid-labile. Most of the methods used in the phosphopeptide enrichment and detection involve acidic treatment, and thus fail to preserve pHis modification. Therefore, dedicated methods and tools are needed to study this PTM.

To date, several methods for detection and analysis of $\mathrm{pHis}$ have been reported. ${ }^{17,29,30}$ Generation of synthetic pHis proteins and peptides has clearly facilitated the development of such methods. Medzihradszky et al. ${ }^{31}$ used potassium phosphoramidate to synthesize histidine phosphorylated peptides. This method is highly selective for histidine and does not phosphorylate any other residues. The complex kinetics of the reaction prove that initially $\pi$-pHis is formed followed by $\pi, \tau$-pHis and $\tau$-pHis. Long reaction times $(>12 \mathrm{~h})$ result in the disappearance of $\pi$-pHis yielding only the latter two isomers. ${ }^{32}$ This method was also successfully used for phosphorylation of proteins. ${ }^{17,18,33}$

Although chemical phosphorylation gives access to $\mathrm{pHis}$ protein and peptide standards, it does not solve the problems related to high acid lability of this modification. For example, attempts to use pHis-based immunogens to produce antibodies failed due to facile dephosphorylation of $\mathrm{pHis}^{34,35}$ To overcome these issues, several stable analogues of pHis have been developed such as phosphonofurylalanine (1), ${ }^{36}$ phosphonopyrrolylalanine $(2)^{29}$ and phsosphonotriazolylalanine $(3,4)^{34,37,38}$ based analogues (Figure 4). 


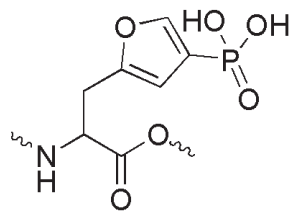

1

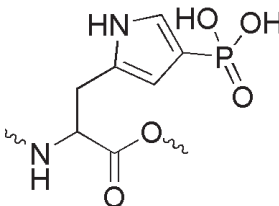

2

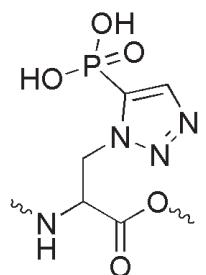

3<smiles>COC(=O)C(CN)Cn1cc(P(=O)(O)O)nn1</smiles>

4

Figure 4. Examples of stable phosphohistidine analogues.

Kee et al..$^{34}$ successfully incorporated analog 3 in human histone $\mathrm{H} 4$ peptide sequence by solid-phase peptide synthesis (SPPS). This peptide was next used as an antigen to raise sequence specific antibody that could recognize histidine phosphorylated histone $\mathrm{H} 4$ but not the unmodified protein. After this first report on successful generation of pHis antibodies, the phosphoryltriazolylbased analogues were used to produce pan-specific polyclonal $\mathrm{pHis}$ antibody ${ }^{39}$ and monoclonal 1- and 3-pHis antibodies. ${ }^{40}$

Despite a remarkable progress in analysis of $\mathrm{pHis}$ in recent years, this area of phosphoproteomics research is still in its infancy, especially in higher eukaryotes. Without a doubt, development of new mild enrichment techniques and advances in mass spectrometry analysis will have significant impact on elucidation of the biological role of pHis.

\section{The role of phosphorylation in disease pathogenesis}

Phosphorylation is responsible for regulation of many important processes such as cell proliferation, differentiation and apoptosis and plays a vital role in signal transduction. Disruptions in signaling pathways, regulated by kinases and phosphatases, are often recognized as a cause or a consequence of various diseases, including cancer, ${ }^{41-43}$ neurodegenerative diseases, ${ }^{44-46}$ cardiovascular diseases, ${ }^{47,48}$ inflammatory diseases, ${ }^{49,50}$ and diabetes. ${ }^{51}$ This has led to an increasing effort to identify kinases and phosphorylated proteins that could serve as disease biomarkers or drug targets, especially in cancer.

More than 1200 proteins have been reported to be differentially expressed in human cancer, ${ }^{52}$ of which many belong to kinase family. These proteins are potential candidates for cancer biomarkers, however, due to technical limita- 
tions in proteomic analysis of low abundant proteins as well as rigorous requirements for marker validation, only a limited number of these proteins has been approved by the US Food and Drug Administration (FDA) for clinical use. In fact, only three kinases were approved so far as cancer biomarkers, i.e. epidermal growth factor receptor for selection of therapy for colon cancer, KIT for diagnosis and selection of therapy of gastrointestinal stromal tumor and Her2 for prognosis, monitoring and selection of therapy for breast cancer. $^{41,53}$

Kinases involved in cancer development can also serve as drug targets. In targeted cancer therapy two main approaches for kinase inhibition have emerged, i.e. based on monoclonal antibodies and small-molecule agents. ${ }^{54}$ The prominent examples of trastuzumab (Herceptin ${ }^{\circledR}$, Genentech) and imatinib (Gleevec $\AA$, Novartis) being the first FDA approved monoclonal antibody (1998) and small-molecule (2001) kinase inhibitors, respectively, paved the way for a new era of targeted cancer therapy. As many as 28 smallmolecule kinase inhibitors have been approved by FDA by June $2015 .^{55,56}$ The fact that 19 of these drugs were approved since 2011, indicates a huge potential of such therapeutic approach.

\section{Limitations in phosphoproteomic studies}

It is evident that advances in phosphoproteomics had an enormous impact on the identification of novel disease biomarkers and drug targets. For a complete understanding of signaling pathways and its role in disease pathogenesis a comprehensive analysis of phosphoproteome is needed. This includes the identification of phosphoproteins and phosphopeptides, localization of the phosphorylation sites as well as quantitation of phosphorylation. ${ }^{13}$ Despite a tremendous advancement in MS-based techniques in recent years, the analysis of phosphoproteins and phosphopeptides is not a trivial task. Main challenges arise from low stoichiometry of phosphorylation, its transient nature and low abundance of signaling molecules. These issues are particularly evident when it comes to analysis of tyrosine phosphorylation. For example, in vertebrate cells, the tyrosine phosphorylation accounts for $0.05 \%$ of total protein phosphorylation. ${ }^{57}$ Furthermore, the ionization of phosphopeptides in MS is often suppressed in presence of nonmodified peptides. ${ }^{13}$ For these reasons, it is a common practice to implement enrichment and/or fractionation steps prior to MS analysis. 


\section{Enrichment strategies for phosphoproteomics}

Over the past years, many techniques to concentrate phosphoproteins and phosphopeptides from complex biological samples have been developed. ${ }^{58-60}$ Overall, these methods can be classified into two categories, i.e. more specific enrichment techniques (e.g. immunoaffinity-based methods, chemical derivatization and affinity chromatography, see Figure 5) and less specific fractionation techniques (HILIC, SAX, SCX). In a comprehensive phosphoproteomic studies enrichment and fractionation methods are often combined for better coverage of phosphoproteome.

\section{Enrichment techniques}

Immunoaffinity-based methods rely on selective capture of phosphoproteins by specific antibodies against phosphorylated serine, threonine and tyrosine residues. ${ }^{61-63}$ In general, however, antibodies raised against $\mathrm{pSer}$ and $\mathrm{pThr}$ suffer from limited selectivity and therefore are not routinely used in phosphoproteomic studies. ${ }^{64}$ Anti-phosphotyrosine antibodies, on the other hand, display high selectivity and are extensively used in the analysis of this low abundant modification at the level of both phosphoproteins ${ }^{65-67}$ and phosphopeptides. ${ }^{68-72}$ Nevertheless, the immunoaffinity-based methods suffer from a number of drawbacks. For example, typically a large amount of protein sample (in mg scale) is required. ${ }^{73}$ Furthermore, the high price of antibodies characterized by low stability and non-reusability along with laborious protocols call for more cost- and time-efficient alternative methods.

Immobilized metal affinity chromatography (IMAC) is based on interactions of negatively charged phosphopeptides with positively charged metal ions $\left(\mathrm{Fe}^{3+}, \mathrm{Al}^{3+}, \mathrm{Ga}^{3+}, \mathrm{Co}^{2+}, \mathrm{Zr}^{4+}\right.$ and $\left.\mathrm{Ti}^{4+}\right)$ chelated to nitrilotriacetic acid or iminodiacetic acid coated beads. This method is applicable for efficient extraction of pSer, pThr and pTyr proteins ${ }^{74}$ and peptides. ${ }^{75-77}$ However, this technique suffers from significant non-specific binding of nonphosphorylated peptides bearing acidic residues. O-methyl esterification of carboxylic side chains was reported to significantly reduce this effect, $^{78}$ nevertheless, this derivatization method is not quantitative, thus it results in an increase of sample complexity. ${ }^{79}$ Alternatively, loading the sample at low $\mathrm{pH}(50 \% \mathrm{ACN}$ $0.1 \%$ TFA) on IMAC resin proved to reduce non-specific binding due to protonation of carboxyl groups of peptides. ${ }^{80}$ Recently Zhou et al. ${ }^{81,}{ }^{82}$ reported novel $\mathrm{Ti}^{4+}$-IMAC resin showing superior selectivity and efficiency compared to $\mathrm{Fe}^{3+}$-IMAC, $\mathrm{Zr}^{4+}$-IMAC, $\mathrm{TiO}_{2}$ and $\mathrm{ZrO}_{2}$ in both semi-complex mixture of 
tryptic peptides as well as digest of mouse liver lysate. The $\mathrm{Cu}^{2+}$-IMAC, on the other hand, was applied for extraction of pHis peptide from histidine phosphorylated protein digest. ${ }^{83}$

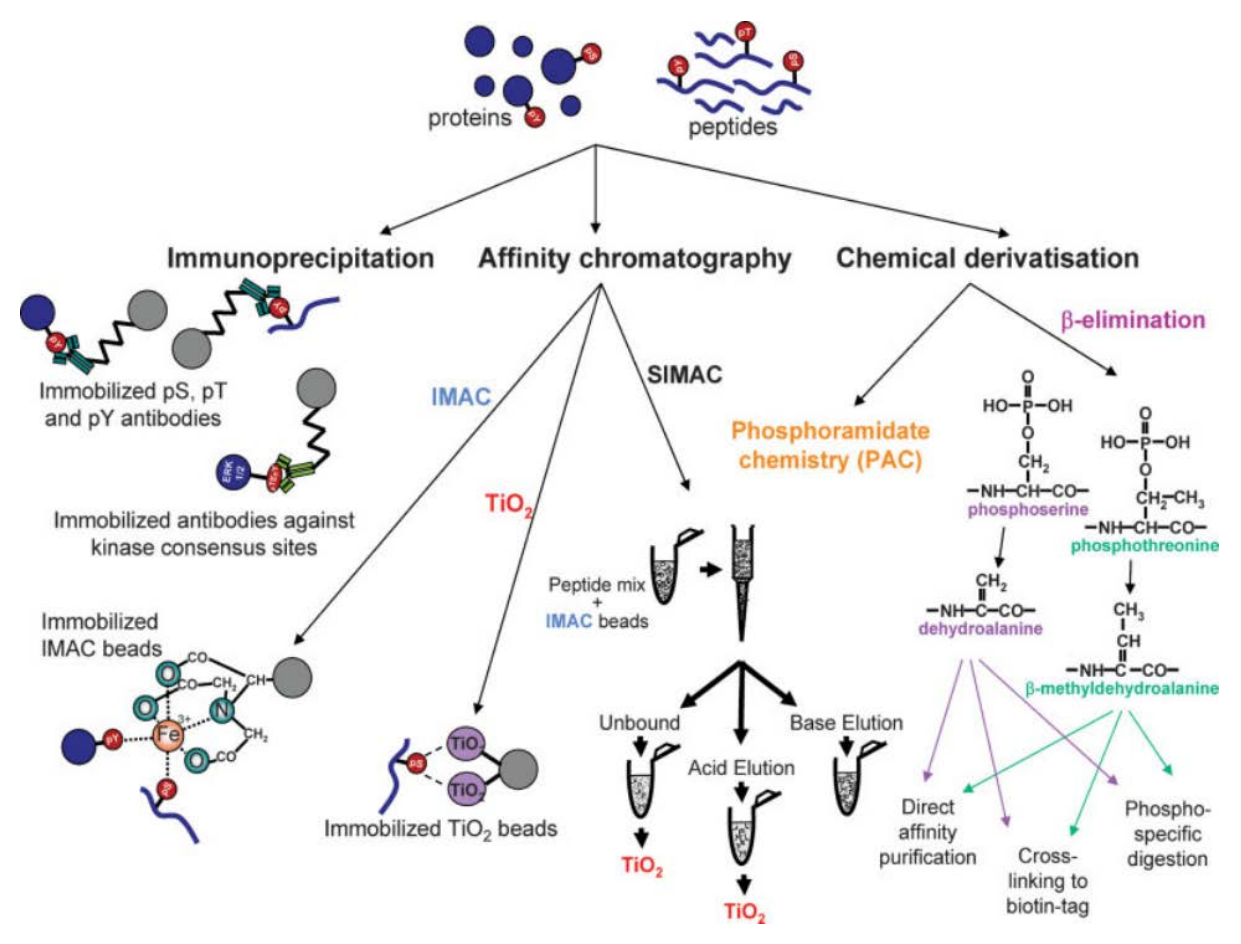

Figure 5. Analytical strategies for phosphoprotein and phosphopeptide enrichment. Reproduced from Thingholm et al. ${ }^{58}$ with permission from John Wiley and Sons.

Metal oxide affinity chromatography (MOAC) is another technique for extraction of phosphopeptides. Although a number of different metal oxides, including zirconium, aluminum, iron, and tin were applied for phosphopeptide enrichment ${ }^{84}$ the titanium dioxide $\left(\mathrm{TiO}_{2}\right)$ is most widely used. ${ }^{85,86}$ The nature of metal oxide and phosphate group interaction is characterized by Lewis ac$\mathrm{id} /$ base interaction with bidentate mode ${ }^{84,87}$ meaning that phosphopeptides are well retained in acidic conditions. Thus, typically loading of the sample is performed at $\mathrm{pH}$ 2-3 while elution occurs in strongly alkaline conditions. In general, $\mathrm{TiO}_{2}$ enrichment is considered to be more specific for binding of phosphopeptides compared to IMAC, ${ }^{60}$ although it is not free from unspecific 
binding of nonphosphorylated peptides. This issue was however largely diminished by optimization of the protocol, e.g. by using additives in the loading step such as 2,5-dihydroxybenzoic acid, ${ }^{86}$ lactic acid, ${ }^{88}$ glycerol ${ }^{89}$ or glycolic ac$\mathrm{id}^{90}$ that compete with nonphosphorylated peptides for binding to low affinity sites. The $\mathrm{TiO}_{2}$-based phosphopeptide enrichment has been employed in several large scale phosphoproteomic studies. ${ }^{91-94}$

Chemical derivatization methods are based on exploiting unique properties of phosphorylated residues that can be selectively modified prior to enrichment step. For example, pSer and pThr undergo facile dephosphorylation via $\beta$-elimination in alkali conditions resulting in dehydroalanine and $\beta$ methyldehdroalanine residues, respectively. A subsequent Michael addition reaction with ethanedithiol allows for modification with biotin tag and consequent enrichment with immobilized avidin ${ }^{95}$ or direct affinity purification on activated thiol resin. ${ }^{96}$ These methods are however specific only for enrichment of pSer and pThr since pTyr does not undergo $\beta$-elimination. Additionally, a co-elution of $O$-glycosylated proteins/peptides, that are susceptible to $\beta$ elimination, can occur. Another method, applicable for enrichment of pSer, pThr and pTyr peptides is based on phosphoramidate chemistry (PAC). ${ }^{97}$ Phosphopeptides are immobilized on a solid support in a multistep process via phosphoramidate bond and subsequently isolated by hydrolysis in acidic media. In general, chemical derivatization methods are not routinely used in phosphoproteomic studies due to laborious protocols and non-quantitative character of reactions that leads to increase of sample complexity.

\section{Fractionation techniques}

Fractionation techniques are usually employed in a form of column liquid chromatography allowing for a gradual separation of a sample based on properties such as charge or hydrophilicity. These methods are not as efficient and specific as enrichment techniques, nevertheless, they are often employed in phosphoproteomics workflows, especially in combination with enrichment techniques.

Ion exchange chromatography allows to separate phosphopeptides from nonphosphorylated peptides due to their different charge states. In strong cation exchange (SCX) negatively charged phosphopeptides interact poorly with anionic stationary phase and therefore elute early from the column. This contrasts with the strong anion exchange (SAX) where phosphopeptides are strongly retained on the cationic stationary phase. ${ }^{98}$ However, the separation is not always straightforward since the charge state of peptides is affected by the 
number of present acidic and basic residues in the sequence. Both SCX and SAX have been used for prefractionation of phosphopeptides prior to enrichment, e.g. with IMAC or $\mathrm{TiO}_{2}$.

In hydrophilic interaction chromatography (HILIC) the neutral hydrophilic stationary phase is used. ${ }^{101}$ Typically the elution is performed in the acetonitrile-water system starting with high organic mobile phase. Thus, peptides are separated according to their hydrophilicity/hydrophobicity with more polar peptides (for example phosphopeptides) eluting later. HILIC was shown to be an efficient prefractionation method prior to specific phosphopeptide enrichment. ${ }^{102}$

\section{Combined methods}

Due to partial complementarity of described methods, it is a common practice to combine two or more techniques in a multidimensional enrichment workflow. Typically, a prefractionation method (e.g. SCX, SAX, HILIC) is applied before specific enrichment step (e.g. IMAC or MOAC) although combination in reverse order has also been reported. ${ }^{103}$ In another approach, the so-called SIMAC (sequential elution from IMAC), ${ }^{104}$ the multi-phosphorylated peptides are bound to IMAC resin while the unbound fraction containing monophosphorylated peptides is loaded on the $\mathrm{TiO}_{2}$. Thus, the elution fractions from IMAC and $\mathrm{TiO}_{2}$ are enriched with multi- and mono-phosphorylated peptides, respectively.

Overall, each of the enrichment and fractionation methods has advantages and limitations and none of these techniques can provide full coverage of phosphoproteome. Due to significant differences in reported protocols such as sample type and amount, instrument setup, data processing, etc. it is very difficult to make a direct comparison of available enrichment methods. Bodenmiller et al. ${ }^{105}$ made an attempt to compare and assess reproducibility and specificity of commonly used methods, i.e. $\mathrm{Fe}^{3+}$-IMAC, $\mathrm{PAC}$ ad $\mathrm{TiO}_{2}$ using tryptic digest of the cytosolic fraction of Drosophila melanogaster Kc167 cells. It was shown that all the investigated methods are highly reproducible, however, IMAC and PAC gave the best result allowing for identification of $>500$ phosphopeptides and insignificant contamination with nonphosphorylated peptides (9 and 34, respectively). Importantly, the overlap of identified phosphopeptides was only $33-35 \%$ indicating differences in selectivity of investigated methods. This confirms that a combination of several methods can increase the coverage of studied phosphoproteome. 


\section{Molecularly imprinted polymers}

Molecular imprinting is an attractive approach to form synthetic materials with molecular recognition properties. ${ }^{106-108}$ This technique is based on copolymerization of functional monomer(s) and crosslinker in presence of a template, which is removed subsequently. Thus, a molecularly imprinted polymer (MIP) possess cavities that are complementary in size, shape and functionality to the template allowing for selective rebinding of the template and its close analogues (Figure 6). This simple concept is applicable to a variety of target molecules ranging from ions and small molecules to macromolecules (e.g. proteins) and microorganisms. Likewise, many different approaches to form strong interactions between template and functional monomer(s) are available, e.g. covalent and noncovalent interactions as well as ligand exchange (Figure 6).

As a result, the molecular imprinting technology (MIT) has found a number of applications including purification and separation, ${ }^{109,}{ }^{110}$ sensing ${ }^{111,112}$ and drug delivery ${ }^{113}$ owing to unique recognition properties of MIPs characterized by high affinity and specificity for target molecule. ${ }^{114}$ Furthermore, MIPs are robust materials with high stability in a wide range of temperature and solvents. The low cost of production and possibility of multiple reuse of the material are additional attractive features of MIPs.

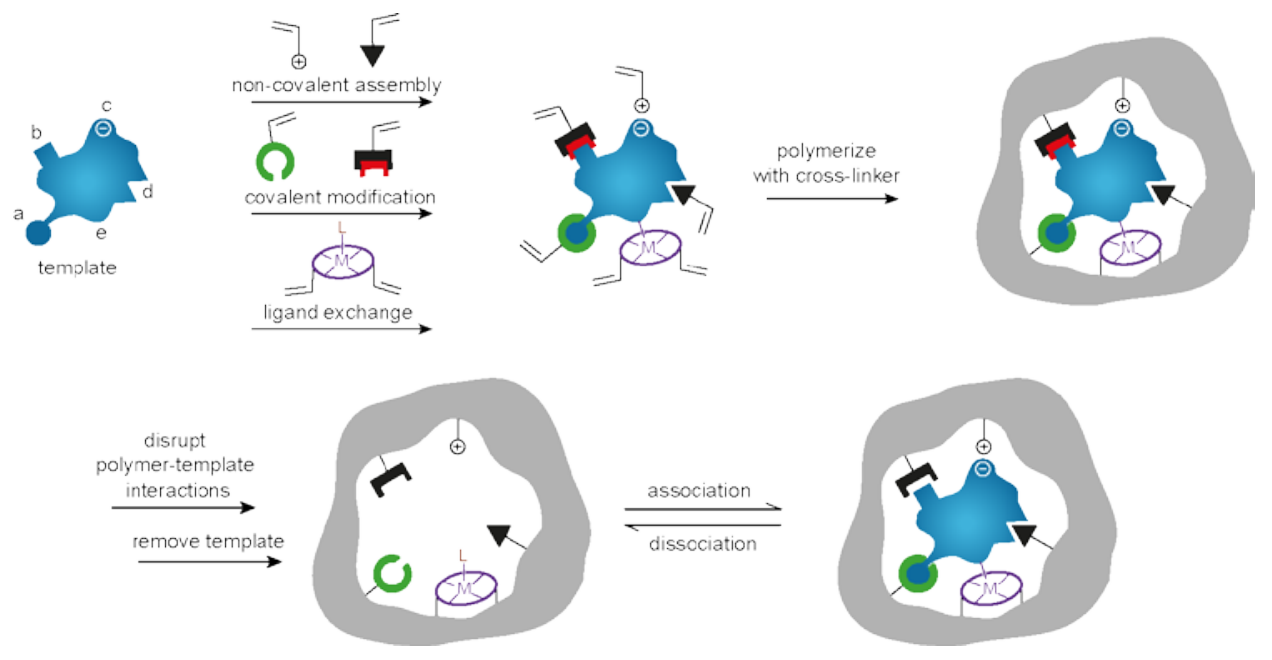

Figure 6. Schematic representation of the molecular imprinting process showing possible interactions between template and functional monomer, including covalent and non-covalent interactions as well as ligand exchange. Reproduced from Alexander et al. ${ }^{115}$ with permission from John Wiley and Sons. 
Nevertheless, the molecular imprinting technology is not free from limitations. Most commonly used non-covalent imprinting approach ${ }^{116}$ suffers from a number of technical challenges owing to the non-covalent nature of interactions between template and functional monomer(s), e.g. hydrogen bonding, van der Waals interactions or hydrophobic interactions. The dynamic nature of prepolymerization self-assembled complex being in equilibrium with free monomers and template leads to formation of heterogeneous binding sites with different affinity for the target analyte. An excess of functional monomer can be used to shift the equilibrium towards monomer-template complex, however, the polymerization of remaining free functional monomer often leads to high degree of non-specific binding. Instead, a stoichiometric imprinting can be used. ${ }^{117,118}$ In this approach the functional monomer interacts very strongly with the template providing a high degree of template complexation, thus it can be used in stoichiometric ratio resulting in more uniform binding sites and low non-specific binding.

Another commonly postulated difficulty in MIT is the imprinting of water soluble biological macromolecules, for example proteins. ${ }^{119,}{ }^{120}$ This is due to large size and complexity of such targets resulting in slow mass transfer to the binding site. Two main approaches to overcome these difficulties were developed, namely epitope imprinting and surface imprinting. The epitope imprinting approach is based on using a small fragment of protein or peptide as a template. ${ }^{121,122}$ The binding sites formed in this way are able to recognize not only template but also larger molecules bearing the imprinted fragment. In the surface imprinting approach, the immobilization of template on the supporting material (e.g. silica micro- and nanoparticles, magnetic nanoparticles or nanowires/nanotubes) enables creation of imprinted sites on the surface of the polymer. ${ }^{123,124}$ As a result the highly accessible binding sites located on the surface of the imprinted material are formed.

\section{MIPs for phosphoproteomics}

Several approaches to develop phosphopeptide selective molecularly imprinted polymers have been reported to date. ${ }^{125-133}$ The first attempt to apply molecular imprinting technology for phosphoproteomics was reported by Sellergren et al. ${ }^{125}$ The neutral urea-based receptor was synthesized using $\mathrm{N}$, C-protected phosphotyrosine as a template and ethylene glycol dimethacrylate (EDMA) as a crosslinker. This crushed monolith material 
showed bias for pTyr peptides in presence of pSer and Tyr peptides. Further optimization and validation of this system resulted in successful extraction of pTyr peptide spiked at a femtomol level in bovine fetuin digest. ${ }^{131}$ Later on, Chen et al. ${ }^{132}$ showed a complementary selectivity of pTyr and pSer imprinted polymers in a mixture of twelve peptides and incorporation of pSer MIP enrichment in combination with SCX in proteomics workflow. The MIP-based method showed superior performance compared to $\mathrm{TiO}_{2}$-based enrichment. Recently, the pTyr MIP-based phosphopeptide enrichment was validated in a comparative study with state of the art phosphopeptide enrichment techniques, i.e. immunoaffinity- and $\mathrm{TiO}_{2}$-based enrichments (Paper I). It was shown that pTyr MIP is an attractive alternative for established phosphoenrichment methods allowing for a controlled bias of material towards specific phosphorylation site.

In another approach, the monodisperse 4-vinylpyridine-based MIPs targeting organophosphates were shown to non-selectively trap phosphorylated peptides (pSer, pThr, pTyr) and phosphopeptides from a tryptic digest of $\alpha$ casein. ${ }^{126}$ Ren et al. ${ }^{127,}{ }^{128}$ have used charged metal ion-based functional monomers $\left(\mathrm{Zn}^{2+}\right.$ and $\left.\mathrm{Ti}^{4+}\right)$ for imprinting of phenylphosphonic acid (PPA) as an epitope template. Obtained materials displayed the affinity for phosphorylated peptides in aqueous solution with a preference for tyrosine phosphorylated peptides as contrasted with unbiased enrichment with $\mathrm{TiO}_{2}$.

Surface imprinting approach has also been employed for development of phosphopeptide selective MIPs. ${ }^{130,133}$ For example, Li et al. ${ }^{133}$ reported on surface imprinted fluorescent receptor based on CdTe quantum dots. The receptor gave linear fluorescence enhancement response to pTyr peptide which could also be detected in a spiked sample of tryptic digest of skim milk. However, the concentration of pTyr peptide tested in this work was in $\mu \mathrm{M}$ range which is well above the range found in biological samples. Recently Chen et al. ${ }^{130}$ reported on phosphate imprinted mesoporous silica nanoparticles using dual-template docking oriented molecular imprinting approach. Obtained imprinted nanoparticles displayed an excellent affinity for template analogue, i.e. adenosine monophosphate (AMP) and were able to extract pSer peptides from $\beta$-casein digest as well as from nonfat milk sample. However, the affinity for peptides phosphorylated on Thr and Tyr residues was not studied. 


\section{Urea-based functional monomers}

The core of this thesis relies on the use of urea-based functional monomer FM1 (Figure 8A) as a recognition unit in MIPs targeting phosphorylated peptides reported in Papers I-IV.

1,3-Disubsituted ureas have long been exploited as neutral receptors for anions such as carboxylates, phosphates and sulfonates. ${ }^{134-136}$ This type of hosts are potent hydrogen bond donors capable of forming two-fold cyclic hydrogen bonds with anion guest (Figure 7). The strength of interaction increases with the acidity of urea protons and basicity of complexed anion. Thiourea is more acidic than urea $\left(\mathrm{pK}_{\mathrm{a}}=21.1\right.$ and 26.9 , respectively in DMSO), ${ }^{136}$ thus thioureas should form stronger hydrogen bonds with guest compared to ureas. ${ }^{137}$

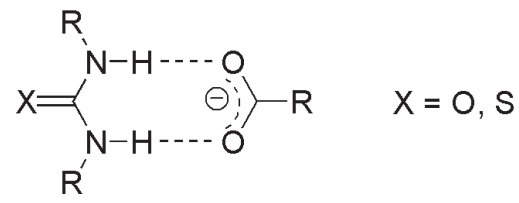

Figure 7. Schematic representation of the interaction between urea $(X=O)$ or thiourea $(\mathrm{X}=\mathrm{S})$ receptors and carboxylate anion.

Another factor influencing the strength of interaction is the type of solvent in which the recognition occurs. Neutral receptors such as ureas and thioureas, which rely solely on hydrogen bond interactions are highly susceptible to competition with polar protic solvents for anion binding. Thus, this type of receptors are most effective in aprotic organic solvents. ${ }^{138}$

Functional monomers FM1-FM4 (Figure 8A) were evaluated by NMR titration experiments with tetrabutylammonium hydrogen-1-naphtyl phosphate (TBAHNP) guest in DMSO-d6 (Figure 8B). The data points obtained for each monomer were fitted to $1: 1$ interaction model to determine values of association constant $\left(K_{a}\right)$ and maximum complexation induced shift $\left(C I S_{\max }\right)$ (Table 2).

The 1,3-diaryl monomers (FM1 and FM2) interacted more strongly with guest compared to alkyl-aryl counterparts (FM3 and FM4). Furthermore, thiourea monomer FM4 interacted more strongly with guest compared to urea analogue FM3 as expected based on the difference in acidity of ureas and thioureas (vide supra). 
Table 2. Values of association constants $\left(K_{a}\right)$ and maximum complexation induced shifts $\left(C I S_{\max }\right)$ for FM1-FM4 titrated with TBAHNP in DMSO-d6.

\begin{tabular}{ccc}
\hline Monomer & $\mathbf{K}_{\mathrm{a}}\left(\mathbf{M}^{-1}\right)$ & $\mathrm{CIS}_{\max }(\mathbf{p p m})$ \\
\hline FM1 & $1489 \pm 7$ & 2.14 \\
FM2 & $743 \pm 10$ & 1.96 \\
\hline FM3 & $266 \pm 14$ & 1.91 \\
\hline FM4 & $439 \pm 5$ & 2.00
\end{tabular}

However, this relationship did not hold true for FM1 and FM2 pair of monomers. This unexpected finding can be ascribed to previously reported preference of diaryl thioureas for $(Z, E)$ conformation as opposed to preferential $(\mathrm{Z}, \mathrm{Z})$ conformation of diaryl ureas ${ }^{139}$ and it is in agreement with the previous study on FM1 and FM2. ${ }^{125}$
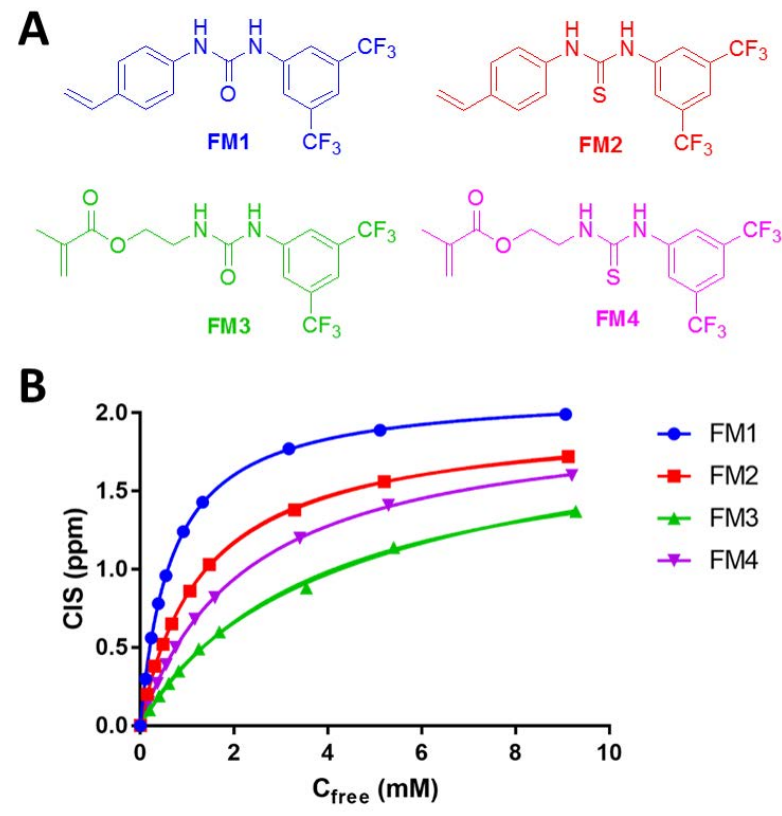

Figure 8. (A) Structures of functional monomers FM1-FM4 and (B) plot of complexation induced shift $(C I S) v s$. free concentration of guest $\left(C_{\text {free }}\right)$ fitted to 1:1 interaction model for ${ }^{1} \mathrm{H}$ MNR titrations of FM1-FM4 with tetrabutylammonium hydrogen-1-naphtyl phosphate (TBAHNP) in DMSO-d6 at $25^{\circ} \mathrm{C}$. 
Based on the above results, the FM1 was selected as a functional monomer for synthesis of molecularly imprinted polymers targeting $\mathrm{pTyr}$ and $\mathrm{pHis}$ peptides (Papers I-IV). Schematic representation of interactions between tyrosine phosphorylated peptide and binding site in the imprinted polymer is shown in Figure 9.

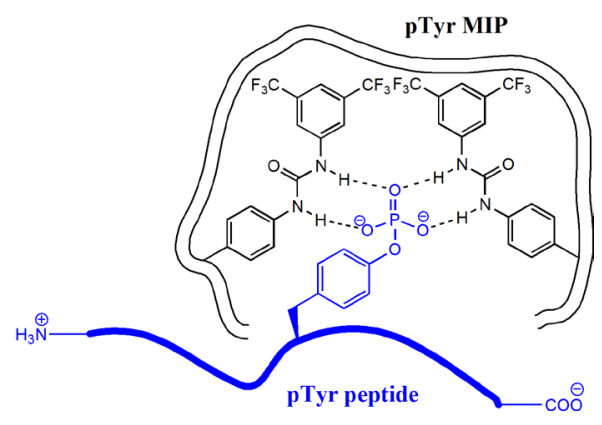

Figure 9. Schematic representation of interactions between tyrosine phosphorylated peptide and phosphotyrosine imprinted polymer (pTyr MIP).

\section{Imidazolium-based functional monomers}

Recognition of anions in water is essential for biological and environmental applications, however, it remains a great challenge in modern supramolecular chemistry. ${ }^{140}$ Neutral receptors bearing urea, amide or pyrrole functionality were extensively studied for recognition of anions, ${ }^{141,}{ }^{142}$ nevertheless, their compatibility with aqueous media is limited. Water is a polar solvent with the ability of hydrogen bond donation and acceptance, thus it effectively competes with neutral receptors for binding anions. Charged receptors, on the other hand, can take advantage of the electrostatic effect, and thus compete more effectively with polar protic solvent.

Commonly used charged receptors for anions based on guanidinium or ammonium employ ${ }^{+} \mathrm{N}-\mathrm{H} \cdot \cdots \mathrm{X}^{-}$type of ionic hydrogen bond. In contrast, imidazolium-based receptors can interact with anions through $(\mathrm{C}-\mathrm{H})^{+} \cdots \mathrm{X}^{-}$ type of ionic hydrogen bond (Figure 10). ${ }^{143}$ 


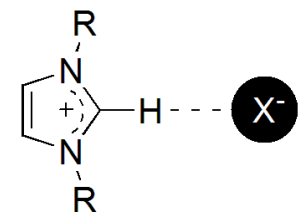

Figure 10. Schematic representation of the ionic hydrogen bond interaction between imidazolium receptor and anion $\mathrm{X}^{-}$.

A number of such receptors was reported before in the literature and reviewed elsewhere. ${ }^{144-147}$ For example, Kwon et al. ${ }^{148}$ reported water-soluble imidazolium anthracene derivative (Figure 11) which acts as a potential fluorescent receptor for guanosine 5 '-triphosphate (GTP) in 100\% aqueous solution. The value of $K_{a}$ derived from the fluorescence titration with GTP in 10 mM HEPES buffer $(\mathrm{pH}=7)$ was $87000 \mathrm{M}^{-1}$.

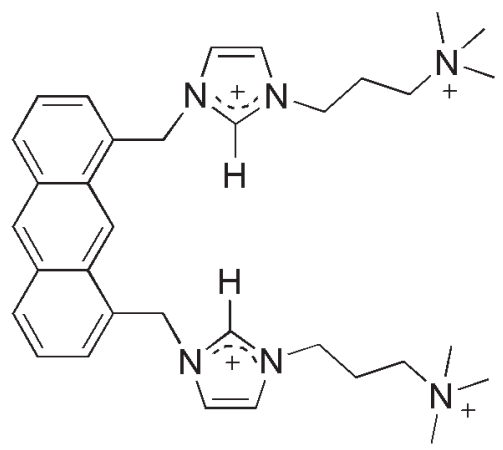

Figure 11. Fluorescent receptor for GTP.

In Paper $\mathrm{V}$ a set of imidazolium-based functional monomers was used to synthesize MIPs. Materials prepared in capillary monolith format were able to strongly retain phosphopeptides in highly aqueous mobile phase as opposed to nonphosphorylated ones. 


\section{METHODS}

Analytical methods for identification, purification, separation and quantification of chemical compounds as well as material characterization techniques were extensively used in this thesis. This section explains the basic principles of the most important methods used during the course of this work. Details about instrumentation and conditions of all analyses are given in Experimental Sections of Papers I-V.

\section{Batch binding test}

One of the most basic and simple tests for characterization of binding properties of MIPs is the batch binding test. ${ }^{149}$ It relies on equilibration of a known amount of the polymer ( $m$, in $\mathrm{g})$ with the solution of a known amount of the analyte $\left(n_{0}\right.$, in moles) until the equilibrium is reached. The polymer is then separated from the solution and the amount of unbound analyte $\left(n_{\text {free }}\right.$, in moles) in the solution is measured. The amount of bound analyte per unit mass of the polymer $\left(B\right.$, in $\left.\mathrm{mol} \mathrm{g}^{-1}\right)$ can be then calculated from equation (1):

$$
B=\left(n_{0}-n_{\text {free }}\right) / m
$$

The experiment is typically done in parallel for both MIP and NIP under identical conditions (Figure 12). The difference between materials originating from the imprinting phenomenon can be expressed as imprinting factor $(I F)$ and it can be calculated from equation (2):

$$
I F=\frac{D_{M I P}}{D_{N I P}}=\frac{B_{M I P} / C_{\text {free } M I P}}{B_{N I P} / C_{\text {free } N I P}}
$$

Where $D\left(\mathrm{~L} \mathrm{~g}^{-1}\right)$ is the distribution ratio and $C_{\text {free }}\left(\mathrm{mol} \mathrm{L}^{-1}\right)$ is the concentration of the unbound analyte. 


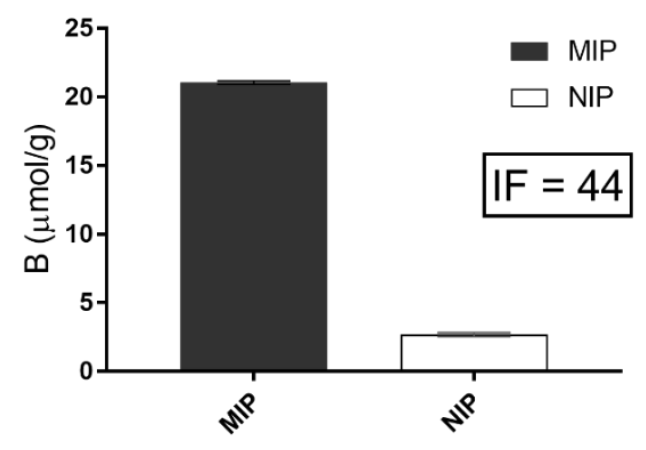

Figure 12. Results of the batch binding test of Fmoc-pTyr-OH for microspherical phosphotyrosine imprinted polymer (MIP) and the corresponding non-imprinted polymer (NIP). The test was performed using $0.5 \mathrm{~mL}$ of $0.5 \mathrm{mM}$ solution of the analyte in $95 \% \mathrm{ACN}$ and $2 \mathrm{~h}$ equilibration with $10 \mathrm{mg}$ of the polymer (Paper III). The imprinting factor (IF) was calculated using equation (2).

However, the imprinting factor is dependent on the amount of the analyte $\left(n_{0}\right)$, the amount of the polymer $(m)$ and the volume of the sample $(V)$. Thus, it is recommended to do batch binding test for an array of different $n_{0}$ while keeping $m$ and $V$ constant. The obtained data points can be represented on the graph of $B v s . C_{\text {free }}$, the so-called binding isotherm (Figure 13).

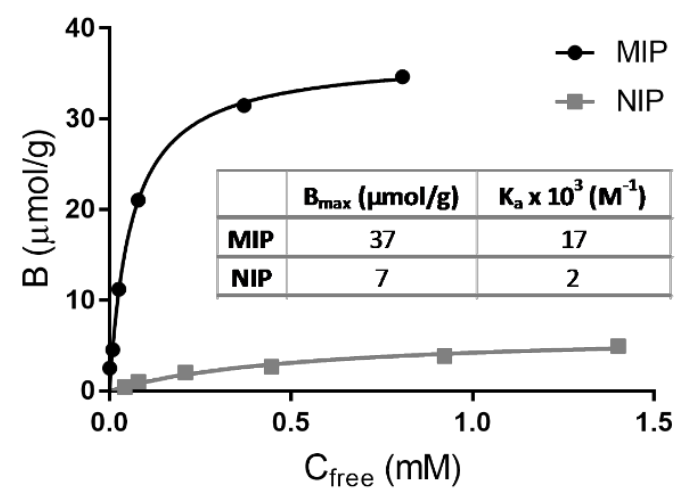

Figure 13. Binding isotherm for the same polymers and conditions as described in Figure 12. The data points were recorded for $0.05-1.5 \mathrm{mM}$ concentration of the analyte. The values of $B_{\max }$ and $K_{a}\left(K_{a}=1 / K_{d}\right)$ were obtained from data fit to monoLangmuir model (Paper III). 
The experimental data can be fitted to a theoretical model using a graph fitting software, for example GraphPad Prism (GraphPad Software, La Jolla, CA, USA) or OriginPro (Originlab Corporation, Wellesley Hills, MA, USA). A number of such theoretical binding isotherm models can be used to characterize binding sites of the imprinted polymer. ${ }^{150}$ The simplest mono-Langmuir model assumes that there is only one type of homogeneous binding sites (Table 3). It allows to calculate values of the maximum amount of analyte bound to the polymer particles at saturation $\left(B_{\max }\right)$ and the dissociation constant $\left(K_{d}\right)$ which is a reverse of the association constant $\left(K_{a}\right)$.

Table 3. Adsorption isotherm models. Reproduced from Ansell ${ }^{149}$ with permission from Springer.

\begin{tabular}{ccc}
\hline Model & Equation & $\begin{array}{c}\text { Description of binding } \\
\text { sites }\end{array}$ \\
\hline $\begin{array}{c}\text { Mono- } \\
\text { Langmuir }\end{array}$ & $B=\frac{B_{\text {max }} \cdot C_{\text {free }}}{K_{d}+C_{\text {free }}}$ & $\begin{array}{c}\text { One type } \\
\text { homogeneous }\end{array}$ \\
\hline $\begin{array}{c}\text { Bis- } \\
\text { Langmuir }\end{array}$ & $B=\frac{B_{\max 1} \cdot C_{\text {free }}}{K_{d 1}+C_{\text {free }}}+\frac{B_{\text {max } 2} \cdot C_{\text {free }}}{K_{d 2}+C_{\text {free }}}$ & $\begin{array}{c}\text { Two classes of binding } \\
\text { sites }\end{array}$ \\
\hline Freundlich & & $\begin{array}{c}\text { Continuous distribution } \\
\text { of binding sites. Infinite } \\
\text { number of weak sites de- } \\
\text { caying to few strong } \\
\text { ones }\end{array}$ \\
\hline \begin{tabular}{c} 
Langmuir- $_{\text {Freundlich }}{ }^{\text {a }}$ \\
\hline
\end{tabular} & $B=\frac{B_{\text {max }} \cdot a \cdot C_{\text {free }}}{1+a \cdot C_{\text {free }}^{m}}$ & $\begin{array}{c}\text { Gaussian distribution of } \\
\text { binding sites }\end{array}$ \\
\hline
\end{tabular}

${ }^{a} A, a$ and $m$ are empirical constants.

The mono-Langmuir model is a great simplification given the heterogeneous nature of the binding sites typically observed in MIPs. Thus, the data should be fitted to several models and the one giving the best fit (the best description of binding sites) should be used. The most common models used to fit MIP binding isotherms are listed in Table $3 .^{149}$ 


\section{Molecularly imprinted solid phase extraction}

Another type of experiment used in this work to probe binding properties of polymers is the molecularly imprinted solid phase extraction (MISPE) test which is a variation of classical SPE test. ${ }^{151,152}$ The sample is loaded on the conditioned polymer packed in the SPE cartridge (Figure 14). The flowthrough fraction contains all unbound analytes. The washing step is performed to remove all non-specifically bound analytes (washing fraction) and it is followed by the elution step.

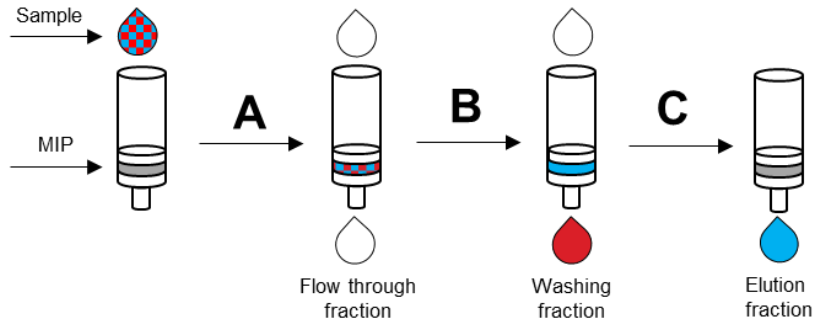

Figure 14. Schematic representation of the solid phase extraction (SPE) experiment with (A) loading, (B) washing and (C) elution steps.

The amount of each analyte in collected fractions can be measured and expressed as a percentage of initial sample amount (Figure 15).
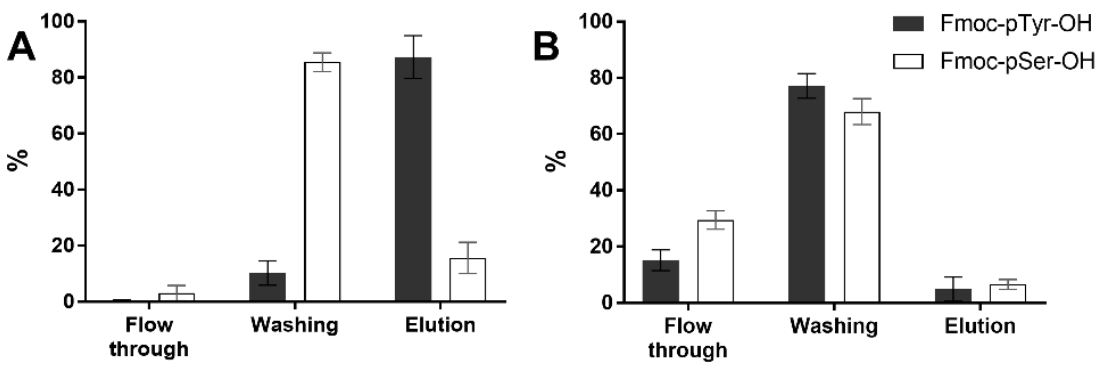

Figure 15. Results of the SPE test for (A) bulk pTyr MIP and (B) the corresponding NIP showing \% of initial amount of each analyte in the flow-through, washing and elution fractions. Conditions: loading $100 \% \mathrm{ACN}$, washing $95 \% \mathrm{ACN}$, elution $80 \% \mathrm{MeOH}+1 \%$ TFA. 
In contrast to batch binding test, the binding in SPE test does not necessarily occur under equilibrium conditions. Thus, data cannot be fitted to theoretical models and information about $B_{\max }$ and $K_{a}$ cannot be obtained. Nevertheless, such test is a useful source of information about binding properties of MIP.

\section{High-performance liquid chromatography}

High-performance liquid chromatography (HPLC) is a separation method that allows to purify, identify and quantify compounds and can be used both in analytical and preparative scale. ${ }^{153}$ The liquid solvent (mobile phase) containing sample is passed through the column filled with the sorbent (stationary phase) at high pressure with the aid of a pump. The separation of individual components of the sample is based on a difference in their affinity to the stationary phase. Eluted compounds can be detected, for example, by measurement of ultra-violet (UV) absorbance, refractive index or by mass spectrometry analysis.

Polymers developed in this work were characterized by batch binding and SPE tests with a mixture of compounds (e.g. Fmoc-amino acids or peptides). The concentration of analytes in samples was measured by HPLC-UV analysis. This required development of methods for separation of mixtures of three or four compounds. Parameters for developed methods for separation of Fmocamino acids and peptides are given in Table 4 and examples of chromatograms are shown in Figure 16. 

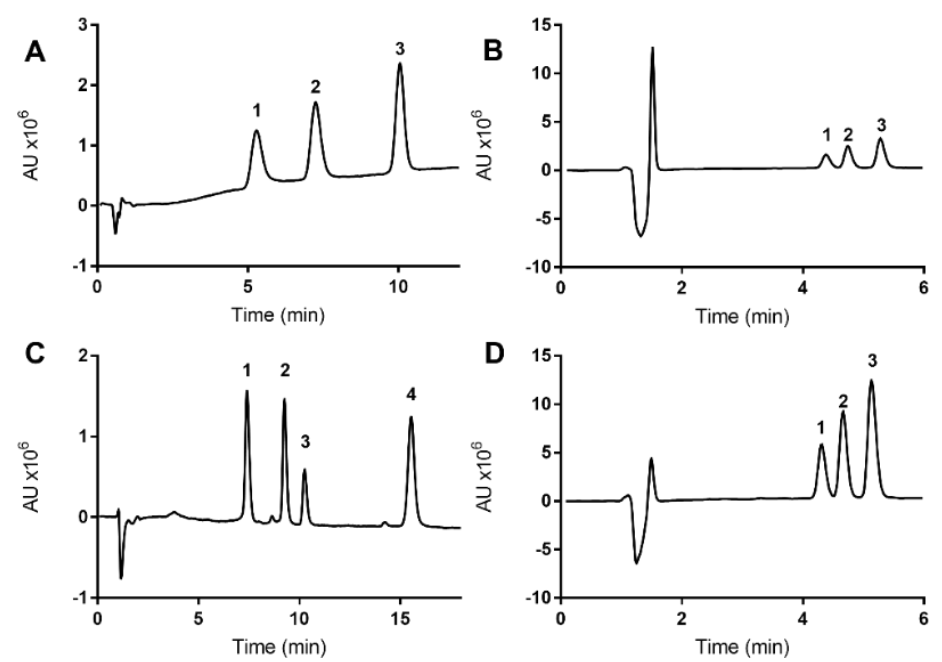

Figure 16. HPLC-UV chromatograms of separated mixtures of (A) Fmoc-pSer-OH [1], Fmoc-pTyr-OH [2] and Fmoc-Tyr-OH [3]; (B) VpSI [1], VpYI [2] and VYI [3]; (C) VpSI [1], VpHI [2], VEI [3] and VHI [4]; (D) DRVpSIHPF [1], DRVpYIHPF [2] and DRVYIHPF [3]. 


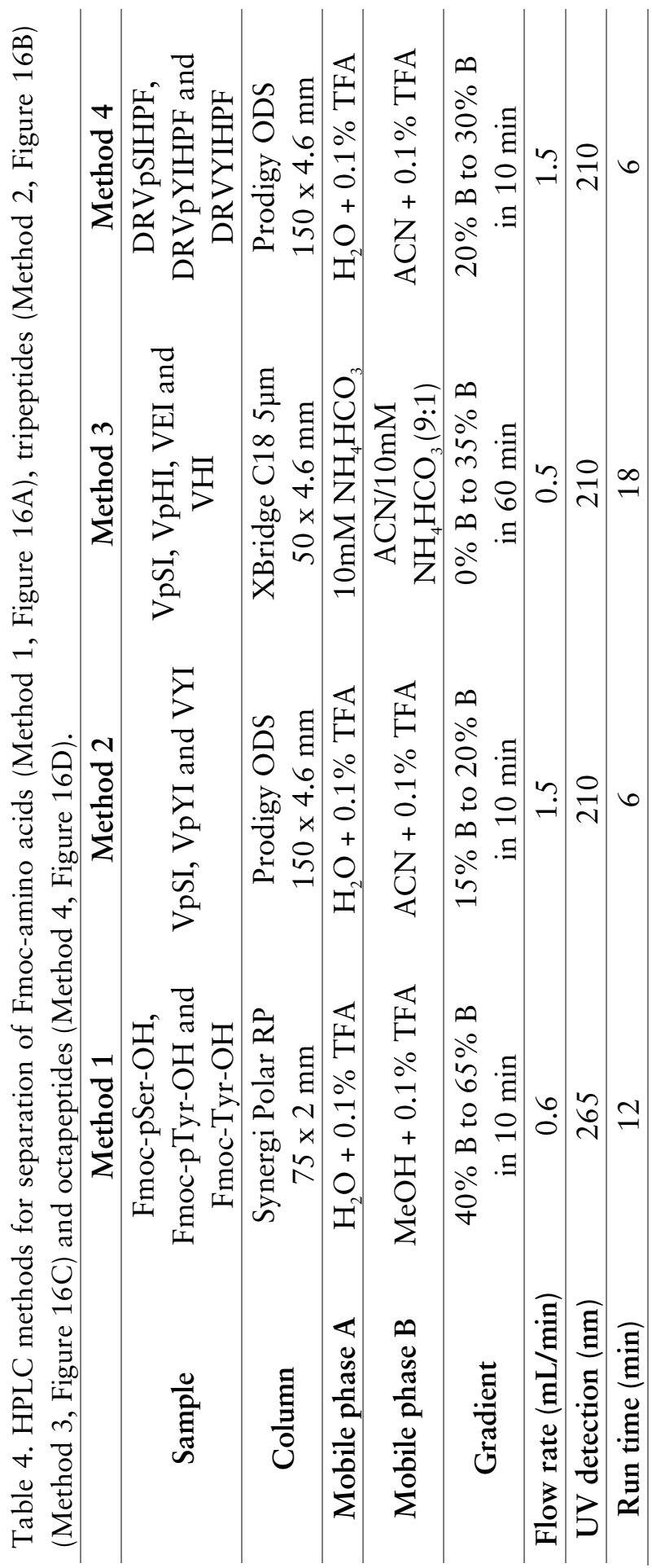




\section{Mass spectrometry}

Mass spectrometry (MS) is an analytical technique where ionized compounds are separated based on their mass to charge $(\mathrm{m} / \mathrm{z})$ ratio. Regardless of technical differences, typically mass spectrometer is composed of three parts, i.e. ion source, mass analyzer and detector (Figure 17). ${ }^{154}$ In a typical MS analysis sample is introduced trough the inlet system into the ion source where compounds are ionized. Subsequently, the ions are separated according to their $\mathrm{m} / \mathrm{z}$ ratio in the mass analyzer and detected in the detector.

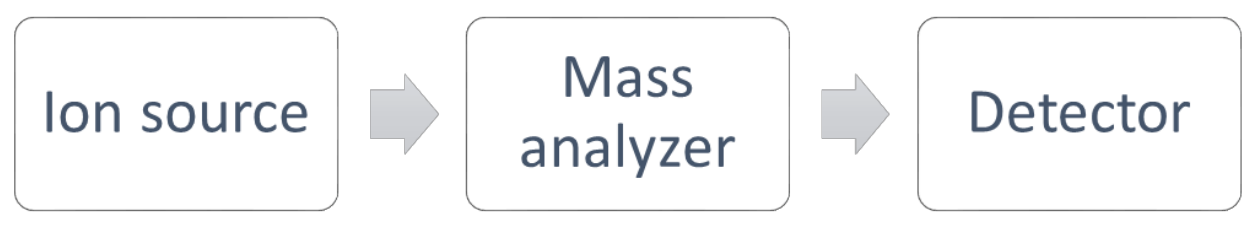

Figure 17. Components of the mass spectrometer.

Mass spectrometry is widely used in proteomic studies and a number of different setups of the instrumentation are available. ${ }^{155}$ Two most commonly used techniques to vaporize and ionize the sample are electrospray ionization (ESI) and matrix-assisted laser desorption/ionization (MALDI).

The mechanism of ESI is based on the formation of gas phase ions from sprayed droplets of the sample passed through a capillary maintained at high voltage $(2-5 \mathrm{kV}) .{ }^{156}$ The ions are transferred to gas phase due to evaporation of the solvent from charged droplets of the sample. This happens with the aid of elevated temperature of the ion source and the flow of nitrogen. An advantage of ESI is the compatibility with chromatographic separation module (HPLC).

In MALDI the sample is deposited on a metal plate along with the matrix compound in a dry, crystalline form. The pulsed laser irradiation leads to the sublimation and ionization of the sample. The matrix compound is responsible for absorption of the laser beam and converting it to heat energy, thus facilitating sample desorption and ionization. ${ }^{157}$ Both ESI and MALDI are soft ionization methods and do not lead to the fragmentation of analyzed compounds.

The ionized sample is introduced to the mass analyzer which is the key element of the mass spectrometer, determining sensitivity, resolution and mass accuracy of the method. Four most commonly used in proteomics mass analyzers are time-of-flight (TOF), ion trap, quadrupole and Fourier transform 
ion cyclotron resonance (FT-ICR). ${ }^{155}$ In the work presented in this thesis, mass spectrometers with the former three types of mass analyzers were used.

The TOF mass analyzer is usually coupled with MALDI. Ions are accelerated by an electric field and separated along the flight tube as a result of different velocities. Ions with a lower $m / z$ have higher velocity, and thus reach detector faster than ions with a higher $m / z$ value. ${ }^{158}$ MALDI-TOF/TOF-MS was used in Papers I-III.

Orbitrap is one of the most recently invented mass analyzers. It is a type of ion trap analyzer where ions are trapped around central spindle electrode. The $\mathrm{m} / \mathrm{z}$ values of ions are derived from their oscillation frequencies. ${ }^{159}$ The nanoLC-ESI-MS/MS with Orbitrap mass analyzer was used in Paper II.

The quadrupole mass filter is composed of four parallel rods. Depending on the electric field applied to quadrupole rods only ions of specified $\mathrm{m} / \mathrm{z}$ are allowed to pass through the analyzer. ${ }^{160}$ LC-ESI-MS with quadrupole mass analyzer was used in Paper IV.

\section{Nuclear magnetic resonance}

Nuclear magnetic resonance (NMR) spectroscopy is a technique used to study the structure of compounds and interactions between various molecules. ${ }^{161}$ When nuclei with a non-zero spin (e.g. ${ }^{1} \mathrm{H},{ }^{13} \mathrm{C},{ }^{19} \mathrm{~F}$ or ${ }^{31} \mathrm{P}$ have spin $\mathrm{I}=1 / 2$ ) is placed in a strong magnetic field $B_{0}$, spins of the nuclei are aligned with it. Delivery of radiofrequency (RF) pulses generates a temporary magnetic field $B_{1}$ which twists the spins out of the alignment with $B_{0}$. As spins return to alignment with $B_{0}$ the energy gained upon RF pulse is released and recorded as a function of signal intensity $v$ s. time which is called the free induction decay (FID). This is then converted to spectrum using the Fourier Transformation.

The NMR spectroscopy was extensively used in this thesis for confirmation of the structure and purity check of synthesized compounds including templates and functional monomers (Figure 18). 


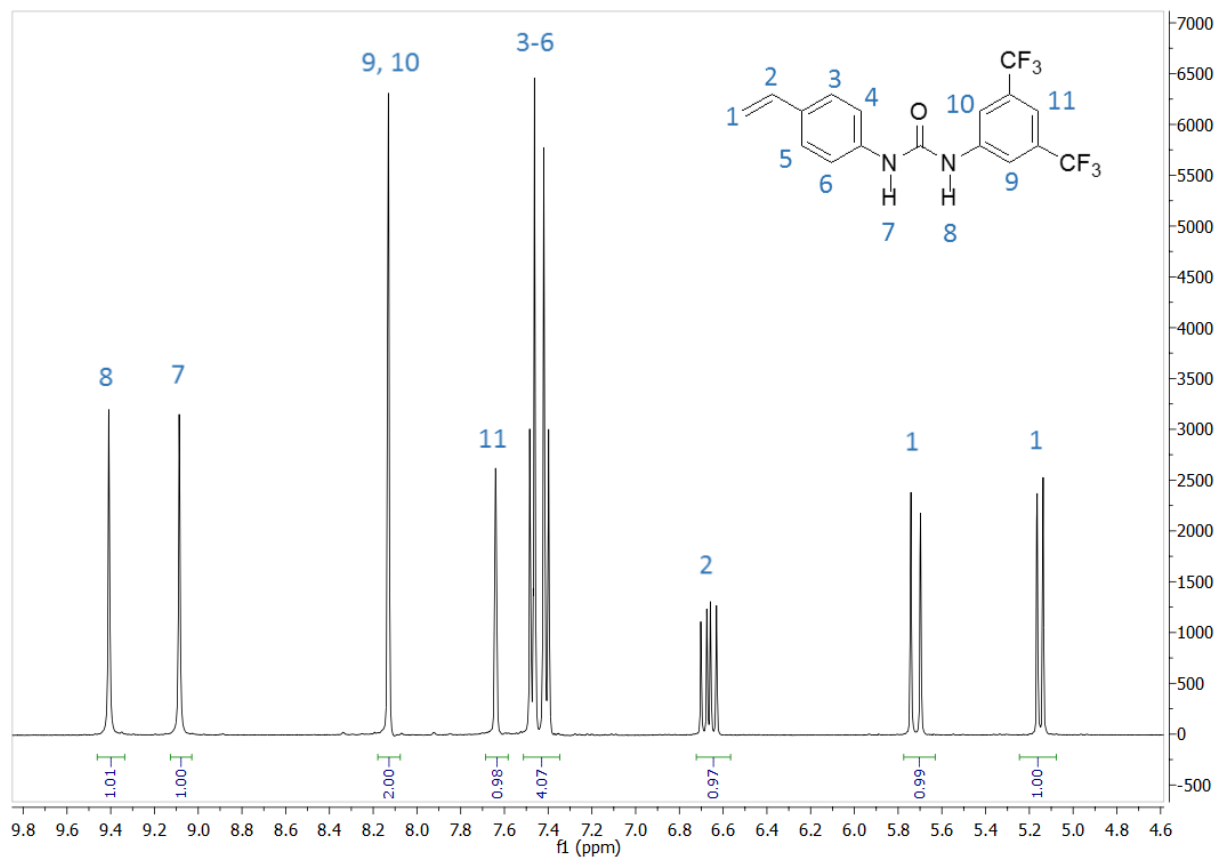

Figure 18. Zoomed portion $(4.6-9.8 \mathrm{ppm})$ of the ${ }^{1} \mathrm{H}$ NMR spectra of functional monomer FM1 recorded in DMSO-d6 at $25^{\circ} \mathrm{C}$ using an Agilent (Varian) Mercury $400 \mathrm{MHz}$ instrument.

NMR titration experiments were used to study interactions between functional monomers and templates or template analogs. Typically, the functional monomer (host) was titrated with an increasing amount of the template (guest). The change of NMR shielding, and thus chemical shift is observed upon formation of host-guest complexes (Figure 19A). The obtained data plotted as complexation induced shift $v s$. free concentration of guest can be fitted to one of the binding models to derive the value of association constant $\left(K_{a}\right)^{162}$ Titration data of functional monomer FM1 with tetrabutylammonium salt of phenylphosphonic acid (TBAHPPA) was fitted to 1:1 interaction model and the calculated $K_{a}$ was $7350 \pm 320 \mathrm{M}^{-1}$ (Paper V, Figure 19). 

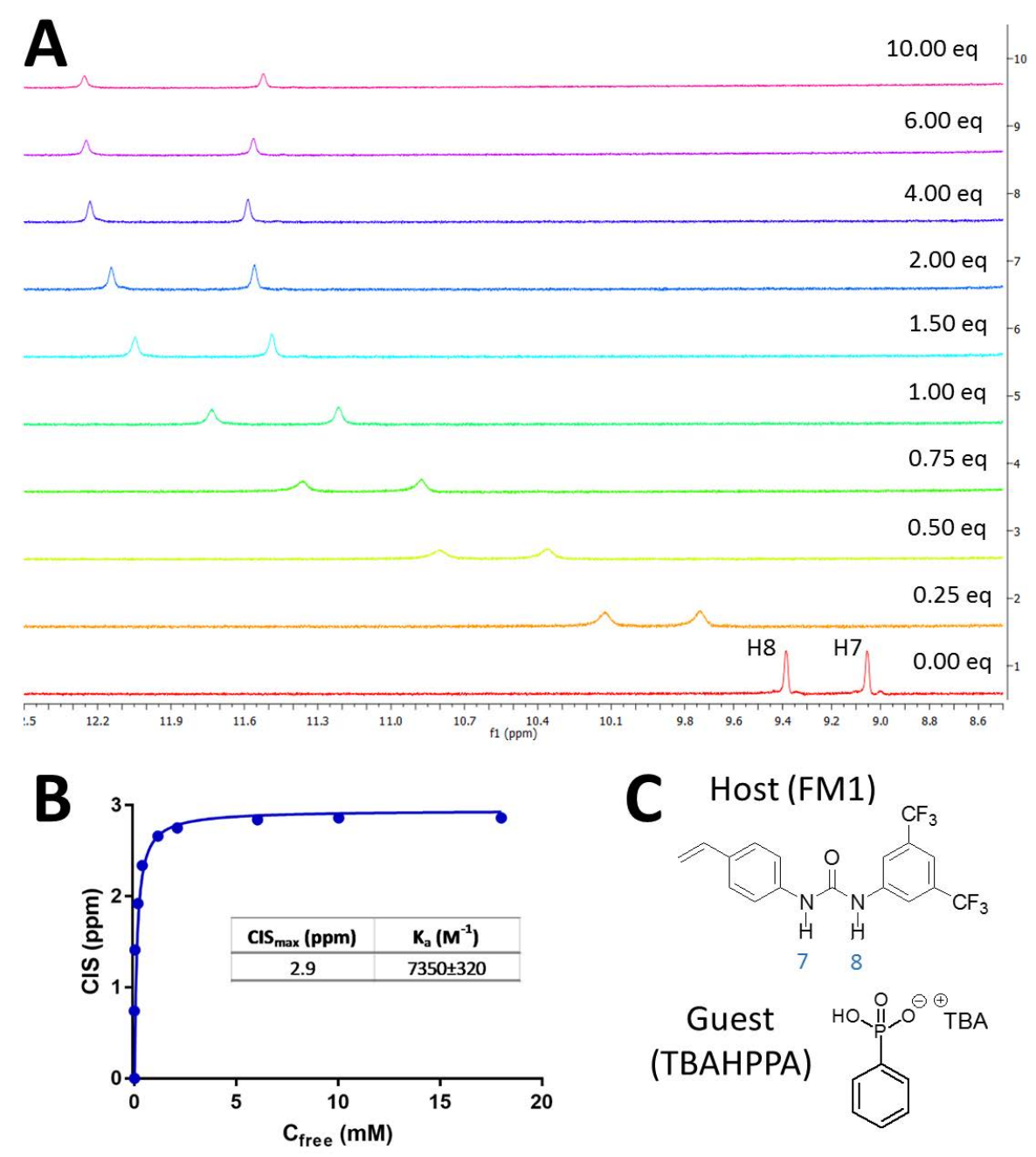

Figure 19. (A) Zoomed portion $(8.5-12.5 \mathrm{ppm})$ of the ${ }^{1} \mathrm{H}$ NMR spectra of functional monomer FM1 (host) titrated with an increasing amount of guest $(0-10$ equivalents) recorded in DMSO-d6 at $25^{\circ} \mathrm{C}$ using an Agilent (Varian) Mercury $400 \mathrm{MHz}$ instrument. (B) Plot of the average complexation induced shift (CIS) of protons $\mathrm{H} 7$ and $\mathrm{H} 8$ vs. free concentration of guest $\left(C_{\text {free }}\right)$ fitted to 1:1 interaction model and calculated values of maximum CIS at saturation $\left(C I S_{\max }\right)$ and association constant $\left(K_{a}\right)$. (C) Structures of host and guest. 


\section{Thermogravimetric analysis}

Thermogravimetric analysis (TGA) is a type of thermal analysis where the amount and the rate of change in the mass of the sample is measured as a function of temperature or time. ${ }^{163}$ This method is most often used to determine thermal stability and compositional properties of materials.

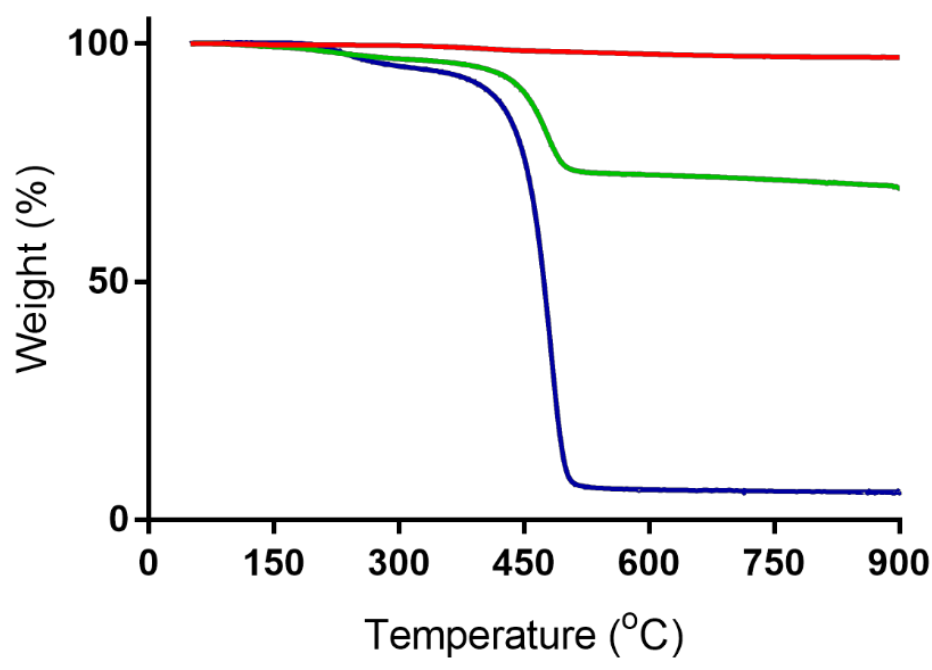

Figure 20. TGA curves obtained for silica beads used for the preparation of microspherical pTyr polymer (red trace, $3 \%$ weight loss), pTyr MIP polymer-silica composite (green trace, $30 \%$ weight loss) and pTyr MIP-M after etching of silica (blue trace, $94 \%$ weight loss). Samples were heated from 50 to $900{ }^{\circ} \mathrm{C}$ with a heating rate of $20^{\circ} \mathrm{C} / \mathrm{min}$, under the nitrogen atmosphere (Paper III).

In Paper III, microspherical polymer beads were synthesized using porous silica particles as a vessel for polymerization. TGA analysis was used to evaluate removal of silica after polymer synthesis. Silica particles do not decompose during TGA analysis (Figure 20, red trace), thus weight loss is insignificant. Polymer, on the other hand, made of organic building blocks, undergoes thermal degradation resulting in significant weight loss of the sample (Figure 20 , blue trace). The amount of removed silica was determined by comparison of the weight loss of samples before (Figure 20, green trace) and after etching of the silica. 


\section{RESULTS AND DISCUSSION}

\section{PAPER I}

Validation of molecularly imprinted polymers for side chain selective phosphopeptide enrichment.

It was previously shown that a phosphotyrosine molecularly imprinted polymer (pTyr MIP) utilizing urea-based functional monomer FM1 (Figure 21) can be used for biased enrichment of tyrosine phosphorylated (pTyr) peptides. ${ }^{125}$ In Paper I the pTyr MIP-based protocol for selective extraction of pTyr peptides was further developed and optimized. The method was validated on both simple mixture of thirteen peptides (four pTyr, five pSer and four nonphosphorylated) and complex sample of the digested mouse brain lysate spiked with these peptides. Moreover, the method was compared with commonly used phosphoenrichment techniques, i.e. $\mathrm{TiO}_{2}$ affinity chromatography and immunoaffinity.<smiles>C=Cc1ccc(NC(=O)Nc2cc(C(F)(F)F)cc(C(F)(F)F)c2)cc1</smiles>

Figure 21. Structure of the functional monomer FM1.

Enrichment of phosphopeptides from model peptide mixture confirmed that the pTyr MIP preferentially binds to pTyr peptides (four pTyr and three pSer 
peptides were found in the elution fraction). This contrasted with $\mathrm{TiO}_{2}$ method which extracted eight out of nine phosphopeptides (except doubly tyrosine phosphorylated peptide) which is in agreement with previous reports showing unbiased affinity of $\mathrm{TiO}_{2}$ to phosphopeptides. ${ }^{164}$ Each of three commonly used anti-phosphotyrosine antibodies extracted only one pTyr peptide from the same sample. This was likely due to a multistep protocol that increases the risk of sample loss, as the higher amount of sample (200 pmol compared to 1 pmol) used for enrichment resulted in the identification of all pTyr peptides. The selectivity of investigated phosphoenrichment methods was also reflected in a test with a complex sample of digested mouse brain lysate spiked with model peptide mixture where similar results were obtained.

The study reported in Paper I shows that the pTyr MIP-based method is an attractive alternative to established phosphopeptide enrichment techniques allowing for biased enrichment of low abundant pTyr peptides. Furthermore, it offers the advantage of simple protocol that minimizes sample handling, and thus reduces the risk of sample loss.

Although results presented in Paper I are promising it was crucial to demonstrate that pTyr MIP can be used for extraction of endogenous, low abundant pTyr peptides from a biological sample.

\section{PAPER II}

Phosphotyrosine biased enrichment of tryptic peptides from cancer cells exploiting combined pY MIP and $\mathrm{TiO}_{2}$ affinity.

In Paper II, the implementation of pTyr MIP in phosphoproteomic workflows using tryptic digest of HeLa cells lysate is reported. Four methods including pTyr MIP, $\mathrm{TiO}_{2}$ and combinations thereof (pTyr MIP - $\mathrm{TiO}_{2}$ and $\mathrm{TiO}_{2}-\mathrm{pTyr}$ MIP) were evaluated and compared in terms of selectivity towards pTyr, pSer and pThr phosphorylation sites, number and signal intensity of identified phosphopeptides and their physicochemical properties.

The complex biological sample posed a great challenge for pTyr MIP alone as the number of identified phosphopeptides and $\mathrm{pTyr}$ peptides was significantly lower compared to other methods involved in this study (Table 5). The presence of a large number of nonphosphorylated peptides in the elution fraction from pTyr MIP indicates a high degree of non-specific binding. This is most likely driven by the hydrophobic interactions of peptides with the poly- 
mer surface which is an important limitation of this method. It was previously reported for phosphoserine molecularly imprinted polymer (pSer MIP) featuring the same FM1 functional monomer (Figure 21) that the combination of the pSer MIP-based enrichment with SCX prefractionation of the sample significantly increased the number of phosphopeptides extracted from a tryptic digest of HEK 293T cell lysate. ${ }^{132}$ In Paper II, the pTyr MIP enrichment was combined with $\mathrm{TiO}_{2}$-based method which is known to have an unbiased affinity for phosphopeptides and it was expected to improve sample cleanup. Thus, $\mathrm{TiO}_{2}$ was implemented both before and after sample treatment with pTyr MIP $\left(\mathrm{TiO}_{2}-\right.$ pTyr MIP and pTyr MIP - $\mathrm{TiO}_{2}$ methods, respectively). The combined methods provided a slightly lower number of identified phosphopeptides compared to $\mathrm{TiO}_{2}$ alone (Table 5) which is likely due to more sample handling steps resulting in sample loss. A closer look at the ratios of identified pSer, pThr and pTyr peptides (Table 5) revealed that $\mathrm{TiO}_{2}$ following pTyr MIP ( $\mathrm{pTyr} \mathrm{MIP}-\mathrm{TiO}_{2}$ ) increased the relative number of identified $\mathrm{pTyr}$ peptides compared to the reference $\mathrm{TiO}_{2}$ method.

Table 5. Number of phosphopeptides identified with four enrichment methods studied in Paper II and the ratio of peptides with different phosphorylated residues (pSer, pThr and pTyr).

\begin{tabular}{|c|c|c|c|c|}
\hline Method & $\begin{array}{c}\text { Number of } \\
\text { phosphopeptides }\end{array}$ & $\begin{array}{l}\text { pSer } \\
(\%)^{b}\end{array}$ & $\begin{array}{l}\text { pThr } \\
(\%)^{\text {b }}\end{array}$ & $\begin{array}{l}\text { pTyr } \\
(\%)^{\mathrm{b}}\end{array}$ \\
\hline pTyr MIP & $412(258)$ & 91.9 & 5.8 & 4.6 \\
\hline $\mathrm{TiO}_{2}$ & 1843 (1209) & 88.1 & 7.9 & 8.5 \\
\hline $\mathrm{TiO}_{2}-$ pTyr MIP & $1328(909)$ & 88.8 & 5.7 & 6.9 \\
\hline pTyr MIP $-\mathrm{TiO}_{2}$ & $1695(1081)$ & 84.2 & 7.4 & 9.5 \\
\hline
\end{tabular}

${ }^{a}$ Accumulated number of phosphopeptides identified in three replicates. Numbers in parentheses refer to peptides identified in minimum two replicates. ${ }^{b}$ Calculated considering peptides identified in minimum two replicates.

Enhanced selectivity of pTyr MIP - $\mathrm{TiO}_{2}$ method towards pTyr peptides was also reflected in the increased intensity of $70 \%$ of pTyr peptides commonly identified with the $\mathrm{TiO}_{2}$ method. This was not observed when the sample was treated by the two enrichment methods in reversed order $\left(\mathrm{TiO}_{2}-\mathrm{pTyr} \mathrm{MIP}\right)$. It indicates that pTyr MIP indeed can enrich phosphopeptides with a bias towards pTyr peptides, however, it requires additional sample processing to remove non-specifically bound peptides which otherwise disturb MS-based analysis of phosphopeptides. 
The analysis of physicochemical properties of phosphopeptides enriched by the four studied methods revealed that pTyr MIP and pTyr MIP-TiO ${ }_{2}$ methods extracted less acidic and more basic phosphopeptides when compared with $\mathrm{TiO}_{2}$ and $\mathrm{TiO}_{2}$-pTyr MIP methods. This implies that in case of combined methods, the method used as a first in the sequence predetermines the properties of enriched phosphopeptides. The bias of $\mathrm{TiO}_{2}$ method towards acidic phosphopeptides is in agreement with previous reports. ${ }^{132}$ Furthermore, three methods based on pTyr MIP displayed a preference for mono-phosphorylated and relatively short peptides (6-24 residues). In contrast, $\mathrm{TiO}_{2}$ enriched significantly more multi-phosphorylated and larger ( $\geq 25$ residues) phosphopeptides. As it was concluded in Paper III the preference of pTyr MIP for shorter peptides is related to the broad pore size distribution of the material with a significant number of pores in the micro- to low mesoporous regime $(1-20 \mathrm{~nm})$. This size bias can be changed using pore templating approaches.

Interestingly, the overlap of phosphopeptides identified by $\mathrm{TiO}_{2}$ and $\mathrm{pTyr}$ MIP $-\mathrm{TiO}_{2}$ or $\mathrm{TiO}_{2}-$ pTyr MIP was only 50 and $45 \%$, respectively. This indicates that implementation of pTyr MIP in phosphoproteomic workflows can provide access to previously unknown phosphorylation sites.

\section{PAPER III}

\section{Hierarchically templated beads with tailored pore structure for phosphopeptide capture and phosphoproteomics.}

Paper III describes the design, synthesis and evaluation of pTyr MIP in the format of porous microspherical beads. The classical bulk polymerization via free radical polymerization is by far the most commonly used method to synthesize MIPs. The simple protocol and compatibility with many functional groups determined the utility of this technique for generation of synthetic MIP receptors. Although commonly used, this approach is not free from limitations. Firstly, the polymer prepared in bulk format requires tedious and timeconsuming processing by crushing and sieving to obtain particles in desired size range. This often leads to significant loss of the material, thus making the process cost-ineffective especially when used template or monomers are expensive. Secondly, the obtained particles are irregularly shaped and sized which limits their application, for example in chromatography. Furthermore, the binding sites can be destroyed by grinding, thus reducing the capacity of the 
polymer. For these reasons alternative MIP formats have been developed, for example micro- and nanobeads, membranes or monoliths. ${ }^{165-167}$

There are even more drawbacks of crushed bulk MIPs when it comes to the analysis of large molecules, for example peptides or proteins. The diffusion of such bulky entities to the binding pocket is slow and it can be hampered by insufficient porosity of the material.

Phosphoproteomic studies are most commonly based on a bottom-up approach where digested protein fragments with the mass up to roughly $3 \mathrm{kDa}$ are analyzed. In recent years, however, an increasing interest in top-down (analysis of whole proteins) and middle-down (analysis of large protein fragments, typically 3-20 kDa) approaches has been observed. ${ }^{168}$ The invaluable piece of information gained thanks to these techniques is the combinatorial nature of the PTMs located in distant parts of the protein which is lost in the bottom-up approach. ${ }^{169}$ Certainly, enrichment of peptides and large protein fragments requires dedicated tools compatible with the size of these molecules.

In an attempt to enhance the compatibility of previously reported crushed bulk pTyr MIP (Papers I and II) with the size of tryptic phosphopeptides, the polymer was prepared in the format of porous microspherical beads (Paper III). Mesoporous silica particles ( $30 \mu \mathrm{m}$ average particle size) were used as vessels for polymerization in two variants, i.e. with template either dissolved in monomer cocktail (pTyr MIP-M) or immobilized on the silica surface (pTyr MIP-H). Both new materials were characterized by increased surface area and average pore size compared to the crushed bulk pTyr MIP. After the initial evaluation of the materials on simple ternary mixtures of amino acids and peptides, polymers were challenged with the sample of twelve digested proteins (including three phosphorylated on serine residues) spiked with standard pTyr, pSer and Tyr peptides. The samples were analyzed using MALDI-MS. The study of the normalized signal intensities of spiked peptides in elution fractions from MIPs and in the sample before enrichment revealed that all polymers reduced sample background and enriched phosphorylated peptides. The $\mathrm{pTyr}$ MIP-M proved to give highest values of $\mathrm{pTyr} / \mathrm{pSer}$ and $\mathrm{pTyr} / \mathrm{Tyr} \mathrm{ra}-$ tios after enrichment. It was also more effective in the enrichment of larger peptides compared to the bulk pTyr MIP which is ascribed to increased porosity and surface area of the microspherical polymer.

In summary, silica templated MIP synthesis is a useful approach to bias phosphopeptide enrichment to larger peptide size. Moreover, it allows to control size and shape of obtained polymer beads and results in high yield of material as contrasted with classical bulk polymerization. 


\section{PAPER IV}

\section{Selective enrichment of histidine phosphorylated peptides combining $\boldsymbol{\beta}$-elimination and MIP-based $\mathrm{pHis}$ capture.}

For many years modifications localized on serine, threonine and tyrosine residues were in the spotlight of phosphoproteomics research. The blossom of this area would not be possible without all the effort to develop tools for detection and analysis of these modifications. Phosphohistidine, one of the elusive cousins of phosphohydroxy amino acids, was overlooked for a long time due to its unique acid-labile nature and the consequent lack of adequate tools for its analysis.

In Paper IV the spotlight is turned to pHis modification. Currently, the limited choice of techniques for the enrichment of pHis peptides is one of the main factors hampering the study of this modification. Methods commonly used for extraction of O-phosphorylated peptides (for example MOAC and IMAC) are not appropriate for $\mathrm{pHis}$ peptides since they involve acidic conditions. Thus, mild enrichment methods preserving pHis modification, ideally avoiding acidic treatment of the sample are needed.

Paper IV describes a method for enrichment of $\mathrm{pHis}$ peptides with the use of a molecularly imprinted polymer. The pHis MIP was synthesized using a stable analogue of phosphohistidine (Fmoc-pTza-OEt) as a template and functional monomer FM1 (Figure 21). The polymer displayed affinity towards model pHis peptide in basic conditions $(95 \% \mathrm{ACN}+0.1 \% \mathrm{TEA})$ even in the complex sample of digested bovine serum albumin (BSA). These conditions, however, despite the compatibility with pHis modification did not provide sufficient selectivity of the polymer in presence of other phosphopeptides. The interfering affinity for pSer modification, being the most abundant phosphorylation in biological samples, was eliminated by treatment of the sample with a strong base capable of selective dephosphorylation of pSer (via $\beta$-elimination) in presence of pHis. This approach was proven successful on the sample of BSA tryptic digest spiked with model pHis and pSer peptides. Importantly, the proposed workflow did not involve any acidic treatment, thus the labile pHis modification could be preserved.

In conclusion, the MIP-based protocol reported in Paper IV is an attractive alternative to currently available techniques for the enrichment of $\mathrm{pHis}$ peptides. New enrichment methods compatible with pHis modification will certainly facilitate the progress in research on this PTM. 


\section{PAPER V}

Cationic $\mathrm{pTyr} / \mathrm{pSer}$ imprinted polymers based on a bis-imidazolium host monomer: Phosphopeptide recognition in aqueous buffers demonstrated by $\mu$ liquid chromatography and monolithic columns.

As shown in Papers I-IV, the urea-based imprinted polymers can effectively capture phosphorylated peptides even from complex samples. However, the recognition of phosphopeptides with this type of material is most effective in high organic media such as $95 \% \mathrm{ACN}$. This is very different from natural, aqueous environment of proteins. Such a dramatic change of the solvent system from aqueous to highly organic can result in problems with solubility of the sample.

In Paper $\mathrm{V}$ an attempt to generate pTyr selective MIPs compatible with protic and aqueous media is reported. A series of functional monomers (FM5FM7, Figure 22) bearing imidazolium group were studied and compared with the reference urea-based monomer FM1 (Figure 21).<smiles></smiles>

FM5<smiles></smiles>

FM6<smiles></smiles>

Figure 22. Structures of functional monomers FM5-FM7.

NMR titration study revealed that FM1 interacted strongly with mono-TBA salt of phenylphosphonic acid (PPA.TBA) in DMSO-d6 $\left(K_{a}=7350 \pm 320 \mathrm{M}^{-1}\right)$ while imidazolium-based monomers FM5-FM7 displayed significantly weaker association constants in the same conditions $\left(K_{a}<350 \mathrm{M}^{-1}\right)$. This proves domination of hydrogen bond interactions in aprotic media. When solvent was 
changed to $\mathrm{CD}_{3} \mathrm{OD}$ no complexation induced shift $(C I S)$ was observed for FM1 and FM5 while FM6 showed a rather weak response $(C I S=0.015 \mathrm{ppm})$ which nevertheless confirms the contribution of electrostatic interactions. Thus, FM6 was titrated with PPA.2TBA in $\mathrm{CD}_{3} \mathrm{OD}$ to reveal significantly stronger interactions with $K_{a}=1680 \pm 121 \mathrm{M}^{-1}$.

Binding properties of crushed bulk polymers featuring monomers FM1, FM5-FM7 were evaluated in methanol using template analogue Fmoc-pTyr$\mathrm{OH}$. As expected, the polymer prepared with FM1 displayed lowest values of $K_{a}$ and maximum capacity $\left(B_{\max }\right)$. This was ascribed to the effect of protic polar solvent that competes with imprinted cavities for binding the target analyte. Polymers featuring imidazolium-based monomers FM5-FM7 showed improved binding properties in these conditions as a result of combined electrostatic interactions and ionic hydrogen bonds. The most promising functional monomer FM6 was then used for preparation of pTyr and pSer imprinted and non-imprinted capillary monoliths $(250 \mu \mathrm{m}$ i.d.). These monolith columns were evaluated by micro-liquid chromatography using a mixture of Fmocprotected amino acids and octapeptides of general sequence Fmoc-X-OH and DRVXIHPF, respectively, where X stands for pTyr, pSer, Tyr or Ser residue. It was found that for both types of sample, imprinted capillaries displayed high retention of phosphorylated entities with the preference for the residue that was used for imprinting (i.e. pTyr imprinted capillary retained more strongly pTyr analyte than pSer analyte and vice versa). In contrast, the non-imprinted capillary did not retain any of these analytes. Importantly, this behavior of materials was observed in both high organic $(95 \% \mathrm{ACN})$ and low organic (10\% ACN - 90\% HEPES buffer $\mathrm{pH} 7.4)$ mobile phases.

The promising results reported in Paper $\mathrm{V}$ prove that receptors combining electrostatic interactions and ionic hydrogen bonds can effectively compete for binding anions in polar protic solvents. Thus, imidazolium-based functional monomers employed in MIPs improve recognition of phosphorylated peptides in aqueous media. 


\section{CONCLUDING REMARKS AND FUTURE OUTLOOK}

The work presented in this thesis is focused on development and validation of enrichment tools and methods for phosphoproteomics with the use of molecular imprinting technology.

It was shown that the pTyr MIP is capable of biased enrichment of pTyr peptides from a complex biological sample. The overlap of phosphopeptides identified by pTyr MIP-based method and $\mathrm{TiO}_{2}$ reaching only about $50 \%$ suggests that the pTyr MIP can access distinct parts of phosphoproteome, possibly revealing new previously unknown phosphorylation sites. Currently, the greatest limitation of the pTyr MIP in the analysis of complex biological samples is the high level of non-specific binding. This effect can be reduced by coupling pTyr MIP with other phosphoenrichment and/or fractionation techniques. Nevertheless, further optimization of the polymer design and composition to reduce non-specific interactions with nonphosphorylated peptides is recommended. This was achieved to some extent by changing the format of the pTyr MIP to microspherical beads. This newly developed material displayed improved selectivity for phosphorylated peptides as compared to a classical crushed bulk polymer.

The molecular imprinting technology was also used to develop a novel method for enrichment of $\mathrm{pHis}$ peptides. It was demonstrated that $\mathrm{pHis}$ MIP can extract $\mathrm{pHis}$ peptide from BSA protein digest. These promising results are the first step to place MIPs on the map of enrichment techniques for elusive phosphorylations such as pHis. Further optimization and validation of the method can provide an efficient tool facilitating research on this important PTM. 
Moreover, relying on the principles of supramolecular chemistry, it was shown that an improved recognition of phosphopeptides in aqueous media can be achieved with the use of imidazolium-based functional monomers.

Successful application of MIPs in the field of phosphoproteomics is not a trivial task. However, given the unique advantages offered by MIPs such as affinity and selectivity, robustness and low production cost it is worth the effort to make it happen. 


\section{ACKNOWLEDGEMENTS}

The completion of this thesis would not be possible without the support from many people.

First of all, I would like to thank my supervisor Börje Sellergren for the opportunity to develop my research and scientific skills and knowledge. In particular, I am grateful for the guidance, detailed discussions on the project and for always enthusiastic and optimistic attitude.

I would also like to thank my co-supervisor Thomas Arnebrant for advice and constant support.

I am thankful to collaborators in PEPMIP project who hosted me for secondments. Ole N. Jensen, Silje B. Torsetnes and Uwe Möginger for help with mass spectrometry assays during my stay at the University of Southern Denmark in Odense. Ian Nicholls and Gustaf Olsson for revealing the mystery of molecular dynamic simulations at Linnaeus University in Kalmar.

I am immensely grateful to all people involved in PEPMIP project for making a great atmosphere and collaboration. In particular, I would like to thank co-authors of articles and manuscripts: Jing Chen, Prabal Subedi, Sudhir Shinde, Stefan Helling, Katrin Marcus, Loreta Bllaci, Silje B. Torsetnes, Ole N. Jensen, Adelina Rogowska-Wrzesinska, Mingquan Liu, Knut Irgum, Kishore Kumar Jagadeesan, Simon Ekström and Thomas Laurell.

Many thanks to exchange students Kasia Gajoch, Radek Krzemieniecki and David Bauer for assistance in research projects and challenging my supervising skills.

I would like to thank my colleagues and friends: Sing Yee Yeung and Elena González Arribas because nobody understands a $\mathrm{PhD}$ student better than another PhD student, thank you girls for a nice company at work and afterwork. Prabal Subedi for valuable feedback on my thesis and an exceptional sense of humor, Sudhir Shinde for sharing your knowledge about MIPs and 
endless conversations about science and life, Peter Falkman, thank you for help with SEM, NMR and all technical problems and for a nice company during lunch, Vivek Chaturvedi thanks for many cheerful moments and delicious spicy Indian food, Mark Galat thank you for always being friendly and helpful.

My sincere gratitude goes to all present and former colleagues at Malmö University for a friendly atmosphere at work: Guoqing Pan, Qianjin Li, Tautgirdas Ruzgas, Yana Znamenskaya, Marija Jankuniec, Selma Marić, Tania Lind, Sebastian Björklund, Javier Sotres, Abdullah Ali, Catherine Albèr, Olga Aleksejeva, Sabrina Valetti, Magnus Falk, Vida Krikstolaityte, Madhuri Anu, Phạm AnhĐức, Xiantao Shen, Zahra El-Schich, Anna Runnsjö, Dmitry Pankratov, Monzer el-Dakkak, Eva Nilsson and people who visited Malmö for short time: Kyra Kujawski, Klaudia Ciurkot, Adrien Créancier, Maedeh Akhoundian, Mona Mohamed, Kathrin Hering, Anne Louise Hemdrup, Axel Rüter, Peter Erzog.

Many thanks to group members in Dortmund: Melanie Berghaus, Emelie Fritz, Annabell Tenboll, Patrick Lindemann, Mahadeo Halhalli, Reza Mohammadi, Abed Abdel Quader and Farid Ramezany for help at the very beginning of this journey.

The financial support of the European Commission through the Marie Curie ITN project PEPMIP (PITN-GA-2010-569 264699) and Malmö University, Biofilms - Research Center for Biointerfaces is gratefully acknowledged.

Special thanks go to Krzysztof Skowerski for sharing all ups and downs, inspiring and motivating scientific conversations and for the front illustration for this thesis.

Dziękuję również mojej rodzinie, kochanej mamie, Władkowi, Kacprowi i babci za nieustanne wsparcie i że zawsze mogę na was liczyć. 


\section{REFERENCES}

1. M. Mann and O. N. Jensen, Nat Biotechnol, 2003, 21, 255-261.

2. O. N. Jensen, Nat Rev Mol Cell Bio, 2006, 7, 391-403.

3. C. T. Walsh, S. Garneau-Tsodikova and G. J. Gatto, Angew Chem Int Edit, 2005, $44,7342-7372$.

4. V. G. Allfrey and A. E. Mirsky, Science, 1964, 144, 559-\&.

5. E. Verdin and M. Ott, Nat Rev Mol Cell Bio, 2015, 16, 258-264.

6. A. Drazic, L. M. Myklebust, R. Ree and T. Arnesen, Bba-Proteins Proteom, 2016, 1864, 1372-1401.

7. R. Desrosiers and R. M. Tanguay, J Biol Chem, 1988, 263, 4686-4692.

8. J. Najbauer, J. Orpiszewski and D. W. Aswad, Biochemistry, 1996, 35, 5183-5190.

9. K. W. Moremen, M. Tiemeyer and A. V. Nairn, Nat Rev Mol Cell Biol, 2012, 13, 448-462.

10. S. Defaus, P. Gupta, D. Andreu and R. Gutierrez-Gallego, Analyst, 2014, 139, 2944-2967.

11. R. L. Welchman, C. Gordon and R. J. Mayer, Nat Rev Mol Cell Bio, 2005, 6, 599609.

12. J. A. Ubersax and J. E. Ferrell, Nat Rev Mol Cell Bio, 2007, 8, 530-541.

13. M. Mann, S. E. Ong, M. Gronborg, H. Steen, O. N. Jensen and A. Pandey, Trends Biotechnol, 2002, 20, 261-268.

14. J. C. Venter et al., Science, 2001, 291, 1304-1351.

15. T. Hunter and B. M. Sefton, P Natl Acad Sci-Biol, 1980, 77, 1311-1315.

16. P. G. Besant and P. V. Attwood, Mol Cell Biochem, 2009, 329, 93-106.

17. X. L. Zu, P. G. Besant, A. Imhof and P. V. Attwood, Amino Acids, 2007, 32, $347-$ 357.

18. R. C. Oslund, J. M. Kee, A. D. Couvillon, V. N. Bhatia, D. H. Perlman and T. W. Muir, J Am Chem Soc, 2014, 136, 12899-12911. 
19. J. M. Kee, R. C. Oslund, D. H. Perlman and T. W. Muir, Nat Chem Biol, 2013, 9, 416-U428.

20. S. R. Fuhs, J. Meisenhelder, A. Aslanian, L. Ma, A. Zagorska, M. Stankova, A. Binnie, F. Al-Obeidi, J. Mauger, G. Lemke, J. R. Yates and T. Hunter, Cell, 2015, 162, 198-210.

21. A. Khorchid and M. Ikura, Int J Biochem Cell B, 2006, 38, 307-312.

22. D. M. Li, O. A. Agrellos and R. Calderone, Curr Opin Microbiol, 2010, 13, 424430.

23. A. Herivaux, Y. S. So, A. Gastebois, J. P. Latge, J. P. Bouchara, Y. S. Bahn and N. Papon, Plos Pathog, 2016, 12.

24. P. G. Besant, E. Tan and P. V. Attwood, Int J Biochem Cell B, 2003, 35, 297-309.

25. E. L. Tan, P. G. Besant, X. L. Zu, C. W. Turck, M. A. Bogoyevitch, S. G. Lim, P. V. Attwood and G. C. Yeoh, Carcinogenesis, 2004, 25, 2083-2088.

26. G. E. Schaller, Adv Bot Res, 2000, 32, 109-148.

27. P. V. Attwood, Biochem Soc T, 2013, 41, 1023-1028.

28. H. R. Matthews, Pharmacol Therapeut, 1995, 67, 323-350.

29. P. V. Attwood, M. J. Piggott, X. L. Zu and P. G. Besant, Amino Acids, 2007, 32, 145-156.

30. J. M. Kee and T. W. Muir, ACS Chem Biol, 2012, 7, 44-51.

31. K. F. Medzihradszky, N. J. Phillipps, L. Senderowicz, P. Wang and C. W. Turck, Protein Sci, 1997, 6, 1405-1411.

32. Y. F. Wei and H. R. Matthews, Method Enzymol, 1991, 200, 388-414.

33. U. M. Hohenester, K. Ludwig and S. Konig, Curr Drug Deliv, 2013, 10, 58-63.

34. J. M. Kee, B. Villani, L. R. Carpenter and T. W. Muir, J Am Chem Soc, 2010, 132, 14327-14329.

35. M. J. Piggott and P. V. Attwood, Nat Chem Biol, 2013, 9, 411-412.

36. C. Schenkels, B. Erni and J. L. Reymond, Bioorg Med Chem Lett, 1999, 9, 14431446.

37. T. E. McAllister, M. G. Nix and M. E. Webb, Chem Commun (Camb), 2011, 47, 1297-1299.

38. J. M. Kee, R. C. Oslund, A. D. Couvillon and T. W. Muir, Org Lett, 2015, 17, $187-$ 189.

39. J. M. Kee, R. C. Oslund, D. H. Perlman and T. W. Muir, Nat Chem Biol, 2013, 9, 416-421.

40. S. R. Fuhs, J. Meisenhelder, A. Aslanian, L. Ma, A. Zagorska, M. Stankova, A. Binnie, F. Al-Obeidi, J. Mauger, G. Lemke, J. R. Yates, 3rd and T. Hunter, Cell, 2015, 162, 198-210.

41. L. R. Yu, H. J. Issaq and T. D. Veenstra, Proteom Clin Appl, 2007, 1, 1042-1057.

42. H. C. Harsha and A. Pandey, Mol Oncol, 2010, 4, 482-495. 
43. C. Sun and R. Bernards, Trends Biochem Sci, 2014, 39, 465-474.

44. M. Steger, F. Tonelli, G. Ito, P. Davies, M. Trost, M. Vetter, S. Wachter, E. Lorentzen, G. Duddy, S. Wilson, M. A. Baptista, B. K. Fiske, M. J. Fell, J. A. Morrow, A. D. Reith, D. R. Alessi and M. Mann, Elife, 2016, 5.

45. Y. Y. Bahk, B. Mohamed and Y. J. Kim, J Microbiol Biotechn, 2013, 23, 279-288.

46. M. H. Flight, Nat Rev Drug Discov, 2013, 12, 739.

47. S. Hartmann, A. J. Ridley and S. Lutz, Front Pharmacol, 2015, 6.

48. R. Kumar, V. P. Singh and K. M. Baker, J Mol Cell Cardiol, 2007, 42, 1-11.

49. J. D. Clark, M. E. Flanagan and J. B. Telliez, J Med Chem, 2014, 57, 5023-5038.

50. R. Galien, Pharmacol Rep, 2016, 68, 789-796.

51. A. S. Banks, F. E. McAllister, J. P. Camporez, P. J. Zushin, M. J. Jurczak, D. Laznik-Bogoslavski, G. I. Shulman, S. P. Gygi and B. M. Spiegelman, Nature, 2015, 517, 391-395.

52. M. Polanski and N. L. Anderson, Biomarker insights, 2007, 1, 1-48.

53. J. A. Ludwig and J. N. Weinstein, Nature reviews. Cancer, 2005, 5, 845-856.

54. K. Imai and A. Takaoka, Nature reviews. Cancer, 2006, 6, 714-727.

55. P. Wu, T. E. Nielsen and M. H. Clausen, Trends in pharmacological sciences, 2015, 36, 422-439.

56. P. Wu, T. E. Nielsen and M. H. Clausen, Drug discovery today, 2016, 21, 5-10.

57. K. Machida, B. J. Mayer and P. Nollau, Mol Cell Proteomics, 2003, 2, 215-233.

58. T. E. Thingholm, O. N. Jensen and M. R. Larsen, Proteomics, 2009, 9, 1451-1468.

59. H. Rosenqvist, J. Ye and O. N. Jensen, Methods Mol Biol, 2011, 753, 183-213.

60. L. v. Stechow, ed., Phospho-Proteomics. Methods and Protocols, Springer-Verlag New York, 2016.

61. M. Gronborg, T. Z. Kristiansen, A. Stensballe, J. S. Andersen, O. Ohara, M. Mann, O. N. Jensen and A. Pandey, Mol Cell Proteomics, 2002, 1, 517-527.

62. H. Kaufmann, J. E. Bailey and M. Fussenegger, Proteomics, 2001, 1, 194-199.

63. H. Steen, B. Kuster, M. Fernandez, A. Pandey and M. Mann, Journal of Biological Chemistry, 2002, 277, 1031-1039.

64. M. O. Collins, L. Yu and J. S. Choudhary, Proteomics, 2007, 7, 2751-2768.

65. M. Sevecka and G. MacBeath, Nat Methods, 2006, 3, 825-831.

66. N. Imam-Sghiouar, I. Laude-Lemaire, V. Labas, D. Pflieger, J. P. Le Caer, M. Caron, D. K. Nabias and R. Joubert-Caron, Proteomics, 2002, 2, 828-838.

67. S. Bergstrom Lind, M. Molin, M. M. Savitski, L. Emilsson, J. Astrom, L. Hedberg, C. Adams, M. L. Nielsen, A. Engstrom, L. Elfineh, E. Andersson, R. A. Zubarev and U. Pettersson, J Proteome Res, 2008, 7, 2897-2910.

68. J. Rush, A. Moritz, K. A. Lee, A. Guo, V. L. Goss, E. J. Spek, H. Zhang, X. M. Zha, R. D. Polakiewicz and M. J. Comb, Nat Biotechnol, 2005, 23, 94-101. 
69. J. Villen, S. A. Beausoleil, S. A. Gerber and S. P. Gygi, Proc Natl Acad Sci U S A, 2007, 104, 1488-1493.

70. K. Marcus, D. Immler, J. Sternberger and H. E. Meyer, Electrophoresis, 2000, 21, 2622-2636.

71. S. B. Lind, M. Molin, M. M. Savitski, L. Emilsson, J. Astrom, L. Hedberg, C. Adams, M. L. Nielsen, A. Engstrom, L. Elfineh, E. Andersson, R. A. Zubarev and U. Pettersson, Journal of Proteome Research, 2008, 7, 2897-2910.

72. K. Rikova, A. Guo, Q. Zeng, A. Possemato, J. Yu, H. Haack, J. Nardone, K. Lee, C. Reeves, Y. Li, Y. Hu, Z. P. Tan, M. Stokes, L. Sullivan, J. Mitchell, R. Wetzel, J. MacNeill, J. M. Ren, J. Yuan, C. E. Bakalarski, J. Villen, J. M. Kornhauser, B. Smith, D. Li, X. Zhou, S. P. Gygi, T. L. Gu, R. D. Polakiewicz, J. Rush and M. J. Comb, Cell, 2007, 131, 1190-1203.

73. P. J. Boersema, L. Y. Foong, V. M. Y. Ding, S. Lemeer, B. van Breukelen, R. Philp, J. Boekhorst, B. Snel, J. den Hertog, A. B. H. Choo and A. J. R. Heck, Mol Cell Proteomics, 2010, 9, 84-99.

74. M. Machida, H. Kosako, K. Shirakabe, M. Kobayashi, M. Ushiyama, J. Inagawa, J. Hirano, T. Nakano, Y. Bando, E. Nishida and S. Hattori, FEBS J, 2007, 274, 15761587.

75. A. Gruhler, J. V. Olsen, S. Mohammed, P. Mortensen, N. J. Faergeman, M. Mann and O. N. Jensen, Mol Cell Proteomics, 2005, 4, 310-327.

76. S. Li and C. Dass, Anal Biochem, 1999, 270, 9-14.

77. T. S. Nuhse, A. Stensballe, O. N. Jensen and S. C. Peck, Mol Cell Proteomics, 2003, 2, 1234-1243.

78. S. B. Ficarro, M. L. McCleland, P. T. Stukenberg, D. J. Burke, M. M. Ross, J. Shabanowitz, D. F. Hunt and F. M. White, Nat Biotechnol, 2002, 20, 301-305.

79. J. C. Trinidad, C. G. Specht, A. Thalhammer, R. Schoepfer and A. L. Burlingame, Mol Cell Proteomics, 2006, 5, 914-922.

80. M. Kokubu, Y. Ishihama, T. Sato, T. Nagasu and Y. Oda, Anal Chem, 2005, 77, 5144-5154.

81. H. Zhou, M. Ye, J. Dong, E. Corradini, A. Cristobal, A. J. Heck, H. Zou and S. Mohammed, Nat Protoc, 2013, 8, 461-480.

82. H. Zhou, M. Ye, J. Dong, G. Han, X. Jiang, R. Wu and H. Zou, J Proteome Res, 2008, 7, 3957-3967.

83. S. Napper, J. Kindrachuk, D. J. Olson, S. J. Ambrose, C. Dereniwsky and A. R. Ross, Anal Chem, 2003, 75, 1741-1747.

84. A. Leitner, Trac-Trend Anal Chem, 2010, 29, 177-185.

85. M. W. H. Pinkse, P. M. Uitto, M. J. Hilhorst, B. Ooms and A. J. R. Heck, Analytical Chemistry, 2004, 76, 3935-3943.

86. M. R. Larsen, T. E. Thingholm, O. N. Jensen, P. Roepstorff and T. J. D. Jorgensen, Mol Cell Proteomics, 2005, 4, 873-886. 
87. P. A. Connor and A. J. McQuillan, Langmuir, 1999, 15, 2916-2921.

88. N. Sugiyama, T. Masuda, K. Shinoda, A. Nakamura, M. Tomita and Y. Ishihama, Mol Cell Proteomics, 2007, 6, 1103-1109.

89. I. Fukuda, Y. Hirabayashi-Ishioka, I. Sakikawa, T. Ota, M. Yokoyama, T. Uchiumi and A. Morita, Journal of Proteome Research, 2013, 12, 5587-5597.

90. S. S. Jensen and M. R. Larsen, Rapid Communications in Mass Spectrometry, 2007, 21, 3635-3645.

91. H. Molina, D. M. Horn, N. Tang, S. Mathivanan and A. Pandey, P Natl Acad Sci USA, 2007, 104, 2199-2204.

92. L. R. Yu, Z. Y. Zhu, K. C. Chan, H. J. Issaq, D. S. Dimitrov and T. D. Veenstra, Journal of Proteome Research, 2007, 6, 4150-4162.

93. S. Zanivan, F. Gnad, S. A. Wickstrom, T. Geiger, B. Macek, J. Cox, R. Fassler and M. Mann, Journal of Proteome Research, 2008, 7, 5314-5326.

94. Y. Kyono, N. Sugiyama, K. Imami, M. Tomita and Y. Ishihama, Journal of Proteome Research, 2008, 7, 4585-4593.

95. Y. Oda, T. Nagasu and B. T. Chait, Nat Biotechnol, 2001, 19, 379-382.

96. D. T. McLachlin and B. T. Chait, Analytical Chemistry, 2003, 75, 6826-6836.

97. H. L. Zhou, J. D. Watts and R. Aebersold, Nat Biotechnol, 2001, 19, 375-378.

98. A. Leitner, in Phospho-Proteomics: Methods and Protocols, ed. L. von Stechow, Springer New York, New York, NY, 2016, DOI: 10.1007/978-1-4939-3049-4_7, pp. 105-121.

99. T. S. Nuhse, A. Stensballe, O. N. Jensen and S. C. Peck, Mol Cell Proteomics, 2003, 2, 1234-1243.

100. J. V. Olsen, B. Blagoev, F. Gnad, B. Macek, C. Kumar, P. Mortensen and M. Mann, Cell, 2006, 127, 635-648.

101. P. J. Boersema, S. Mohammed and A. J. Heck, Anal Bioanal Chem, 2008, 391, 151159.

102. D. E. McNulty and R. S. Annan, Mol Cell Proteomics, 2008, 7, 971-980.

103. Q. R. Li, Z. B. Ning, X. L. Yang, J. R. Wu and R. Zeng, Electrophoresis, 2012, 33, 3291-3298.

104. T. E. Thingholm, O. N. Jensen, P. J. Robinson and M. R. Larsen, Mol Cell Proteomics, 2008, 7, 661-671.

105. B. Bodenmiller, L. N. Mueller, M. Mueller, B. Domon and R. Aebersold, Nature Methods, 2007, 4, 231-237.

106. K. Mosbach and O. Ramstrom, Bio-Technol, 1996, 14, 163-170.

107. G. Wulff, Angewandte Chemie-International Edition in English, 1995, 34, 1812 1832.

108. K. J. Shea, Abstr Pap Am Chem S, 1994, 208, 467-Poly. 
109. B. Sellergren, in Chiral Separation Techniques, Wiley-VCH Verlag GmbH, 2000, DOI: $10.1002 / 3527600361 . c h 6$, pp. 151-184.

110. F. Lanza and B. Sellergren, Adv Chromatogr, 2001, 41, 137-173.

111. S. A. Piletsky and A. P. F. Turner, Electroanalysis, 2002, 14, 317-323.

112. K. Haupt and K. Mosbach, Chemical Reviews, 2000, 100, 2495-2504.

113. D. Cunliffe, A. Kirby and C. Alexander, Adv Drug Deliv Rev, 2005, 57, 1836-1853.

114. L. X. Chen, X. Y. Wang, W. H. Lu, X. Q. Wu and J. H. Li, Chem Soc Rev, 2016, 45, 2137-2211.

115. C. Alexander, H. S. Andersson, L. I. Andersson, R. J. Ansell, N. Kirsch, I. A. Nicholls, J. O'Mahony and M. J. Whitcombe, J Mol Recognit, 2006, 19, 106-180.

116. R. Arshady and K. Mosbach, Die Makromolekulare Chemie, 1981, 182, 687-692.

117. C. Lübke, M. Lübke, M. J. Whitcombe and E. N. Vulfson, Macromolecules, 2000, 33, 5098-5105.

118. G. Wulff, T. Gross and R. Schönfeld, Angewandte Chemie International Edition in English, 1997, 36, 1962-1964.

119. D. S. Janiak and P. Kofinas, Anal Bioanal Chem, 2007, 389, 399-404.

120. N. W. Turner, C. W. Jeans, K. R. Brain, C. J. Allender, V. Hlady and D. W. Britt, Biotechnol Prog, 2006, 22, 1474-1489.

121. A. Rachkov and N. Minoura, Biochim Biophys Acta, 2001, 1544, 255-266.

122. A. Rachkov and N. Minoura, J Chromatogr A, 2000, 889, 111-118.

123. E. Yilmaz, K. Haupt and K. Mosbach, Angewandte Chemie International Edition, 2000, 39, 2115-2118.

124. M. M. Titirici, A. J. Hall and B. Sellergren, Chemistry of Materials, 2002, 14, 2123.

125. M. Emgenbroich, C. Borrelli, S. Shinde, I. Lazraq, F. Vilela, A. J. Hall, J. Oxelbark, E. De Lorenzi, J. Courtois, A. Simanova, J. Verhage, K. Irgum, K. Karim and B. Sellergren, Chem-Eur J, 2008, 14, 9516-9529.

126. J. Haginaka, H. Tabo and H. Matsunaga, Anal Chim Acta, 2012, 748, 1-8.

127. L. Xu, Y. F. Hu, F. Shen, Q. S. Li and X. Q. Ren, Journal of Chromatography A, 2013, 1293, 85-91.

128. Q. S. Li, F. Shen, X. Zhang, Y. F. Hu, Q. X. Zhang, L. Xu and X. Q. Ren, Anal Chim Acta, 2013, 795, 82-87.

129. X. Yang and Y. Xia, Journal of separation science, 2016, 39, 419-426.

130. Y. Chen, D. Li, Z. Bie, X. He and Z. Liu, Anal Chem, 2016, 88, 1447-1454.

131. S. Helling, S. Shinde, F. Brosseron, A. Schnabel, T. Muller, H. E. Meyer, K. Marcus and B. Sellergren, Analytical Chemistry, 2011, 83, 1862-1865.

132. J. Chen, S. Shinde, M. H. Koch, M. Eisenacher, S. Galozzi, T. Lerari, K. Barkovits, P. Subedi, R. Kruger, K. Kuhlmann, B. Sellergren, S. Helling and K. Marcus, Sci Rep-Uk, 2015, 5. 
133. D. Y. Li, Y. P. Qin, H. Y. Li, X. W. He, W. Y. Li and Y. K. Zhang, Biosens Bioelectron, 2015, 66, 224-230.

134. M. C. Etter and T. W. Panunto, J Am Chem Soc, 1988, 110, 5896-5897.

135. P. J. Smith, M. V. Reddington and C. S. Wilcox, Tetrahedron Letters, 1992, 33, 6085-6088.

136. E. Fan, S. A. Van Arman, S. Kincaid and A. D. Hamilton, J Am Chem Soc, 1993, 115, 369-370.

137. D. E. Gomez, L. Fabbrizzi, M. Licchelli and E. Monzani, Org Biomol Chem, 2005, 3, 1495-1500.

138. in Anion Receptor Chemistry, eds. J. L. Sessler, P. A. Gale and W.-S. Cho, The Royal Society of Chemistry, 2006, DOI: 10.1039/9781847552471-00001, pp. 1-26.

139. C. Roussel, M. Roman, F. Andreoli, A. D. Rio, R. Faure and N. Vanthuyne, Chirality, 2006, 18, 762-771.

140. M. J. Langton, C. J. Serpell and P. D. Beer, Angew Chem Int Edit, 2016, 55, 19741987.

141. E. J. Cho, J. W. Moon, S. W. Ko, J. Y. Lee, S. K. Kim, J. Yoon and K. C. Nam, J Am Chem Soc, 2003, 125, 12376-12377.

142. in Anion Receptor Chemistry, eds. J. L. Sessler, P. A. Gale and W.-S. Cho, The Royal Society of Chemistry, 2006, DOI: 10.1039/9781847552471-00171, pp. 171-226.

143. in Anion Receptor Chemistry, eds. J. L. Sessler, P. A. Gale and W.-S. Cho, The Royal Society of Chemistry, 2006, DOI: 10.1039/9781847552471-00027, pp. 27-130.

144. J. Yoon, S. K. Kim, N. J. Singh and K. S. Kim, Chem Soc Rev, 2006, 35, 355-360.

145. Z. Xu, S. K. Kim and J. Yoon, Chem Soc Rev, 2010, 39, 1457-1466.

146. S. K. Kim, N. J. Singh, S. J. Kim, H. G. Kim, J. K. Kim, J. W. Lee, K. S. Kim and J. Yoon, Org Lett, 2003, 5, 2083-2086.

147. S. K. Kim, N. J. Singh, J. Kwon, I.-C. Hwang, S. J. Park, K. S. Kim and J. Yoon, Tetrahedron, 2006, 62, 6065-6072.

148. J. Y. Kwon, N. J. Singh, H. N. Kim, S. K. Kim, K. S. Kim and J. Yoon, J Am Chem Soc, 2004, 126, 8892-8893.

149. R. J. Ansell, Adv Biochem Eng Biotechnol, 2015, 150, 51-93.

150. J. A. Garcia-Calzon and M. E. Diaz-Garcia, Sensor Actuat B-Chem, 2007, 123, 1180-1194.

151. C. F. Poole, A. D. Gunatilleka and R. Sethuraman, Journal of Chromatography A, 2000, 885, 17-39.

152. B. Buszewski and M. Szultka, Crit Rev Anal Chem, 2012, 42, 198-213.

153. M. C. McMaster, in HPLC, John Wiley \& Sons, Inc., 2007, DOI: 10.1002/9780470079096.ch1, pp. 1-13.

154. A. Westman-Brinkmalm and G. Brinkmalm, in Mass Spectrometry, John Wiley \& Sons, Inc., 2008, DOI: 10.1002/9780470395813.ch2, pp. 15-87. 
155. R. Aebersold and M. Mann, Nature, 2003, 422, 198-207.

156. C. S. Ho, C. W. K. Lam, M. H. M. Chan, R. C. K. Cheung, L. K. Law, L. C. W. Lit, K. F. Ng, M. W. M. Suen and H. L. Tai, The Clinical Biochemist Reviews, 2003, 24, 3-12.

157. K. Hjernø and O. N. Jensen, in MALDI MS, Wiley-VCH Verlag GmbH \& Co. KGaA, 2013, DOI: 10.1002/9783527335961.ch3, pp. 105-131.

158. H. Wollnik, Mass Spectrometry Reviews, 1993, 12, 89-114.

159. R. A. Zubarev and A. Makarov, Analytical Chemistry, 2013, 85, 5288-5296.

160. P. E. Miller and M. B. Denton, J Chem Educ, 1986, 63, 617-622.

161. N. E. Jacobsen, in NMR Spectroscopy Explained, John Wiley \& Sons, Inc., 2007, DOI: $10.1002 / 9780470173350 . c h 1$, pp. 1-38.

162. P. Thordarson, Chem Soc Rev, 2011, 40, 1305-1323.

163. R. B. Prime, H. E. Bair, S. Vyazovkin, P. K. Gallagher and A. Riga, in Thermal Analysis of Polymers, John Wiley \& Sons, Inc., 2009, DOI: 10.1002/9780470423837.ch3, pp. 241-317.

164. M. D. Chamberlain, L. A. Wells, A. Lisovsky, H. Guo, R. Isserlin, I. TaliorVolodarsky, R. Mahou, A. Emili and M. V. Sefton, Proc Natl Acad Sci U S A, 2015, 112, 10673-10678.

165. B. Sellergren, in Journal of Chromatography Library, eds. T. B. T. František Švec and D. Zdeněk, Elsevier, 2003, vol. Volume 67, pp. 277-300.

166. A. G. Mayes, in Techniques and Instrumentation in Analytical Chemistry, ed. S. Börje, Elsevier, 2001, vol. Volume 23, pp. 305-324.

167. M. Ulbricht, Journal of Chromatography B, 2004, 804, 113-125.

168. J. M. Perkel, Science, 2015, 349, 1243-1245.

169. B. A. Garcia, Journal of the American Society for Mass Spectrometry, 2010, 21, 193-202. 

PAPERS I-V 



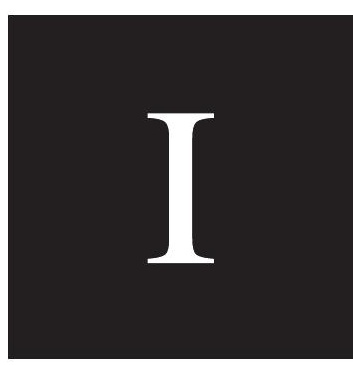





\title{
Validation of molecularly imprinted polymers for side chain selective phosphopeptide enrichment
}

\author{
Jing Chen ${ }^{\mathrm{a}, 1}$, Sudhirkumar Shinde ${ }^{\mathrm{b}, *, 1}$, Prabal Subedi ${ }^{\mathrm{a}}$, Celina Wierzbicka ${ }^{\mathrm{b}}$ \\ Börje Sellergren $^{\mathrm{b}, 1}$, Stefan Helling ${ }^{\mathrm{a}, 1}$, Katrin Marcus ${ }^{\mathrm{a}, *, 1}$ \\ ${ }^{a}$ Medizinisches Proteom-Center, Ruhr-University Bochum, Universitätsstr. 150, 44801 Bochum, Germany \\ ${ }^{\mathrm{b}}$ Department of Biomedical Sciences, Faculty of Health and Society, Malmö University, SE 20506 Malmö, Sweden
}

\section{A R T I C L E I N F O}

\section{Article history:}

Received 16 March 2016

Received in revised form

12 September 2016

Accepted 8 October 2016

Available online 11 October 2016

\section{Keywords:}

Antibody

Molecularly imprinted polymer

Phosphotyrosine

Phosphopeptide enrichment

$\mathrm{TiO}_{2}$

\begin{abstract}
A B S T R A C T
Selective enrichment techniques are essential for mapping of protein posttranslational modifications (PTMs). Phosphorylation is one of the PTMs which continues to be associated with significant analytical challenges. Particularly problematic are tyrosine-phosphorylated peptides (pY-peptides) resulting from tryptic digestion which commonly escape current chemo- or immuno- affinity enrichments and hence remain undetected. We here report on significant improvements in this regard using pY selective molecularly imprinted polymers (pY-MIPs). The pY-MIP was compared with titanium dioxide $\left(\mathrm{TiO}_{2}\right)$ affinity based enrichment and immunoprecipitation (IP) with respect to selective enrichment from a mixture of 13 standard peptides at different sample loads. At a low sample load (1 pmol of each peptide), IP resulted in enrichment of only a triply phosphorylated peptide whereas $\mathrm{TiO}_{2}$ enriched phosphopeptides irrespective of the amino acid side chain. However, with increased sample complexity, $\mathrm{TiO}_{2}$ failed to enrich the doubly phosphorylated peptides. This contrasted with the pY-MIP showing enrichment of all four tyrosine phosphorylated peptides at $1 \mathrm{pmol}$ sample load of each peptide with a few other peptides binding unselectively. At an increased sample complexity consisting of the standard peptides spiked into mouse brain digest, the MIP showed clear enrichment of all four pY- peptides.

(C) 2016 Elsevier B.V. All rights reserved.
\end{abstract}

\section{Introduction}

Phosphorylation is an important post-translational modification affecting the biological properties of carbohydrates, proteins, and lipids. Approximately $30 \%$ of the proteins encoded by the human genome are phosphorylated, and abnormal phosphorylation is now recognized as a cause or a consequence of many human diseases $[1,2]$. The characterization of phosphorylated proteins is a challenging analytical task since many of the proteins targeted for phosphorylation are low abundant and phosphorylation is typically substoichiometric. A small fraction of phosphorylated proteins is modified at tyrosines and are less abundant (0.05\%) than phosphoserine/phosphothreonine (pS 90\%/pT 9.95\%) proteins [2]. Therefore, high throughput analysis using mass spectrometry to elucidate the tyrosine-phosphorylated proteome requires sensitive and efficient enrichment procedures before or after an enzymatic digestion.

\footnotetext{
* Corresponding authors

E-mail addresses: sudhirkumar.shinde@mah.se (S. Shinde), katrin.marcus@rub.de (K. Marcus).

1 First authors and senior authors contributed equally to this work.

In view of the plethora of alternative approaches being proposed, current methods have multiple limitations, as outlined below. (1) There is a notable lack of robust nonimmune-based methods featuring side chain selectivity, for instance, allowing fractionation of pY- and pS-peptides [3]. (2) Current methods require access to a large amount of sample, typically in the milligram range [4]. (3) Current methods notably based on $\mathrm{TiO}_{2}$ affinity display pronounced sequence bias, typically in favor of peptides rich in acidic residues. A large portion of the phosphoproteome may therefore remain invisible using these techniques. (4) Current methods are both complicated and time consuming.

In principle, it is now possible to perform affinity purification experiments using anti- pY-antibodies where tyrosinephosphorylated proteome is enriched and its dynamic changes are monitored [5-7]. However, for an efficient affinity purification of tyrosine-phosphorylated peptides, a large amount of expensive antibodies and sample material are required [3]. Here we wish to report on a successful site selective phosphopeptide enrichment from small sample quantities of model peptide mixtures and biological samples using phosphotyrosine imprinted polymers $[8,9]$. We reveal benefits of this fractionation tool in a comparative study 


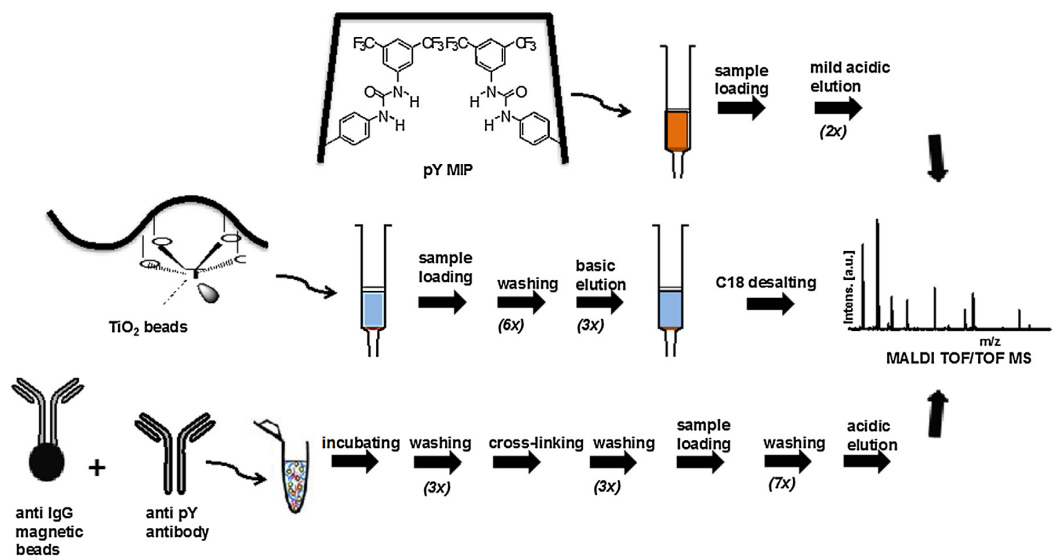

Fig. 1. Workflows for MIP-, $\mathrm{TiO}_{2}$ - and antibody-based enrichment of tyrosine-phosphorylated peptides followed by mass spectrometry based identification and quantification.

(Fig. 1) with reference methods relying on titanium dioxide $\left(\mathrm{TiO}_{2}\right)$ $[10,11]$ and anti pY-antibodies [12,13] based enrichments. In this report, we compare three phosphoenrichment techniques i.e antibodies, $\mathrm{TiO}_{2}$, and pY-MIP. Previous reports have not focused on this aspect $[8,9]$.

\section{Experimental section}

\subsection{MIP washing and conditioning}

$20 \mathrm{mg}$ pY-MIP in a $1.5 \mathrm{~mL}$ Eppendorf tube was washed at room temperature with methanol $(\mathrm{MeOH})(0.1 \% \mathrm{TFA})$ in a Thermomixer (Eppendorf) for $5 \mathrm{~min}, 2 \mathrm{~h}$ and overnight agitation $(1200 \mathrm{rpm})$ sequentially. The sample was centrifuged at $16,000 \times \mathrm{g}$ sedimentation and supernatant discarded after each wash. The conditioning of the MIPs was carried out 2 times for $10 \mathrm{~min}$ and $2 \mathrm{~h}$ in acetonitrile $(\mathrm{MeCN})(0.1 \% \mathrm{TFA})$ sequentially agitated in a thermomixer at room temperature. For every washing and conditioning step, the slurry was centrifuged and the supernatant discarded.

\subsection{Preparation of $p Y$ MIP pipette tips and solid phase extraction}

A-200 $\mu \mathrm{L}$ pipette tip (Eppendorf) was filled with a C8 membrane plug ( $3 \mathrm{M}$ Empore ${ }^{\mathrm{TM}}$ extraction disc, IVA Analysentechnik, Meerbusch) at the bottom. The conditioned MIP material in $500 \mu \mathrm{L}$ $(\mathrm{MeCN})(0.1 \% \mathrm{TFA})$ was vortexed, of which $15 \mu \mathrm{L}$ of the slurry containing ca. $600 \mu \mathrm{g}$ MIP was quickly pipetted into the pipette tip. After 3 min of sedimentation, the remaining solvent was removed by a $20 \mathrm{~mL}$ syringe (Terumo, Leuven, Belgien) equipped with a Chromabond ${ }^{\circledR}$ adapter (Adapter PP-columns, Machery-Nagel). The sample was firstly loaded with loading solvent (95\% MeCN, 0.1\% TFA) and eluted with (E1) $90 \% \mathrm{MeOH}, 0.1 \%$ TFA and water; (E2) $50 \%$ $\mathrm{MeOH}, 0.1 \% \mathrm{TFA}$ and water. The solvent was removed by a microcentrifuge (Eppendorf 5415R) at low speed from $200 \mathrm{x}$ g to $600 \mathrm{x}$ $\mathrm{g}$ accordingly. The resulting fractions were dried and redissolved in $0.1 \%$ TFA and subsequently analyzed by matrix-assisted laser desorption/ionization- mass spectrometry (MALDI-MS) (Fig. 1) for fast peptide detection.

\subsection{Preparation of digested mouse brain tissue and peptide spiking}

For studying the SPE performance for a complex sample, pY, pS and non phosphorylated peptides were spiked in a trypsin digested mouse brain lysate. Mouse brain tissue was lysed with a Dounce homogeniser and a tight pestle stroking 30 times up and down in lysis buffer containing $7 \mathrm{M}$ urea, $30 \mathrm{mM}$ tris(hydroxymethyl)aminomethane and $2 \mathrm{M}$ thiourea in a glass tube on ice. After homogenization, the lysate was sonicated six times for $10 \mathrm{~s}$ with $10 \mathrm{~s}$ intervals to avoid sample heating. Centrifugation was carried out at $16,000 \mathrm{xg}$ for $15 \mathrm{~min}$ and the supernatant was collected. The lysis process was repeated once and two supernatant fractions were pooled in one Eppendorf tube. Protein concentration was determined by Bradford protein assay (Bio-Rad).

Afterwards a short-gel enrichment was performed to remove contaminants from the sample. Hereto, $25 \mu \mathrm{g}$ lysate was mixed with lithium dodecyl sulphate (LDS), heated at $95^{\circ} \mathrm{C}$ for $5 \mathrm{~min}$ then loaded on an acryamide gel. Acylamide gel was polymerized previously for $20 \mathrm{~min}$ in a $10 \mathrm{~mm}$ thick gel chamber (XCellSureLockTMMiniCell). Gel solution contained $12.5 \%$ acylamide, $2.5 \mathrm{M}$ bis(2-hydroxyethyl)amino-tris(hydroxymethyl)methane (pH 6.8) and polymerization was started after addition of $50 \mu \mathrm{L}$ of $40 \%(\mathrm{w} / \mathrm{v})$ ammonium persulfate and $10 \mu \mathrm{L}$ of tetramethylethylenediamine. Electrophoresis was performed with $50 \mathrm{~V}$ for only $15 \mathrm{~min}$ in order to avoid full protein separation. The gel was stained with coomassie blue imperial ${ }^{\mathrm{TM}}$ Protein Stain (Thermo) for $10 \mathrm{~min}$ then destained with water overnight.

The band containing enriched brain proteins was then cut into small pieces and washed with buffer A $(10 \mathrm{mM}$ ammoium hydrogen carbonate) for 10 min and buffer B (buffer A: acetonitrile 50:50) for $10 \mathrm{~min}$ alternating for 6 times until the dye was removed. The gel pieces were dried for $1 \mathrm{~h}$ in the rotational vacuum concentrator. Trypsin was added to the gel pieces (trypsin:protein: 1:20) and gel pieces were incubated at $37^{\circ} \mathrm{C}$ for $16 \mathrm{~h}$. The digestion was stopped by adding $\left(\mathrm{MeCN} / \mathrm{H}_{2} \mathrm{O}: 50 / 50(0.1 \% \mathrm{TFA})\right)$ and using ultrasonic bath for $15 \mathrm{~min}$ twice. The supernatant was collected into a glass vial then dried in the rotational vacuum concentrator, and finally redissolved in $20 \mu \mathrm{L}$ water containing $0.1 \% \mathrm{TFA}$. The peptide concentration was determined by amino acid analysis via an ultra high performance liquid chromatrography (UHPLC) (Acquity UPLC, 
Waters). The peptide mixture $(0.016 \mu \mathrm{g})$ was spiked into the mouse brain digest $(3.4 \mu \mathrm{g})$ before the pY-MIP SPE experiment.

\subsection{Immunoprecipitation (IP) of phosphopeptides with $4 G 10$, PY20, PY100 antibodies}

A peptide mixture sample was reconstituted in IP buffer containing $73 \mathrm{mM}$ sodium chloride, $2.7 \mathrm{mM}$ potassium chloride, $0.02 \%$ Tween 20, $25 \mathrm{mM}$-tris[hydroxymethyl]aminomethane and the $\mathrm{pH}$ was then adjusted to 7.4 using hydrochloric acid. Magnetic beads conjugated with M-280 sheep anti-mouse secondary antibody (Dynabeads, Life Technologies) were incubated with anti-pYimmunoglubin $\mathrm{G}$ (IgG) primary antibody for $3 \mathrm{~h}$ under constant rotation at $4{ }^{\circ} \mathrm{C}$ and washed 3 times followed by crosslinking with $0.2 \mathrm{M}$ dimethyl pimelimidatedihydrochloride in triethanolamine buffer ( $\mathrm{pH} 8.2,20^{\circ} \mathrm{C}$ ) for $30 \mathrm{~min}$ to avoid co-elution of pY-antibody with the peptides. The crosslinking reaction was stopped by adding $1 \mathrm{~mL} 50 \mathrm{mM}$ 2-amino-2-(hydroxymethyl)-1,3-propanediol ( $\mathrm{pH} 7.5$, adjusted by $\mathrm{HCl}$ ), washed 3 times with IP buffer then incubated for 15 min under strong agitation (crosslinking protocol of IgG and magnetic beads by Dynabeads, Life Technologies).The conjugated IgG and magnetic beads (prewashed three times with IP buffer) were added to the sample and incubated overnight at $4{ }^{\circ} \mathrm{C}$ under constant rotation [9]. After incubation, the beads were washed five times with $1 \mathrm{~mL}$ IP buffer (without Tween20) followed by washing twice with $1 \mathrm{~mL}$ water. Peptides were eluted twice with $0.15 \%$ TFA at $20^{\circ} \mathrm{C}$ on a Thermomixer (Eppendorf) with strong agitation for $30 \mathrm{~min}$, dried in rotational vacuum concentrator, then redissolved in $5 \mu \mathrm{L}$ of water containing $0.1 \%$ TFA mixed with $5 \mu \mathrm{L}$ MALDI matrix solution.

\subsection{Phosphopeptide enrichment with $\mathrm{TiO}_{2}$ beads}

$0.6 \mathrm{mg} \mathrm{TiO}$ beads were washed twice with loading buffer composed of $80 \%$ acetronitrile, 5\% TFA and $1 \mathrm{M}$ glycolic acid then packed in a tip column. Sample was loaded twice onto the $\mathrm{TiO}_{2}$ beads, incubated for $3 \mathrm{~min}$ statically and supernatant removed by short centrifugation. The tip column was then washed twice with loading solution, twice with $80 \% \mathrm{MeCN}, 1 \% \mathrm{TFA}$ and then twice with $10 \%$ MeCN, 0.1\% TFA. Three eluting steps were carried out using $50 \mu \mathrm{L}$ elution solvents as follows: elution 1(E1): $250 \mathrm{mM} \mathrm{NH}_{4} \mathrm{HCO}_{3}$ and $\mathrm{NH}_{4} \mathrm{OH}$ pH 9.1; elution 2 (E2): $125 \mathrm{mM} \mathrm{NH}_{4} \mathrm{HCO}_{3}$ and $\mathrm{NH}_{4} \mathrm{OH} \mathrm{pH}$ 10.5; elution 3 (E3): $\mathrm{NH}_{4} \mathrm{OH} \mathrm{pH} 11.3$.

After the three elution steps, the tip column was washed with $2 \mu \mathrm{L} 30 \% \mathrm{MeCN}$. The elution fractions were pooled and then acidified with $15 \mu \mathrm{L}$ formic acid. All washing and elution procedures were accompanied by centrifugation at $1500 \times \mathrm{g}$ for $2 \mathrm{~min}$. After desalting of the samples with $\mathrm{C} 18$ self-made tips (Oligo R3 ${ }^{\mathrm{TM}}$ Bulk Media), they were dried in a rotational vacuum concentrator, redissolved in $5 \mu \mathrm{L}$ of water containing $0.1 \%$ TFA and were mixed with $5 \mu \mathrm{L}$ MALDI matrix solution.

\subsection{MALDI TOF/TOF mass spectrometry}

Mass spectrometric measurement of the fractions collected during analysis was performed with Flex Control software (Bruker Daltonics) using a MALDI reflector time of flight mass spectrometer (Ultraflex II MALDI TOF/TOF; Bruker Daltonics). The MALDI plate used was Anchor Chip target plate with Transponder Technology (Bruker Daltonics). Data collection, in terms of the scanning conditions and number of the scans, was performed identically for all samples unless otherwise noted. The spectra was collected by accumulating 400 laser shots under reflector mode (relative laser focus: $55 \%$ ) and further analyzed with the Flexanalysis 3.0 software (Bruker Daltonics)
Table 1

Tyrosine and serine containing model peptides used to probe the phosphoselectivity of the P1, P2, $\mathrm{TiO}_{2}$, and anti-phosphotyrosine antibodies.

\begin{tabular}{lll}
\hline Peptide Sequence & Abbreviation & {$[\mathrm{M}+\mathrm{H}]^{+1}$} \\
\hline AVPSPPPApSP-amide & T-SpS & 998,609 \\
VILGpSPAHR & GpS & 1029.5241 \\
DRVYIHPF & $\mathbf{Y}$ & 1046,5418 \\
DRVpSIHPF & $\mathbf{p S}$ & 1050,4768 \\
GADDSYYTAR & $\mathbf{Y Y}$ & 1118,475 \\
DRVpYIHPF & $\mathbf{p Y}$ & 1126,5081 \\
AVPSPPPApSPR & $\mathbf{S p S}$ & 1155,5558 \\
GADDSYpYTAR & $\mathbf{Y p Y}$ & 1198,4412 \\
GADDSpYpYTAR & $\mathbf{p Y p Y}$ & 1278,4076 \\
WWGSGPSGSGGSGGGK & $\mathbf{4 S}$ & 1420,624 \\
WWGSGPpSGSGGPSGGGK & $\mathbf{2 S 2 p S}$ & 1580,5567 \\
TRDIYETDYYRK & $\mathbf{3 Y}$ & 1622,7809 \\
TRDIpYETDpYpYRK & $\mathbf{3 p Y}$ & 1862,6799 \\
\hline
\end{tabular}

The sample preparation prior to the MALDI measurements was performed as follows: All fractions were collected in glass vials (HPLC glass insert vial) separately and dried in a rotational vacuum concentrator. After 10 min of drying, the two elution fractions were collected in one vial. The dried samples were dissolved in $5 \mu \mathrm{L}$ of water $(0.1 \%$ TFA) and mixed with $5 \mu \mathrm{L}$ of MALDI matrix with additional ultrasonication for $10 \mathrm{~min} .2 \mu \mathrm{L}$ of this mixture was deposited on the MALDI target plate and dried at room temperature. MALDI matrix solution was prepared by dissolving $40 \mathrm{mg}$ DHB (2, 5-dihydroxybenzoic acid), in MeCN:Water $(1: 1 \mathrm{v} / \mathrm{v}, 1 \mathrm{~mL})$ with $1 \%$ phosphoric acid and $0.1 \%$ TFA.

\section{Results and discussion}

Three experiments comprising phosphopeptide enrichment using either MIPs, $\mathrm{TiO}_{2}$ or pY-antibodies were carried out in replicate and representative results are provided for each of the enrichment strategies.

\subsection{Comparison of $P 1$ and $P 2 p Y-M I P S$}

The pY-MIPs described in our previous report [14] are methacrylic (P1) or acrylic (P2) based highly crosslinked polymers featuring a hydrophobic (P1) or hydrophilic (P2) polymer scaffold and high affinity binding sites for the phosphorylated amino acid side chain. The binding sites incorporate 1,3-disubstituted urea groups acting as quadruple hydrogen bond donors for chelating the phosphate guest acceptor. In contrast to $\mathrm{TiO}_{2}$ or IMAC based enrichments, recognition is here driven by hydrogen bonding involving no charged host species, hence the stationary phase is neutral. This feature we anticipated would reduce any charge dependent sequence bias commonly experienced with the current affinity phases.

Solid phase extraction (SPE) was performed using micro columns in form of disposable pipette tips (Fig. 1) packed with $<1 \mathrm{mg}$ imprinted polymer (P1 or P2); $50 \mu \mathrm{g} \mathrm{TiO} 2$ beads, or $20 \mathrm{pmol}$ of IgG anti-pY- antibodies (see Supporting information) incubated in a reaction tube. Selectivity was probed on a mixture of 13 peptides ( $1 \mathrm{pmol}$ each) (Table 1$)$ containing mono and multiply phosphorylated peptides at either serine or tyrosine in addition to their nonphosphorylated counterparts.

After loading of the mixture the resulting flow through fractions were compared with elution fractions with respect to the presence of tyrosine-, serine- and non-phosphorylated peptides.

P2 (Table S1) prepared using the hydrophilic crosslinker pentaerythritoltriacrylate (PETA) was first compared with P1 (Fig. S1) made using the more hydrophobic crosslinker ethylene glycol dimethacrylate (EGDMA). As expected from our previous report [14], P2 demonstrated the most promising performance. Hence, although P1 clearly enriched mono-phosphorylated and 


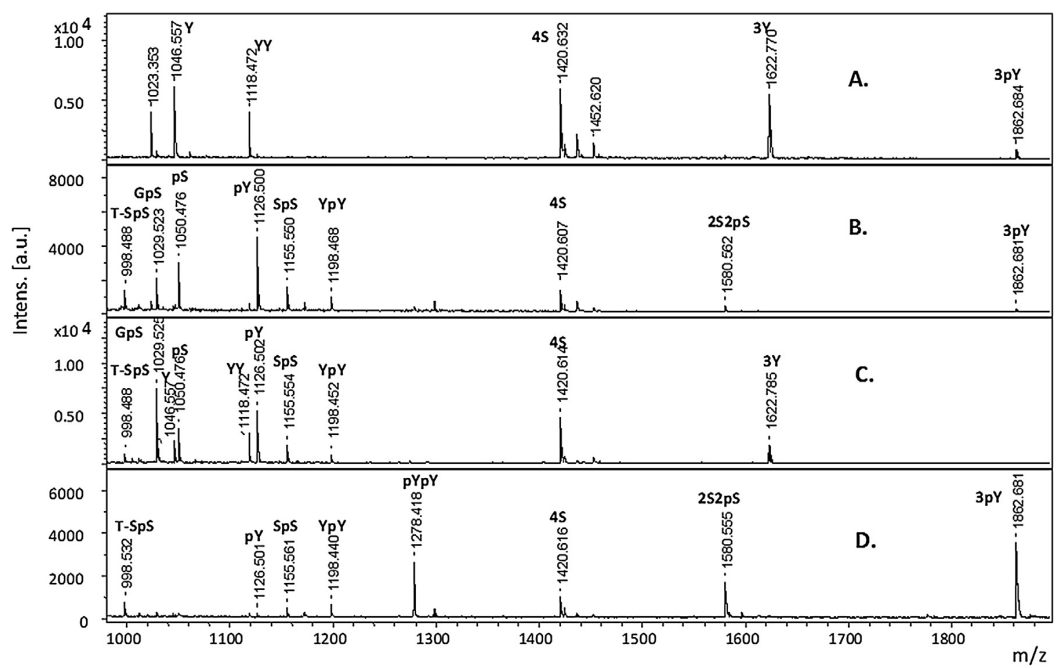

Fig. 2. MALDI-TOF/TOF-MS analysis of phosphorylated peptides from solid phase extraction of a model peptide mixture (1 pmol of each peptide); (A) flow-through from P1 pY-MIP; (B) elution from P1; (C) flow- through from P2 pY-MIP; (D) elution from P2.

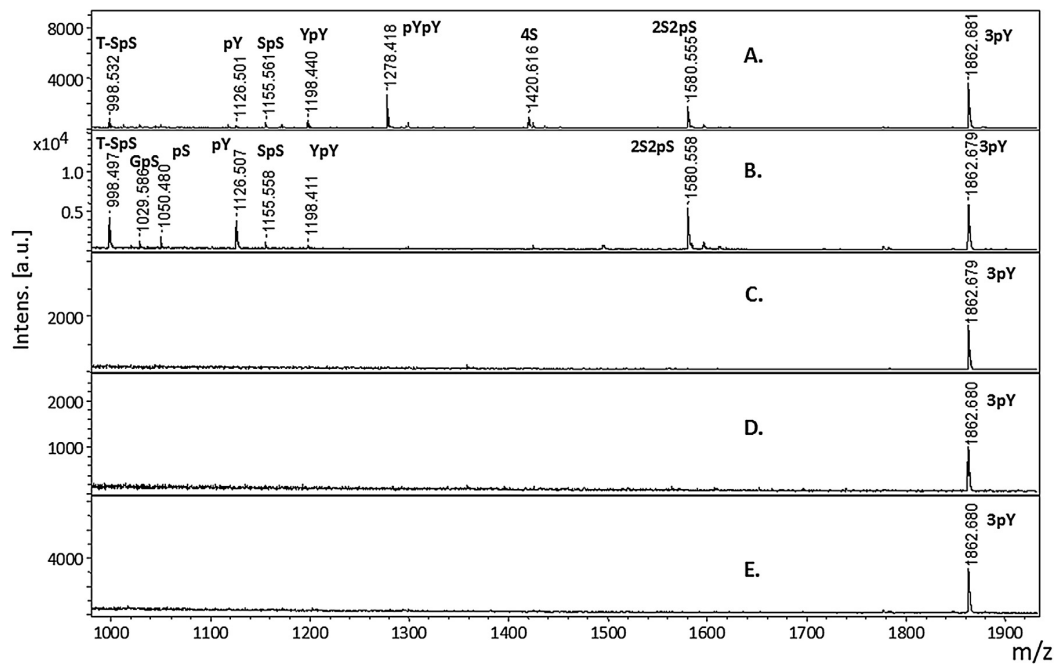

Fig. 3. MALDI-TOF/TOF-MS spectra of SPE fractions after enrichment of a model peptide mixture (1 pmol of each peptide) (A) elution from pY-MIP (P2) material; (B) elution from $\mathrm{TiO}_{2}$ column; (C) elution fraction after immunoprecipitation from phosphotyrosine antibody $4 \mathrm{G} 10$ ( $3 \mu \mathrm{g}$, Merck); (D) elution fraction after immunoprecipitation from phosphotyrosine antibody PY20 (3 $\mu \mathrm{g}$, Biozol); (E) elution fraction after immunoprecipitation from phosphotyrosine antibody PY100 ( $3 \mu \mathrm{g}$, Cell Signaling).

multi-phosphorylated peptides, no clear discrimination between serine- and tyrosine-phosphorylated peptides was observed. This contrasted with the behaviour of P2. The flow-through fractions contained in this case most of the non-phosphorylated and serine-phosphorylated peptides while all tyrosine-phosphorylated peptides could be detected in the elution fraction (Fig. 2). Based on these findings, we continued to compare the performance of the MIP SPE with two established phospho-enrichment techniques based on $\mathrm{TiO}_{2}$ and pY-antibodies. 


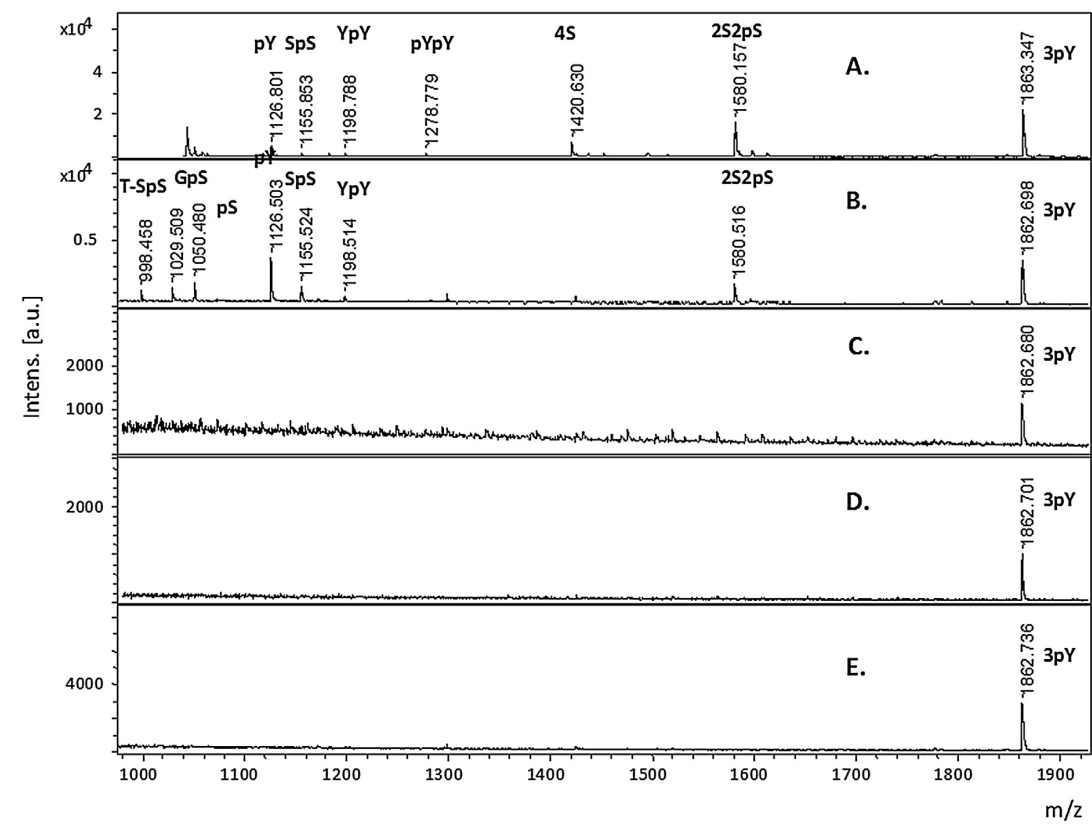

Fig. 4. MALDI-TOF/TOF-MS spectra of SPE fractions, after enrichment of spiked peptides (1 pmol of each peptide) in a digested mouse brain lysate; (A) elution from pY-MIP P2 material; (B) elution from $\mathrm{TiO}_{2}$ column; (C) elution fraction after immunoprecipitation using the phosphotyrosine antibody $4 \mathrm{G} 10$ ( $3 \mu \mathrm{g}$, Merck); (D) elution fraction afte immunoprecipitation using the phosphotyrosine antibody PY20 ( $3 \mu \mathrm{g}$, Biozol); (E) elution fraction after immunoprecipitation using the phosphotyrosine antibody PY100 ( $3 \mu \mathrm{g}$, Cell Signaling).

\subsection{Performance of $\mathrm{TiO}_{2}$ approach}

First we studied $\mathrm{TiO}_{2}$-based affinity enrichment of the model peptide mixture using a well established protocol [15]. $\mathrm{TiO}_{2}$ beads reportedly bind all phosphorylated peptides without discrimination from phosphorylation of serine, tyrosine and threonine and indeed, we found that 8 out of 9 phosphorylated peptides were enriched with $\mathrm{TiO}_{2}$ (Fig. 3). Notably however, the doubly tyrosinephosphorylated peptide pYpY could only be detected at higher sample loads ( $100 \mathrm{pmol}$, Fig. S2) presumably due to the excessive affinity and slow displacement of pYpY from $\mathrm{TiO}_{2}$ columns. This contrasted with the MIP SPE where pYpY was detectable at fmol sample loads and showed that MIP SPE allows a more sensitive detection of tyrosine-phosphorylated peptides.

\subsection{Study of immunoprecipitation approach using 3 anti-pY antibodies}

We thereafter assessed the performance of different pYantibodies. Three generic anti pY-antibodies 4G10 (Merck), pY100 (Cell Signalling) and pY20 (Biozol) widely used in the field of phosphotyrosine research $[12,13,16-18]$ were used to carry out immunoprecipitation (IP) with the 13 peptide mixture. Only the triply tyrosine-phosphorylated peptide (3pY) was enriched by pY-antibodies (Fig. 3; Figs. S3-S5) when low peptide amount was applied, while P2 was able to enrich all four tyrosinephosphorylated peptides (pY, YpY, pYpY, 3pY) at low sample amounts corresponding to $1 \mathrm{pmol}$ of each peptide. To better under- stand the selectivity and sensitivity of the antibodies, an excessive sample of $200 \mathrm{pmol}$ of each peptide was loaded. All tyrosinephosphorylated peptides ( $\mathrm{pY}, \mathrm{YpY}, 2 \mathrm{pY}, 3 \mathrm{pY}$ ) could now be detected by MALDI-MS regardless of the antibody used (Fig. S6). A reason for this high sample load could be that IP involves many washing steps which can lead to a loss of the bound targeted peptides from the antibodies. The large incubation volume (1.5 mL Eppendorf tube) and resulting sample dilution further reduces detection sensitivity in the IP procedure.

A combination of $4 \mathrm{G} 10$ and PY100 is recommended [13] for the identification or the affinity purification of a larger number of tyrosine-phosphorylated peptides. Our study indicated that this combination leads to an increased unspecific binding (Table S2 and Fig. S7). In contrast to antibodies, all tyrosine-phosphorylated peptides were enriched using P2 independent of the sample load (1 pmol or $200 \mathrm{pmol}$ ) (Fig. 2).

Encouraged by the above results, the SPE performance of the pYMIP was further investigated for a complex sample and was again benchmarked against $\mathrm{TiO}_{2}$ and anti-pY-antibodies. The peptide mixture ( $1 \mathrm{pmol}$ of each peptide; ca. $15 \mathrm{ng}$ sample) was therefore spiked in digested mouse brain lysate. The mouse brain lysate was analyzed before spike-in experiment and 44 phosphopeptides out of 10,400 total peptides were identified from $200 \mathrm{ng}$ mouse brain digest (Table S2). Unexpectedly, the MALDI-MS approach could be used to detect the target peptides in a simple and unequivocal way (Fig. 4). Nevertheless, for lower spiking levels ( $0.5 \mathrm{pmol})$, a loss of 2S2pS, pYpY and YpY was observed when the $\mathrm{TiO}_{2}$ method was used (Fig. S8), whereas the P2 method still led to the enrich- 
ment of all tyrosine-phosphorylated peptides (Fig. S9). This result indicates that P2 can be used to extract both mono and mulitiply tyrosine-phosphorylated peptides in complex samples. In addition, the method relying on P2 displayed the highest sensitivity of all methods as reflected in the enrichment of all four tyrosinephosphorylated peptides from complex mouse brain lysate (Fig. S9). In contrast, antibodies (Fig.S9-S12) and $\mathrm{TiO}_{2}$ (Fig.S8) failed at the lower sample loads; the latter as described in our previous work [19].

\section{Conclusion}

The focus of this work has been to compare three phosphopeptide enrichment procedures using otherwise identical experimental conditions (type and amount of loaded sample) concerning their efficiency to capture targets in a spiked brain lysate digest. The results show that imprinted polymers can complement and potentially even substitute well established bioanalytical tools in protein PTM research. Their high affinity and programmable selectivity combined with their compatibility with typical LC-MS hydro-organic mobile phases allow the use of streamlined enrichment protocols which is both time and sample saving. The excessive spiking levels we justify by the use of MALDI-TOF/TOF-MS as the common detection technique as well as the insensitivity of the immunoenrichment protocol to lower spiking levels. Ongoing work will demonstrate the applicability of the method for pY selective enrichment from real samples [20].

\section{Acknowledgments}

This work was supported by DFG projects with the grant agreement numbers MA 3257/4-2, MA 3257/5-1, SE 777/9-1 and the EU-funded Marie Curie ITN project PEPMIP (PITN-GA-2010264699) and by P.U.R.E. (Protein Unit for Research in Europe), a project of North Rhine-Westphalia, a federal state of Germany. The authors sincerely thank K. Mechtler from the Institute of Molecular Pathology (Vienna, Austria), I. Feldmann from ISAS (Dortmund, Germany) for providing self-synthesized peptides.

\section{Appendix A. Supplementary data}

Supplementary data associated with this article can be found, in the online version, at http://dx.doi.org/10.1016/j.chroma.2016.10. 018 .

\section{References}

[1] P. Cohen, The origins of protein phosphorylation, Nat. Cell Biol 4 (2002) E127-E130

[2] K. Machida, B.J. Mayer, P. Nollau, Profiling the global tyrosine phosphorylation state, Mol. Cell. Proteomics 2 (2003) 215-233.
[3] S. Di Palma, A. Zoumaro-Djayoon, M. Peng, H. Post, C. Preisinger, J. Munoz, A.J. Heck, Finding the same needles in the haystack? A comparison of phosphotyrosine peptides enriched by immune-affinity precipitation and metal-based affinity chromatography, J. Proteomics 91 (2013) 331-337.

[4] M. Zarei, A. Sprenger, F. Metzger, C. Gretzmeier, J. Dengjel, Comparision of ERLIC-TiO 2 , HILIC-TiO 2 , and SCX-TiO 2 for global phosphoproteomics approaches, J. Proteome Res. 10 (2011) 3474-3483.

[5] B. Blagoev, S.E. Ong, I. Kratchmarova, M. Mann, Temporal analysis of phosphotyrosine-dependent signaling networks by quantitative proteomics, Nat. Biotechnol. 22 (2004) 1139-1145

[6] K. Rikova, A. Guo, Q. Zeng, A. Possemato, J. Yu, H. Haack, J. Nardone, K. Lee, C. Reeves, Y. Li, Y. Hu, Z. Tan, M. Stokes, L. Sullivan, J. Mitchell, R. Wetzel, J. Macneill, J.M. Ren, J. Yuan, C.E. Bakalarski, J. Villen, J.M. Kornhauser, B. Smith, D. Li, X. Zhou, S.P. Gygi, T.L. Gu, R.D. Polakiewicz, J. Rush, M.J. Comb, Global survey of phosphotyrosine signaling
cancer, Cell 131 (2007) 1190-1203.

[7] K. Schmelzle, S. Kane, S. Gridley, G.E. Lienhard, F.M. White, Temporal dynamics of tyrosine phosphorylation in insulin signaling, Diabetes 55 (2006) dynamics of

[8] M. Emgenbroich, C. Borrelli, S. Shinde, I. Lazraq, F. Vilela, A.J. Hall, J. Oxelbark E.De Lorenzi, J. Courtois, A. Simanova, J. Verhage, K. Irgum, K. Karim, B. E.De Lorenzi, J. Courtois, A. Simanova, J. Verhage, K. Irgum, K. Karim,
Sellergren, A phosphotyrosine-imprinted polymer receptor for the recognition of tyrosine phosphorylated peptides, Chem. Eur. J. 14 (2008) 9516-9529.

[9] S. Helling, S. Shinde, F. Brosseron, A. Schnabel, T. Müller, H.E. Meyer, K. Marcus, B. Sellergren, Ultratrace enrichment of tyrosine phosphorylated peptides on an imprinted polymer, Anal. Chem 83 (2011) 1862-1865.

[10] M.R. Larsen, T.E. Thingholm, O.N. Jensen, P. Roepstorff, T.J. Jørgensen, Highly selective enrichment of phosphorylated peptides from peptide mixtures using titanium dioxide microcolumns, Mol. Cell. Proteomics 4 (2005) 873-886.

[11] T. Thingholm, T. Jorgensen, O.N. Jensen, M. Larsen, Highly selective enrichment of phosphorylated peptides using titanium dioxide, Nat. Protoc. 1 (2006) 1929-1935.

[12] P.J. Boersema, L.Y. Foong, V.M. Ding, S. Lemeer, B. van Breukelen, R. Philp, J. Boekhorst, B. Snel, J. den Hertog, A.B. Choo, A.J. Heck, In-depth qualitative and quantitative profiling of tyrosine phosphorylation using a combination of phosphopeptide immunoaffinity purification and stable isotope dimethy labeling, Mol. Cell. Proteomics. 9 (2010) 84-99.

[13] M. Tinti, A.P. Nardozza, E. Ferrari, F. Sacco, S. Corallino, L. Castagnoli, G. Cesareni, The 4G10, pY20 and p-TYR-100 antibody specificity:profiling by peptide microarrays, N. Biotechnol. 29 (2012) 571-577.

[14] S. Shinde, A. Bunschoten, J.A.W. Kruijtzer, R.M.J. Liskamp, B. Sellergren, Imprinted polymers displaying high affinity for sulfated protein fragments, Angew. Chem. Int. Ed. Engl. 51 (2012) 8326-8329.

[15] T. Thingholm, O.N. Jensen, P.J. Robinson, M. Larsen, SIMAC (sequential elution from IMAC), a phosphoproteomics strategy for the rapid separation of monophosphorylated from multiply phosphorylated peptides, Mol. Cell. Proteomics 7 (2008) 661-671.

[16] C.I. Chang, B. Zoghi, J.C. Liao, L. Kuo, The involvement of tyrosine kinases, cyclic AMP/protein kinase A, and p38 mitogen-activated protein kinase in IL-13-medicated arginase I induction in macrophages: its implications in IL-13-inhibited nitric oxide production, J. Immunol. 165 (2000) 2134-2141.

[17] R.L. Cutler, L. Liu, J.E. Damen, G. Krystal, Multiple cytokines induce the tyrosine phosphorylation of She and its association with Grb2 in hemopoietic cells, J. Biol. Chem. 268 (1993) 21463-21465.

[18] J.R. Glenney Jr., L. Zokas, M.P. Kamps, Monoclonal antibodies to phosphotyrosine, J. Immunol. Methods 109 (1988) 277-285.

[19] J. Chen, S. Shinde, M.H. Koch, M. Eisenacher, S. Galozzi, T. Lerari, K. Barkovits, P. Subedi, R. Krüger, K. Kuhlmann, B. Sellergren, S. Helling, K. Marcus, Low-bias phosphopeptide enrichment from scare samples using plastic antibodies, Sci. Rep. 5 (2015) 11438.

[20] L. Bllaci, et al., (2016), manuscript in preparation. 



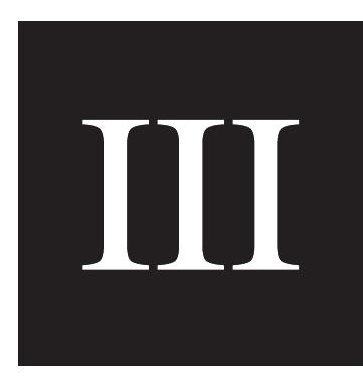





\title{
Hierarchically templated beads with tailored pore structure for phosphopeptide capture and phosphoproteomics
}

\author{
Celina Wierzbicka, $†$ Silje B. Torsetnes, $¥$ Ole N. Jensen, $¥$ Sudhirkumar Shinde† and Börje Sellergren*† \\ † Department of Biomedical Science, Faculty of Health and Society, Malmö University, 20506 Malmö, Sweden \\ ¥ Department of Biochemistry and Molecular Biology and VILLUM Center for Bioanalytical Sciences, University of Southern \\ Denmark, DK-5230 Odense M, Denmark
}

\begin{abstract}
Two templating approaches to produce imprinted phosphotyrosine capture beads with controllable pore structure are reported and compared with respect to their ability to enrich phosphopeptides from tryptic peptide mixture. The beads were prepared by polymerization of urea-based host monomer and crosslinker inside the pores of macroporous silica beads with both free and immobilized template. In the final step the silica was removed by fluoride etching resulting in mesoporous polymer replicas with narrow pore size distributions, pore diameters $\approx 10 \mathrm{~nm}$ and surface area $>260 \mathrm{~m}^{2} / \mathrm{g}$. The beads displayed pronounced phosphotyrosine affinity and selectivity in binding tests using model peptides in acetonitrile rich solutions with a performance surpassing solution polymerized bulk imprinted materials. Tests of the beads for the enrichment of phosphopeptides from tryptic digests of twelve proteins revealed both $\mathrm{pY} / \mathrm{pS}$ and $\mathrm{pY} / \mathrm{Y}$ selectivity. This was reflected in a nearly 6-fold increase in the enrichment factor of a 23-mer $\mathrm{pY}$ peptide and $\mathrm{pY} / \mathrm{pS}$ normalized intensity ratios up to 1.5 , when comparing the template mesoporous beads with the bulk materials.
\end{abstract}

\section{Introduction}

Protein phosphorylation is a reversible post-translational modification (PTM) playing a central role in numerous biological events, several of which are directly linked to disease pathogenesis. $\frac{1}{}$ Phosphoproteomics, i.e. the dynamic mapping of the occurrence of this PTM, has become an essential activity in the development of new drugs and diagnostic methods. $\frac{2-7}{}$ Difficulties in the analysis of phosphorylated proteins arise from their low abundance (e.g. phosphotyrosine) and transient nature. These challenges were addressed in functional proteomics using phosphopeptide specific affinity enrichment techniques and mass spectrometry, recently in parallel high throughput formats. ${ }^{4}$ I Several chemoaffinity-based techniques to concentrate phosphopeptides from complex biological samples have been developed to date, each with their benefits and limitations, the latter generally referring to a lack of side chain selectivity, i.e. recognition of pY, pS and pT respectively, a bias towards certain amino acids or sequence motifs and incompatibility with high throughput formats. $\frac{3}{-}$ Another limitation is inherent in the bottom up proteomics approach per se. ${ }^{8}$ Since this relies on the digestion of proteins to small peptides $(<3$ $\mathrm{kDa}$ ) by trypsin followed by enrichment and LC-MS based readout of the peptide amino acid sequences, it is difficult to pinpoint multiple modifications (e.g. histone acetylation, methylation, phosphorylation) that are far apart from each other. Top down or middle down proteomics analyzing intact proteins or partially digested proteins (3$20 \mathrm{kDa}$ ) respectively address these issues. ${ }^{8}$ Enrichment techniques adapted to larger phosphopeptide targets are therefore needed.
Molecular epitope imprinting has in the above contexts emerged as a possible alternative affinity technique. 9 Several approaches to develop phosphopeptide selective molecularly imprinted polymers (MIPs) have been reported to date. 9-14 In our first report, we introduced an epitope imprinting approach relying on the templating of minimal fragments of the targeted peptides. 9 Hence, imprinting of N, C-protected phosphoamino acids such as $\mathrm{pY}$ and $\mathrm{pS}$ produced binding sites complementary to $\mathrm{pY}$ and pS peptides, respectively. The success of this approach depended on the combined use of lipophilic phosphoamino acid salts and urea-based host monomer in a 1:2 stoichiometry. Incorporation of the resulting ternary complexes in the polymer scaffold followed by template removal left behind binding sites capable of binding the phosphoamino acid guest by quadrupole hydrogen bond interactions.

Having addressed the molecular recognition properties of these materials we have recently turned our attention to their morphological properties. The first generation materials were prepared as porous monoliths following the classical approach to produce macroporous polymers. $\frac{15}{}$ This results in materials displaying a wide distribution of pore sizes with a significant number of pores in the microand low mesoporous range. As a result, the inner pores of such materials show a size dependent binding preference and are likely to be poorly accessible to larger peptides. This will compromise their use for unbiased phosphopeptide enrichment and especially for middle down phosphoproteomics. In order to address this weakness, approaches to control the pore sizes and their distribution are required. 
Grafting of thin polymer films or templated synthesis using inorganic supports of known morphology are very promising in this regard. $\frac{16-18}{\mathrm{~A}}$ prominent example is porous silica which is commonly used as a sacrificial template for the synthesis of mesoporous organic polymer networks with defined particle size, shape and porosity Hierarchical imprinting takes advantage of this morphology control to obtain imprinted polymer beads exhibiting highly accessible binding sites. $\frac{19}{}$ The molecular template can either be immobilized on the walls of the mold $\underline{19}$ or simply dissolved in the monomer mixture. $\underline{20}$ This gives rise to polymer beads featuring enhanced binding site accessibility and faster mass transfer in chromatography. We have here assessed the latter two approaches as means to reduce the size bias in pY selective phosphopeptide enrichments. Micron sized mesoporous polymer beads were thus prepared and compared with a bulk-imprinted benchmark in a mass spectrometry assay of the enrichment of phosphopeptides from tryptic peptide mixtures. We hypothesized that hierarchical imprinting can generate efficient affinity capture for phosphopeptides, particularly of larger phosphopeptides surpassing 3 $\mathrm{kDa}$ that are of interest in studies of PTM crosstalk. Our results demonstrate the feasibility of this approach to boost both overall phosphopeptide and pY selectivity.

\section{Experimental}

\section{Materials}

Pentaerythritol triacrylate (PETA) was from Polysciences (Warrington, PA, USA). 2,2'-azobis(2,4-dimethyl)valeronitrile (ABDV) was from Wako Chemicals GmbH (Neuss, Germany); 1-Hydroxybenzotriazole (HOBt), 1,2,2,6,6 pentamethylpiperidine (PMP), triethylammonium bicarbonate (TEAB) buffer $(1 \mathrm{M})$, acetic anhydride $\left(\mathrm{Ac}_{2} \mathrm{O}\right)$ and formic acid (FA) were from Fluka (Deisenhofen, Germany). Trifluoroacetic acid (TFA), acetonitrile (ACN), methanol $(\mathrm{MeOH})$ were from VWR chemicals. Dry dichloromethane (dry DCM), triethylamine (TEA), ammonium hydrogen difluoride $\left(\mathrm{NH}_{4} \mathrm{HF}_{2}\right), 2,5$-dihydroxybenzoic acid (DHB), piperidine, ninhydrin, acrylamide, iodoacetamide (IAA) and 1,4-dithiothreitol (DTT) were from Sigma-Aldrich (Milwaukee, USA). Dimethylformamide (DMF), dry acetonitrile (dry ACN) were from Acros Organics. Fmoc-pTyr-OH, Fmoc-pSer-OH, Fmoc-Tyr-OH and Fmoc-Gly-OH were from Bachem $\mathrm{GmbH}$ (Weil am Rhein, Germany). Fmoc- $\operatorname{Tyr}\left(\mathrm{PO}\left(\mathrm{NMe}_{2}\right)_{2}\right)-\mathrm{OH}, \mathrm{N}$-ethyldiisopropylamine (DIPEA), (Benzotriazol-1-yloxy)tripyrrolidinophosphonium hexafluorophosphate (PyBOP) and dichloromethane (DCM) were from Merck KGaA (Darmstadt, Germany). Empore C8 extraction disk was from 3M Bioanalytical Technologies (St. Paul, MN, USA). Trypsin was from Promega (Madison, WI, USA).
Proteins and peptides. The twelve proteins used for protein digestion were: Carbonic anhydrase (bovine), Ribonuclease B (bovine pancreas), Serum albumin (bovine), Lactoglobulin (bovine), $\alpha$-Casein (bovine), $\beta$-Casein (bovine), Ovalbumin (chicken), Lysozyme (chicken), Alcohol dehydrogenase (Baker's yeast), Myoglobin (whale skeletal muscle), $\alpha$-Amylase (Bacillus species) and Transferrin (human). Transferrin was from ACE Biosciences A/S (Hilleroed, Denmark), other proteins were from Sigma-Aldrich (Milwaukee, USA). Phosphopeptides YSSDPTGALTEDSIDDTFLPVPEPYINQSVPK, GSHQISLDNPDPYQQDFFPK, MHLPSPTDSNFPYR, RPAGSVQNPVPYHNQPLNPAPSRD, and GSTAENAEpYLR were custom synthesized by GenicBio (Shanghai, China). GADDSpYpYTAR, GADDSYpYTAR, GADDSYYTAR, DRVpYIHPF, DRVpSIHPF, VpYI, VpSI and VYI were custom synthesized by LifeTein LLC (Hillsborough, NJ, USA). DRVYIHPF was from Fluka (Deisenhofen, Germany).

Amino-functionalized macroporous silica beads $\left(\mathrm{NH}_{2} @ \mathrm{Si}\right)$ with an average particle size of $30 \mu \mathrm{m}$, a surface area (S) of $45 \mathrm{~m}^{2} / \mathrm{g}$, average pore diameter $\left(D_{\mathrm{p}}\right)$ of $47.5 \mathrm{~nm}$, and a pore volume $\left(V_{p}\right)$ of $0.81 \mathrm{~mL} / \mathrm{g}$ were purchased from Fuji Silysia Chemical Ltd. (Kozoji-cho, Kasugai Aichi, Japan). $N$-(9-Fluorenylmethoxycarbonyl)-O' $O^{\prime}$-phosphonotyrosine ethyl ester (Fmoc-pTyr-OEt, 2) ${ }^{9}$ and $\mathrm{N}$-3,5-bis(trifluoromethyl)-phenyl- $N^{\prime}$-4-vinylphenylurea (1) ${ }^{21}$ were synthesized as reported elsewhere.

\section{Apparatus and methods}

High-Performance Liquid Chromatography (HPLC). HPLC measurements were carried out on Alliance 2795 instrument equipped with 2996 PDA detector (Waters, Milford, MA, USA).

Scanning Electron Microscopy (SEM). The particle morphology and size were determined using Zeiss EVO LS 10 (E)SEM (Carl Zeiss AG, Oberkochen, Germany) at $\mathrm{T}=25^{\circ} \mathrm{C}, \mathrm{EHT}=15 \mathrm{kV}, \mathrm{WD}=4.5 \mathrm{~mm}$.

Optical microscopy. Optical micrographs were acquired using Nikon Optiphot Epi-Fluorescence microscope equipped with polarizing filters, phase contrast and a DS-U1 digital camera.

Thermogravimetric Analysis (TGA). TGA was carried out using a TGAQ500 (TA Instruments). The sample (5-10 mg) was placed in a platinum pan, which is suspended in a sensitive balance together with the reference pan. The sample was then heated in a furnace with a heating rate of $20^{\circ} \mathrm{C} / \mathrm{min}$, under $\mathrm{N}_{2}$ atmosphere.

Elemental Analysis. Carbon, nitrogen, and hydrogen contents were determined by elemental analysis at the Department of Organic Chemistry, Johannes Gutenberg Universität Mainz using a Heraeus $\mathrm{CHN}$-rapid analyzer ( $\mathrm{Ha}$ nau, Germany).

FT-IR Spectroscopy. Infrared spectra were recorded using a Thermo Nicolet Nexus 6700 instrument (Thermo Scientific, Waltham, MA, USA). 
UV absorbance measurements were performed on a Safire plate reader (Tecan Group Ltd., Männedorf, Switzerland) using a quartz 96-well microplate (Hellma GmbH, Müllheim, Germany).

MALDI-TOF/TOF-MS All mass spectra were obtained using MALDI reflector time of flight mass spectrometer (ultrafleXtreme MALDI-TOF/TOF-MS/MS; Bruker Daltonics, Bremen, Germany) controlled by flexControl software (version 2.4, Bruker Daltonics, Bremen, Germany). The system was operated in positive ion reflector mode only recording MS1 spectra in the $\mathrm{m} / \mathrm{z}$ range of $700-4000$. Dihydroxybenzoic acid (DHB, $40 \mathrm{mg} / \mathrm{mL}$ ) in $50 \% \mathrm{ACN}$ and $1 \%$ phosphoric acid was used as matrix. $\underline{22}$ Relative laser fluence was set at $55 \%$. Signals from 1000 laser shots $(10 \times$ 100 shots at 10 different positions) were averaged. Data collection, in terms of the scanning conditions and number of the scans, was performed identically for all samples unless otherwise noted. Mass spectrometric data analysis was performed using FlexAnalysis 3.4 software (Bruker Daltonik $\mathrm{GmbH}$, Bremen, Germany). The signal intensity threshold for identification of peptides in the sample was arbitrary set at $9000 \mathrm{a}$. u.

For the peptide YSSDPTGALTEDSIDDTFLPVPEPYINQSVPK threshold value was set at 3000 a.u.

Nitrogen sorption Nitrogen sorption measurements were performed on the ASAP2020 Sorption Analyzer (Micrometrics, Norcross, GA, USA). Prior to the measurements, samples (100-150 $\mathrm{mg}$ ) were heated at $105^{\circ} \mathrm{C}$ under high vacuum $\left(10^{-5} \mathrm{~Pa}\right)$ for $8 \mathrm{~h}$. The specific surface areas $\mathrm{S}$ were evaluated by using the Brunauer-Emmett-Teller (BET) method, the specific pore volumes $V_{p}$ and the average pore diameter $D_{p}$ by using the Barrett-Joiner-Halenda (BJH) theory applied to the desorption branch of the isotherm.

Measurement of swelling NMR tubes were filled with dry polymer particles $(100 \mathrm{mg})$ and the height of dry polymer bed was measured. Next ACN $(1 \mathrm{~mL})$ was added and the particles allowed to soak in the solvent for $24 \mathrm{~h}$. The particles were then allowed to settle and the bed height of the swollen particles was measured. The swelling factor was calculated as the ratio of the bed height of the swollen particles to the bed height of the dry particles.

\section{Silica surface modification}

$\mathrm{NH}_{2} @ \mathrm{Si}(20 \mathrm{~g})$ was suspended in DMF $(100 \mathrm{~mL})$ in a $250 \mathrm{~mL}$ round bottomed flask equipped with an overhead stirrer. Next, acetic anhydride was added $(20 \mathrm{~mL})$ and the suspension was stirred at room temperature overnight. Thereafter the silica was filtered off, washed with DMF $(3 \times 50 \mathrm{~mL})$ and $\mathrm{MeOH}(3 \times 50 \mathrm{~mL})$ and dried under vacuum overnight to yield $\mathrm{N}$-acetylated silica (AcNH@Si). Negative ninhydrin test confirmed complete protection of the surface amino groups. The degree of acetylation was confirmed by TGA analysis.

\section{Immobilization of pY-template on silica}

The $p Y$ template was immobilized on the silica surface in a three step process (Figure S1).

Coupling: $\mathrm{NH}_{2} @ \mathrm{Si}(3.0 \mathrm{~g})$ was suspended in DMF/DCM (50/50 v/v; $30 \mathrm{~mL}$ ) under nitrogen in a two neck $100 \mathrm{~mL}$ round bottomed flask equipped with an overhead stirrer. Next, Fmoc-Tyr(PO(NMe $\left.)_{2}\right)-O H(1.0$ eq), PyBOP (1.1 eq), HOBt (1.1 eq) and DIPEA ( $2.2 \mathrm{eq})$ were added according to desired amount of template loading on silica surface (see Table S1 for the specific amounts used in each case). The reaction mixture was stirred under nitrogen atmosphere overnight. The silica was then filtered off and washed on a glass funnel with DMF $(3 \times 10 \mathrm{~mL})$ and DCM $(3 \times 10 \mathrm{~mL})$ and dried in vacuo.

Endcapping: The modified silica from the previous step $(2.5 \mathrm{~g})$ was suspended in DMF $(30 \mathrm{~mL})$ in a $100 \mathrm{~mL}$ round bottomed flask equipped with an overhead stirrer. After addition of acetic anhydride $(2 \mathrm{~mL})$ the reaction mixture was stirred at room temperature for $4 \mathrm{~h}$. Next, the silica was filtered off and washed with DMF $(3 \times 10 \mathrm{~mL})$ and $\mathrm{MeOH}(3 \times 10 \mathrm{~mL})$ and finally dried in vacuo to give Fmoc-p*Tyr@Si. Ninhydrin tests indicated that the protection of the amino groups was complete.

Deprotection: The silica from the previous step $(2.0 \mathrm{~g})$ was suspended in TFA/ $\mathrm{H}_{2} \mathrm{O}(9: 1 \mathrm{v} / \mathrm{v} ; 5 \mathrm{~mL})$ and shaken in a sealed $20 \mathrm{~mL}$ scintillation glass vial overnight. The solid was thereafter filtered off, washed with water $(3 \times 10 \mathrm{~mL})$ and $\mathrm{MeOH}(3 \times 10 \mathrm{~mL})$ and dried in vacuo to yield silica with immobilized template Fmoc-pTyr@S (Fmoc-pTyr@Si-A - Fmoc-pTyr@Si-E, Table S1).

Quantification of the immobilized template: $10 \mathrm{mg}$ of silica containing immobilized template (Fmoc-pTyr@Si-A Fmoc-pTyr@Si-E, Table S1) was mixed with $1 \mathrm{~mL}$ of $20 \%$ piperidine in DMF and shaken for $1 \mathrm{~h}$. Next, the sample was centrifuged and the supernatant analyzed by UV absorbance measurements using a microplate reader $(\lambda=301 \mathrm{~nm})$. The amount of immobilized template was calculated using Fmoc-Gly-OH as an external standard.

\section{Preparation of $\mathrm{pY}$ - imprinted polymers}

Crushed monoliths (MIP-B, NIP-B). Fmoc-pTyr-OEt template (2) (100 mg, $0.20 \mathrm{mmol}$ ) was dissolved in dry ACN $(2.4 \mathrm{~mL})$ in a $20 \mathrm{~mL}$ scintillation glass vial. Next, PMP (71 $\mu \mathrm{l}, 0.40 \mathrm{mmol}$ ), functional monomer 1 (146 mg, $0.40 \mathrm{mmol}$ ), acrylamide (28 $\mathrm{mg}, 0.40 \mathrm{mmol}$ ), PETA $(1.55 \mathrm{~g}, 5.20 \mathrm{mmol})$ and ABDV $(1 \% \mathrm{w} / \mathrm{w}$ of total monomers) were added to the solution. A sample of this prepolymerization mixture $(750 \mu \mathrm{L})$ was saved for subsequent preparation of the polymer beads. The remaining mixture was cooled on ice bath while bubbled with $\mathrm{N}_{2}$ for $10 \mathrm{~min}$ and transferred to a $50 \mathrm{~mL}$ Schlenk tube under continuous $\mathrm{N}_{2}$ flow. Next, tube was closed with glass stopper and placed for $24 \mathrm{~h}$ in a water bath heated to $50{ }^{\circ} \mathrm{C}$. The obtained polymer monolith (MIP-B) was removed from the tube, lightly crushed and washed with 
$\mathrm{MeOH} / 1 \mathrm{M} \mathrm{HCl}(80: 20 \mathrm{v} / \mathrm{v})(3 \times 30 \mathrm{~mL})$ followed by solvent extraction with $\mathrm{MeOH}$ in a Soxhlet apparatus for $24 \mathrm{~h}$. The course particles were then crushed and sieved. The fraction of particles with the size range $25-50 \mu \mathrm{m}$ was used in all experiments. Non-imprinted polymer (NIP-B) used as a control was prepared in the same way but with the omission of template.

Polymer microspheres (MIP-M, NIP-M). Samples of AcNH@Si (1.0 g) were first deaerated in $50 \mathrm{~mL}$ Schlenk tubes (three cycles vacuum- $\mathrm{N}_{2}$ ) and then allowed to soak in MIP-B or NIP-B prepolymerization mixtures $(750 \mu \mathrm{l}$, vide supra) under continuous $\mathrm{N}_{2}$ flow while stirring with a spatula until the particles were freely flowing (indicating completion of the pore filling). Next, the tubes were closed with glass stopper and the polymerization was thereafter initiated by placing the tubes in a water bath heated to $50{ }^{\circ} \mathrm{C}$. After $24 \mathrm{~h}$ the resulting composite beads were transferred to $50 \mathrm{~mL}$ polypropylene centrifugation tubes followed by addition of the etching solution ( $3 \mathrm{M} \mathrm{NH}_{4} \mathrm{HF}_{2}$ in water). The tubes were subsequently shaken on a rocking table for $24 \mathrm{~h}$. Thereafter, the polymers were washed with $\mathrm{MeOH} / 1 \mathrm{M} \mathrm{HCl}(80: 20 \mathrm{v} / \mathrm{v})$ $(3 \times 40 \mathrm{~mL})$ and solvent extracted in a Soxhlet apparatus with $\mathrm{MeOH}$ for $24 \mathrm{~h}$. The resulting polymer beads (MIP$\mathrm{M}, \mathrm{NIP}-\mathrm{M})$ were dried in vacuo overnight.

Hierarchically imprinted microspheres (MIP-H, NIP-H). Fmoc-pTyr@Si-(A-E) (1.0 g each) were each soaked in dry ACN ( $2 \mathrm{~mL}$ ) in $50 \mathrm{~mL}$ Schenk tubes. Next, PMP and functional monomer 1 (both 2 eq with respect to template loading) were added and the solvent thereafter removed under vacuum. Next, the silica samples were deaerated (three cycles vacuum- $\mathrm{N}_{2}$ ) and kept under continuous $\mathrm{N}_{2}$ flow. A monomer mixture consisting of acrylamide (28 $\mathrm{mg}, 0.39 \mathrm{mmol})$, PETA $(1.55 \mathrm{~g}, 5.20 \mathrm{mmol})$ and ABDV ( $1 \% \mathrm{w} / \mathrm{w}$ based on total monomers) dissolved in acetonitrile $(2.4 \mathrm{~mL})$ was prepared. The silica samples were thereafter soaked in $750 \mu \mathrm{L}$ of the monomer mixture. For the non-imprinted material the monomer mixture $(750 \mu \mathrm{L})$ was mixed with urea monomer (the same amount as for corresponding MIP) prior to addition to the silica. The tubes were closed with glass stoppers and placed in a water bath heated to $50{ }^{\circ} \mathrm{C}$ for $24 \mathrm{~h}$. Next, the materials were submitted to etching, washing and solvent extraction as in the case of MIP-M and NIP-M described above. Five hierarchically imprinted MIPs (MIP$\mathrm{HA}-\mathrm{MIP}-\mathrm{HE}$ ) and corresponding NIPs (NIP-HA - NIP-HE) were obtained (Table S2).

\section{Solid phase extraction}

Polymer particles $(20 \mathrm{mg}$ ) were packed in single fritted SPE cartridges (ISOLUTE, Biotage) and protected with a frit on top. The polymers were first conditioned with $95 \%$ $\mathrm{ACN}+0.1 \% \mathrm{FA}(2 \times 1 \mathrm{~mL})$ followed by loading of an equimolar mixture of Fmoc-pTyr-OH, Fmoc-pSer-OH and Fmoc-Tyr-OH ( $1 \mathrm{~mL}$, each at $100 \mu \mathrm{M}$ concentration) in $95 \% \mathrm{ACN}+0.1 \% \mathrm{FA}$. The washing step was performed with $80 \% \mathrm{ACN}+0.1 \% \mathrm{FA}(1 \mathrm{~mL})$ and it was followed by elution with $80 \% \mathrm{MeOH}+1 \%$ TFA $(1 \mathrm{~mL})$. Flow-through (FT), washing (W) and elution (E) fractions were analyzed by reversed phase HPLC to determine the unbound amount of each compound. The column was Synergi $4 \mu \mathrm{m}$ POLAR-RP $80 \AA \AA$ (Phenomenex, $75 \times 2 \mathrm{~mm}$ ). Mobile phases were (A) $\mathrm{H}_{2} \mathrm{O}+0.1 \%$ TFA and (B) $\mathrm{MeOH}+0.1 \%$ TFA. A linear gradient method of $40 \% \mathrm{~B}$ to $80 \% \mathrm{~B}$ in $15 \mathrm{~min}$ at a flow rate of $0.6 \mathrm{~mL} / \mathrm{min}$ was used. The injection volume was $20 \mu \mathrm{L}$ and the detection was performed by UV absorbance measurement at $265 \mathrm{~nm}$. The resulting peak areas were used to calculate the amount of bound analytes $(B)$ on the polymer according to equation (1). The results are averages of three independent experiments.

$$
B=\left(C_{0}-c\right) v / m
$$

Where $C_{0}$ is the initial solute concentration, $c$ is the final free solute concentration in the supernatant, $v$ is the total volume of the adsorption mixture, and $m$ is the mass of polymer in each vial.

\section{Binding isotherms}

The polymers (10 mg each) were separately mixed with $0.5 \mathrm{~mL}$ of Fmoc-pTyr-OH at 0.05, 0.1, 0.25, 0.50, 1.0 and $1.5 \mathrm{mM}$ concentration in $95 \% \mathrm{ACN}$ and shaken vigorously for $2 \mathrm{~h}$. Next, the samples were centrifuged and the supernatant analyzed by reversed phase HPLC using method described above to determine concentration of unbound Fmoc-pTyr-OH. The amount of bound amino acid per unit mass of polymer $(B)$ was calculated according to equation (1). Each experiment was performed three times. Binding curves were constructed by plotting $B$ against free concentration $c$ and were subsequently fitted by non-linear regression in the GraphPad Prism 7 software (GraphPad Software, La Jolla, CA, USA) to a Langmuir mono-site model

$$
B=B_{\max } \cdot c /\left(K_{d}+c\right)
$$

where $B_{\max }$ is the maximum amount of solute bound by the polymer particles at saturation. The association constants $K_{a}$ were calculated as the inverse of the dissociation constants $\left(K_{d}\right)$.

\section{Equilibrium binding tests}

The polymers (10 $\mathrm{mg}$ each) were suspended in $0.5 \mathrm{~mL}$ of a mixture of $\mathrm{VpYI}, \mathrm{VpSI}$ and $\mathrm{VYI}$ (each $20 \mu \mathrm{M}$ ) in $95 \% \mathrm{ACN}$ $+0.1 \% \mathrm{FA}$ and shaken vigorously for $2 \mathrm{~h}$. Next, the samples were centrifuged and the supernatant $(400 \mu \mathrm{L})$ was dried (Genevac EZ-2 evaporator), dissolved in 15\% ACN $(200 \mu \mathrm{L})$ and analyzed by reversed phase HPLC. The column was Prodigy $5 \mu \mathrm{m}$ ODS-3 $100 \AA \AA$ (Phenomenex, $150 \mathrm{x}$ $4.6 \mathrm{~mm}$ ). Mobile phases were (A) $\mathrm{H}_{2} \mathrm{O}+0.1 \%$ TFA and (B) $A C N+0.1 \%$ TFA. A linear gradient method of $15 \% B$ to $20 \% \mathrm{~B}$ in $10 \mathrm{~min}$ at a flow rate of $1.5 \mathrm{~mL} / \mathrm{min}$ was used. 
The injection volume was $100 \mu \mathrm{L}$ and the detection was performed by UV absorbance measurement at $210 \mathrm{~nm}$. The amount of bound peptide per unit mass of the polymer $(B)$ was calculated according to equation (1). Each experiment was performed three times. The test was repeated for octapeptides, using instead a mixture of DRVpYIHPF, DRVpSIHPF and DRVYIHPF (each $20 \mu \mathrm{M}$ ) in $95 \% \mathrm{ACN}+0.1 \%$ TFA. The method for HPLC analysis was a linear gradient of $20 \%$ B to $30 \%$ B in 10 min with other parameters remaining unchanged.

\section{Extraction of phosphopeptides from protein digest \\ Protein digestion}

The twelve proteins, three thereof phosphorylated on serine residues ( $\alpha$-Casein, $\beta$-Casein and Ovalbumin), were separately dissolved in TEAB $(50 \mathrm{mM})$ to concentrations of $20 \mathrm{pmol} / \mu \mathrm{L}$. Proteins were reduced with $10 \mathrm{mM}$ DTT at $56{ }^{\circ} \mathrm{C}$ for $30 \mathrm{~min}$. The proteins were subsequently alkylated with $40 \mathrm{mM}$ IAA at room temperature for $30 \mathrm{~min}$ kept in dark. The proteins were digested with trypsin $(1 \% \mathrm{w} / \mathrm{w})$ at $37^{\circ} \mathrm{C}$ for $12 \mathrm{~h}$. The protein digest sample was prepared by mixing the peptides originating from the proteins in equimolar ratio and dilution with $0.1 \%$ TFA to reach a final concentration of $1 \mathrm{pmol} / \mu \mathrm{L}$. The mixture was stored at $-20^{\circ} \mathrm{C}$ until further use.

The protein digest $(20 \mu \mathrm{L}, 1 \mathrm{pmol} / \mu \mathrm{L})$ and peptide mixture ( $5 \mu \mathrm{L}, 1 \mathrm{pmol} / \mu \mathrm{L}$ of each peptide, see Table 2$)$ were diluted to $1 \mathrm{~mL}$ with loading solvent ( $95 \% \mathrm{ACN}+1 \% \mathrm{FA}$ ) (diluted digest). Polymers ( $2 \mathrm{mg}$ each) were mixed with $100 \mu \mathrm{L}$ of diluted digest and agitated in a Thermomixer at $25^{\circ} \mathrm{C}(1300 \mathrm{rpm})$ for $30 \mathrm{~min}$. The polymer suspension was transferred to a pipette tip microcolumn $(200 \mu \mathrm{l})$ protected with a C8 plug and passed through the column with the aid of a syringe and the flow-through fraction was collected. Thereafter washing was performed with $95 \% \mathrm{ACN}+1 \% \mathrm{FA}(100 \mu \mathrm{L})$. The flow-through and washing fractions were pooled. Finally elution was performed with $80 \% \mathrm{MeOH}+0.1 \%$ TFA $(100 \mu \mathrm{L})$ and the elution fraction saved. The combined flow-through and washing (FTW) and elution (E) fractions as well as a fraction of the sample before MIP treatment were dried in a speedvac and redissolved in $0.1 \%$ TFA $(5 \mu \mathrm{L})$. Each sample $(0.5 \mu \mathrm{L})$ was spotted together with the DHB matrix $(0.5 \mu \mathrm{L})$ on the MALDI target plate, dried and analyzed by MALDITOF/TOF mass spectrometry.

\section{Results and discussion}

\section{Preparation of materials}

The purpose of the study was to investigate the influence of porosity parameters in phosphotyrosine (pY) imprinted materials on their static and dynamic peptide binding properties. We therefore decided to compare the performance of our previously reported pY-MIP (used as a benchmark) featuring a broad pore size distribution, with controlled pore size formats based on silica templating (Figure 1).

The benchmark polymer was prepared using the functional monomer 1 and the bis-PMP salt of Fmoc-pTyr-OEt dissolved in ACN in a 2:1 stoichiometric ratio. Acrylamide was added as a supplementary monomer to provide additional hydrogen bond stabilization and pentaerythritoltriacrylate (PETA) was used as a crosslinking monomer. Conventional azo-initiated thermal polymerization at $50{ }^{\circ} \mathrm{C}$ subsequently afforded the imprinted and nonimprinted polymers which were subsequently crushed and sieved to a $25-36 \mu \mathrm{m}$ particle size fraction. The particles were subjected to template removal by washing with acidified $\mathrm{MeOH}$, followed by extraction with $\mathrm{MeOH}$ and drying.
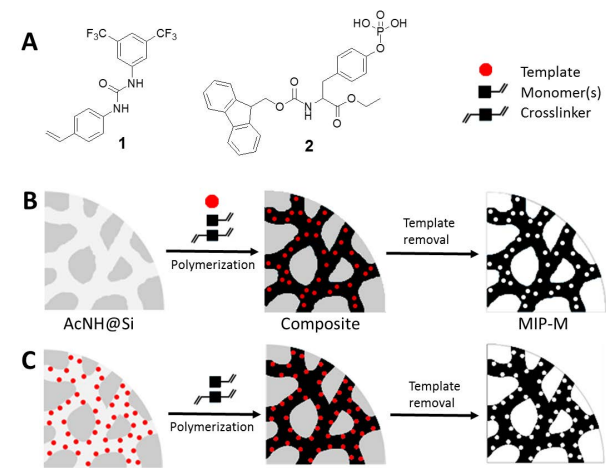

Fmoc-pTyr@Si-A-E
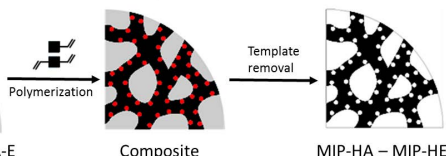

Figure 1. (A) Structures of the urea-based functional monomer (1) and Fmoc-pTyr-OEt template (2); Schematic representation of the preparation of (B) MIP-M and (C) hierarchically imprinted MIPs (MIP-HA - MIP-HE).

The silica templated polymers were subsequently prepared following two alternative approaches (Figure 1). In both approaches we used mesoporous $\left(D_{p} \approx 50 \mathrm{~nm}\right.$ ) spherical silica microparticles as vessels for polymerization in two variants, i.e. with free or immobilized template. In the former approach (Figure 1B) endcapped silica was allowed to soak in the prepolymerization mixture (identical to the one used to prepare the benchmark polymer, i.e. containing $\mathrm{pY}$ template, monomers and initiator) whereafter the particles were thermally cured at $50^{\circ} \mathrm{C}$. This contrasted with the latter approach (Figure $1 \mathrm{C}$ ) where the template had been pre-immobilized on the surface of the silica pore walls (Figure S1). After $24 \mathrm{~h}$ curing the silica mold was dissolved by treatment with an aqueous solution of $\mathrm{NH}_{4} \mathrm{HF}_{2}$ leaving behind organic polymer beads with a size and morphology reflecting those of the original silica (Figures S3 and S4).

A crucial parameter in the latter approach is the surface coverage with immobilized template. A high coverage 
may lead to template clustering which precludes the formation of separate binding sites whereas a low coverage leads to materials featuring insufficient binding capacity. We therefore studied this parameter in more detail and compared polymers prepared from five different silica templates with increasing template coverages (Table S1). The polymers were characterized by elemental analysis (Table S3), optical and scanning electron microscopy (SEM) (Figure S3 and Figure S4), IR-spectroscopy (Figure S6), swelling measurements and nitrogen sorption analysis (Table 1, Figure S5). This confirmed their identity and near identical chemical compositions. The SEM images confirmed that the silica templated materials retained the spherical shape and size of the silica scaffold after etching. This indicates that the residual beads originated from the polymer formed in the silica pore system.

Otherwise only the nitrogen sorption technique, which provides information concerning the porous properties of the materials, and associated swelling tests gave evidence for differences between the polymers (Table 1, Figure S5).

Table 1. Physical properties of imprinted and non-imprinted polymers. ${ }^{a}$

\begin{tabular}{|c|c|c|c|c|}
\hline $\begin{array}{c}\text { Poly- } \\
\text { mer }\end{array}$ & $\mathbf{S}\left(\mathbf{m}^{2} / \mathbf{g}\right)$ & $\mathbf{V}_{\mathbf{p}}(\mathbf{m L} / \mathbf{g})$ & $\mathbf{D}_{\mathbf{p}}(\mathbf{n m})$ & Swelling $(\mathbf{m L} / \mathbf{m L})$ \\
\hline MIP-B & 72 & 0.06 & 3.4 & 2.3 \\
\hline NIP-B & 248 & 0.48 & 8.5 & 1.4 \\
\hline MIP-M & 264 & 0.84 & 12.4 & 2.1 \\
\hline NIP-M & 325 & 1.22 & 15.1 & 1.7 \\
\hline MIP-HE & 326 & 0.94 & 10.4 & 1.9 \\
\hline NIP-HE & 201 & 0.89 & 17.0 & 1.9 \\
\hline
\end{tabular}

The BET specific surface area $(S)$, specific pore volume $\left(V_{p}\right)$ and average pore diameter $\left(D_{p}\right)$ were calculated from the nitrogen adsorption isotherm whereas the swelling was determined by soaking $100 \mathrm{mg}$ of packed bed of polymer particles in $\mathrm{ACN}$ as described in the experimental section.

Thus, all polymers except MIP-B exhibited a mesoporous morphology with surface areas larger than $200 \mathrm{~m}^{2} / \mathrm{g}$ and relatively narrow pore size distributions (Figure $\mathrm{S} 5$ ) with average pore diameters exceeding $10 \mathrm{~nm}$. This contrasted with MIP-B, featuring nearly no dry state porosity but significant swelling in acetonitrile. In view of the contrasting MIP/NIP properties in this case, the origin of this effect is template related. It has previously been attributed to a template induced delay in the phase separation. .9

We gratefully noted that the silica-templated materials featured significantly increased surface areas and average pore sizes. It remained to be investigated how this morphology difference translated into the peptide binding properties of the materials.

\section{Binding isotherms and imprinting efficiency}

In order to compare the affinity and capacity of the materials we recorded the binding isotherms of all materials for the template analogue Fmoc-pTyr-OH in $95 \%$ ACN
(Figure 2A and Figure S2). This solvent was also used in the polymerization step and will hence promote polymer chain conformers present during imprinting, this in turn enhancing imprinting efficiency. Generally, binding to the imprinted polymers exceeded by far that to the corresponding non-imprinted polymers, the latter displaying binding capacities not exceeding $8 \mu \mathrm{mol} / \mathrm{g}$. Comparing different isotherm models $\underline{23}$ it was clear from the correlation coefficients that the data for all imprinted polymers fitted well to a 1:1 binding model (Table S4). Hence, the imprinted sites appear uniform in this concentration interval. $\underline{24}$ This is in agreement with imprinting stemming from a near stoichiometric monomer-template complex formation. Indeed, ${ }^{1} \mathrm{H}$ NMR titrations revealed strong interactions between the two species with $K_{a}$ exceeding $10000 \mathrm{M}^{-1}$
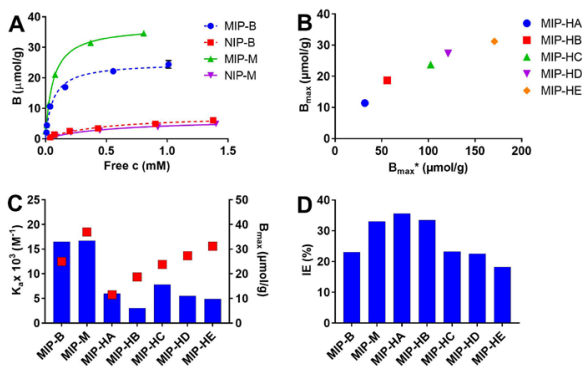

Figure 2. (A) Binding isotherms of Fmoc-pTyr-OH (concentration range 0.05 $1.5 \mathrm{mM}$ ) for MIP-B (blue circles), NIP-B (red squares), MIP-M (green triangles), NIP-M (purple triangles). The results are averages of three replicates with error bars representing standard deviation. (B) Nominal $\left(B_{\max }{ }^{*}\right)$ versus measured $\left(B_{\max }\right)$ capacity of MIPs. (C) Association constants ( $K_{a}$, blue bars) and binding capacities ( $B_{\text {max }}$, red squares) for Fmoc-pTyr-OH interacting with imprinted polymers in $95 \% \mathrm{ACN}$. The binding parameters were obtained by fitting of the binding data in Figure $2 \mathrm{~A}$ and Figure S2 to a Langmuir mono-site binding model. (D) Imprinting efficiency (IE) of MIPS.

Figure $2 \mathrm{C}$ shows the binding constants and capacity estimated by non-linear curve fitting of the data in Table S4 assuming a Langmuir mono-site binding model. The silicatemplated polymer MIP-M prepared using free template displayed the most promising performance after ranking of the polymers in terms of both binding constant and saturation capacity (Figure 2C). This is likely to be the result of a more open pore system (Table 1 ) offering improved accessibility for the guest to the imprinted sites. However, a direct comparison of saturation capacities may be misleading given the different template loads used when synthesizing the materials. Instead, it is interesting to compare the imprinting efficiency which relates the experimentally determined capacity to the nominal value based on the actual load of the template. The silica 
templated materials (e.g. MIP-M, MIP-HA) show the highest values approaching 35\% imprinting efficiency, to be compared with an efficiency of $23 \%$ for the benchmark material MIP-B (Figure 2D, Table S4). Turning to the hierarchically imprinted materials two striking features should be noted. First of all, the template immobilization seems to compromise the binding affinity as seen in the $\mathrm{ca}$. three times lower binding constants for these materials compared to the benchmark MIP-B and MIP-M. Immobilization prevents imprinting memory with respect to the C-terminal substituent of the template. Nevertheless, the absence of a clear trend when comparing MIP-H(A-E) indicates that the quality of the binding sites is similar for these materials, also in agreement with the strong monomer template interactions (vide supra). The second striking feature is the apparent correlation between the measured capacity and the nominal value (Figure 2B). Also this observation is in agreement with the presence of stable monomer template complexes. It is interesting to note that the efficiency decreases with template coverage. This we attribute to template clustering and site coalescence as a result thereof.

\section{Investigation of binding selectivity}

In order to probe the binding selectivity of the materials a competitive solid-phase extraction (SPE) experiment was performed. An equimolar mixture of three amino acids (Fmoc-pTyr-OH, Fmoc-pSer-OH and Fmoc-Tyr-OH) was loaded onto each material packed in SPE cartridges (see experimental part) followed by a washing and an elution step. The amount of each analyte in each fraction was quantified by reversed phase HPLC analysis (Figure 3 and Figure S7).

Non-imprinted materials showed an overall weak retention of the analytes, all of which were quantitatively recovered in the load and wash fractions (Figure S7). Nevertheless, as can be seen in the wash fraction recoveries, a weak preference for the phosphorylated analytes, notably $\mathrm{pY}$, was present. This effect was clearest for the materials prepared in presence of free template (MIP-B, MIP-M). When considering the imprinted materials all of them showed a pronounced selectivity for phosphorylated amino acids with a clear preference for phosphotyrosine. MIP-B, MIP-M and MIP-H(C-E) retained phosphotyrosine very strongly while phosphoserine was mainly found in the wash fractions. The retention of phosphotyrosine on the hierarchically imprinted materials increased with the order of increasing template load, a result corroborated by the measured saturation capacities.

To gain insight into the potential phosphopeptide preference of the materials we designed a model system based on the peptide hormone angiotensin II (DRVYIHPF) including different phosphorylated analogues and truncated sequences. The ability of the receptors to discrimi- nate $\mathrm{pY}$ and $\mathrm{pS}$ in the same sequence context and in peptides of different sizes was thus investigated by comparing the retention of the phosphorylated peptides DRVpYIHPF, DRVpSIHPF, VpYI, VpSI, with the nonphosphorylated peptides DRVYIHPF and VYI.
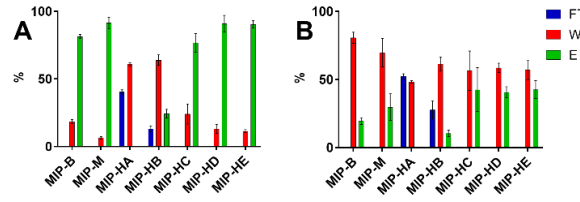

Figure 3. Results of SPE test with Fmoc-pTyr-OH (A) and Fmoc-pSer-OH (B) showing \% of each analyte in the flow-through (FT), washing (W) and elution (E) fractions. The following conditions were applied: loading $95 \% \mathrm{ACN}+0.1 \%$ $\mathrm{FA}$, washing $80 \% \mathrm{ACN}+0.1 \% \mathrm{FA}$, elution $80 \% \mathrm{MeOH}+1 \% \mathrm{TFA}$. The bars show an average of three replicas and the error bars represent standard deviation.

We first investigated binding of the shorter sequences $\mathrm{VpYI}, \mathrm{VpSI}$ and VYI. A ternary mixture of these peptides was thus equilibrated with each of the materials followed by measurement of unbound fractions. The uptakes calculated for the imprinted materials showed a pronounced phosphopeptide preference, in the case of MIP-B and MIP-M accompanied by a notable $\mathrm{pY}$ selectivity (Figure 4). An interesting reversal of the binding preference was observed for the non-imprinted materials which all exhibited a strong $\mathrm{pS}$ selectivity. We believe this to be related to the different basicities of the alkyl versus aryl phosphate groups ( $\mathrm{pY}: \mathrm{pK}_{2}=5.80 ; \mathrm{pS}: \mathrm{pK}_{2}=6.19$ ).
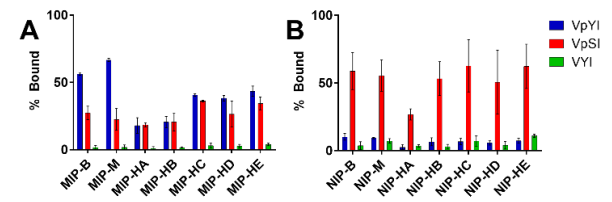

Figure 4. Results of binding equilibrium test with an equimolar mixture of $\mathrm{VpYI}, \mathrm{VpSI}$ and VYI in $95 \% \mathrm{ACN}+0.1 \%$ FA for (A) MIPs and (B) NIPs. The bars show an average of three replicas and the error bars represent standard deviation.

Turning to the native octapeptides (DRVpYIHPF, DRVpSIHPF and DRVYIHPF) we narrowed the investigation to include MIP-B, MIP-M and MIP-HE. Equilibrium binding tests using an equimolar mixture of the three peptides led to the binding results shown in Figure 5. Considering first the uptakes measured for the pY peptide we note that these are significantly lower on the imprinted materials prepared using free template (MIP-B and MIP-M: ca. 22 and $18 \%$ respectively) compared to the uptakes displayed by the hierarchically surface imprinted 
material (MIP-HE: 50\%). Moreover, the uptakes shown by the former materials are lower than those measured for the tripeptides.

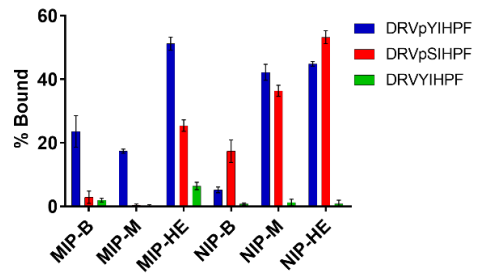

Figure 5. Results of binding equilibrium test of an equimolar ternary mixture of DRVPYIHPF, DRVPSIHPF and DRVYIHPF in $95 \%$ ACN + 0.1\% TFA. The bars show an average of three replicas and the error bars represent standard de viation.

All in all, this indicates that the binding sites in these materials are more buried and therefore less accessible. This also explains the high binding specificity which is reflected in the lack of uptake of the ps peptide. On the other hand, MIP-HE, featuring the surface imprinted sites, did bind this peptide, albeit to a lower extent than the $\mathrm{pY}$ peptide. The non-imprinted materials NIP-M and NIP-HE showed either no side chain selectivity or a preference for $\mathrm{pS}$ (NIP-B).

\section{Phosphopeptide enrichment from complex peptide mixtures}

To validate the ability of the controlled pore size materials to enrich phosphopeptides from complex peptide mixtures we turned to protein digests. Hence, a sample originating from the tryptic digestion of 12 proteins (of which three contain a high abundance of serine-phosphorylated residues, i.e. ovalbumin, $\alpha$-casein and $\beta$-casein $) \underline{25}$ was spiked with $8 \mathrm{pY}$ peptides one pS peptide and two Y peptides (Table 2).

The size of the peptides ranged from 8 to 31 amino acids with charges spanning from -5 to +0.1 and GRAVY index from -1.27 to -0.26 (for the parent nonphosphorylated peptides). Phosphotyrosine peptides represented less than $1 \%$ (by mass) of all peptides in the sample. The polymers $(2 \mathrm{mg}$ ) were equilibrated with the spiked protein digest sample in the loading buffer for $30 \mathrm{~min}$. Thereafter, the particle suspensions were transferred with the pipette to tip columns and the packing then protected with a C8 plug. The flow-through (FT) fraction was collected and pooled with the fraction collected in the washing step (W). Thereafter elution was performed and the resulting fraction (E) collected and saved. All fractions were dried, redissolved and analyzed by MALDI-MS with respect to the presence of $\mathrm{pY}, \mathrm{pS}$ and nonphosphorylated peptides.
As can be seen in Figure 6A, five out of the eight spiked pY peptides along with four pS peptides from the protein digest and the spiked pS peptide were identified in the crude sample before enrichment (Figure 6A, Table S5). The sample clean-up performed with the MIPs allowed the reduction of ion signals stemming from nonphosphorylated peptides to a great extent (Figure 6B-D, Table S5) for improved detection of phosphopeptides. MIP-B was able to extract seven out of the eight spiked $\mathrm{pY}$ peptides whereas spherical MIPs (MIP-M and MIP-HE) extracted all spiked $\mathrm{pY}$ peptides. The combined flowthrough and washing fractions from the MIPs, on the other hand, contained four (MIP-B and MIP-M) or two (MIP-HE) pS peptides and only two (MIP-B, MIP-M) or three (MIP-HE) of the eight pY peptides (Table S5, Figure S8).

\begin{tabular}{l}
\hline Table 2. Model peptides spiked in the twelve protein tryptic digest. \\
\begin{tabular}{|c|c|c|c|c|}
\hline Peptide sequence & Size $^{\mathbf{a}}$ & {$[\mathbf{M}+]^{+}$} & $\begin{array}{c}\text { Net } \\
\text { charge }^{\text {b }}\end{array}$ & $\begin{array}{c}\text { GRAVY } \\
\text { index }^{\mathbf{c}}\end{array}$ \\
\hline DRVYIHPF & 8 & 1046.54 & 0.1 & -0.32 \\
\hline DRVpSIHPF & 8 & 1050.48 & 0.1 & -0.26 \\
\hline GADDSYYAR & 10 & 1118.47 & -1 & -1.24 \\
\hline DRVPYIHPF & 8 & 1126.51 & 0.1 & -0.32 \\
\hline GADDSYpYTAR & 10 & 1198.44 & -1 & -1.24 \\
\hline GADDSpYpYTAR & 10 & 1278.41 & -1 & -1.24 \\
\hline GSTAENAEpYLR & 11 & 1290.54 & -1 & -0.98 \\
\hline MHLPSPTDSNFpYR & 13 & 1644.68 & +1 & -1.00 \\
\hline GSHQISLDNPDPYQQDFFPK & 19 & 2316.00 & -1 & -1.27 \\
\hline $\begin{array}{c}\text { RPAGSVQNPVpY- } \\
\text { HNOPLNPAPSRD }\end{array}$ & 23 & 2594.23 & +2 & -1.25 \\
\hline $\begin{array}{c}\text { YSSDPTGALTED- } \\
\text { SIDDTFLPVPEpYINQSVPK }\end{array}$ & 31 & 3478.58 & -5 & -0.55 \\
\hline
\end{tabular}
\end{tabular}

a Number of amino acids; ${ }^{b}$ Net charge at $\mathrm{pH} 7$; ${ }^{\mathrm{c}}$ GRAVY index for the parent nonphosphorylated peptide.

Peptide ion signal intensities in MALDI-MS are dependent on the ionization efficiency of each of the analytes and the solvent/matrix composition. $\underline{26}$ This precludes its use for direct quantitative analysis unless special precautions are taken and carefully optimized internal standards are used. Changes in the relative abundance of a given compound can, however, be determined by comparing normalized signal intensities. $\underline{\underline{26}}$ Hence, we calculated the relative signal intensities of the $\mathrm{pY}, \mathrm{pS}$ and $\mathrm{Y}$ peptides respectively to the total intensity of all selected peptides in a given fraction (Table S6, Figure 7). The increase in the relative signal intensities of the $\mathrm{pY}$ peptides together with a decrease of the nonphosphorylated peptide signals show that the MIPs in principle work as expected and confirm our previous observations. ${ }^{10}$

A more refined analysis of the data allows further conclusions concerning the relative performance of the materials. Hence, we compared the normalized signal intensities collectively for all pY and pS peptides (Figure 8A) and of all $\mathrm{pY}$ and $\mathrm{Y}$ peptides (Figure $8 \mathrm{~B}$ ). 


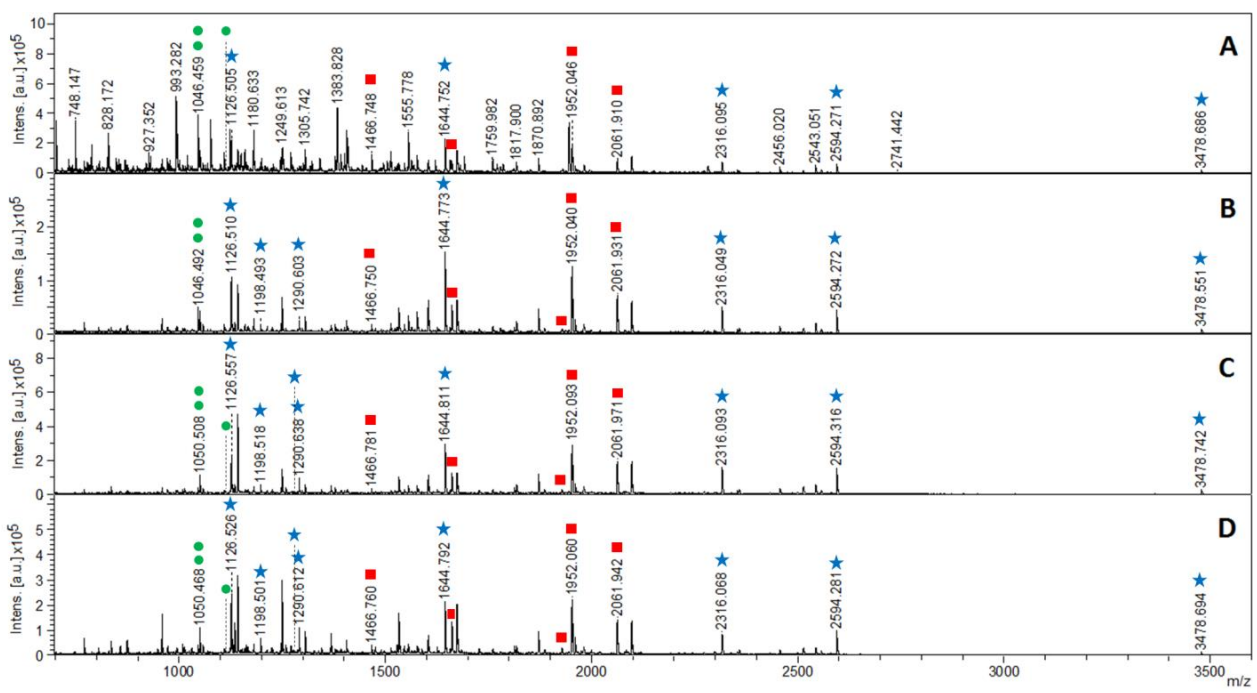

Figure 6. MALDI mass spectra obtained for peptide mixture before enrichment (A), elution fraction from MIP-B (B), MIP-M (C) and MIP-HE (D). Marked are spiked phosphotyrosine peptides (asterisk), phosphoserine peptides (square) and spiked phosphoserine and nonphosphorylated peptides (circle).

This showed that the overall $\mathrm{pY} / \mathrm{pS}$ ratio increased significantly after enrichment. On the other hand, the highest phosphopeptide specific enrichment factor $(\mathrm{pY} / \mathrm{Y})$ was obtained using the templated materials MIP-M and MIP$\mathrm{HE}$. Hence, the nonphosphorylated peptides were depleted from the sample treated with these MIPs. MIP-M here proved to be the most successful in removing the $Y$ peptide (angiotensin II).

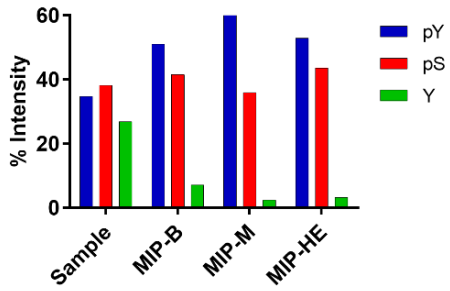

Figure 7. Normalized signal intensities for the $\mathrm{pY}, \mathrm{pS}$ and $\mathrm{Y}$ peptides found in the elution fractions given as a percentage of accumulated intensity of selected ions in a given fraction.

Given the aim of enriching larger phosphopeptide fragments, we were interested in how the selectivity and enrichment responded to the size of the peptide. For this purpose, we compared groups of peptides (one pY, one $\mathrm{pS}$ and one nonphosphorylated peptide) of similar size with the pY being of size $8,14,19$ and 24 amino acids.

A
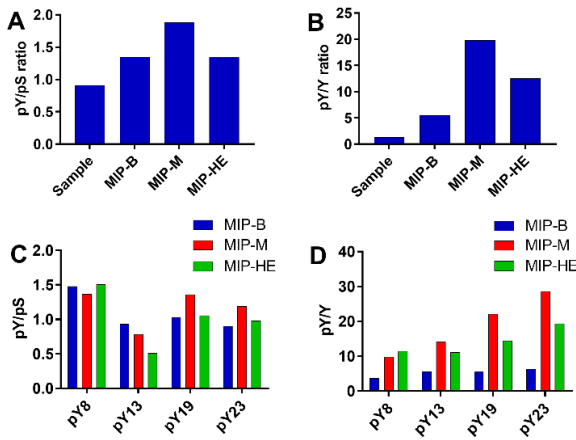

Figure 8. Ratios of normalized signal intensities of the $\mathrm{pY}, \mathrm{pS}$ and $\mathrm{Y}$ peptides for nontreated and treated samples $(A, B)$ and with respect to peptide size for the treated samples (C, D).

The octapeptides corresponding to the angiotensin II model system (vide supra) offer the most stringent test for the $\mathrm{pY} / \mathrm{pS}$ selectivity since it features peptides of identical sequences at the $\mathrm{C}$ and $\mathrm{N}$ terminus. In spite of the 
sequence similarity, the MIPs showed a marked $\mathrm{pY}$ selectivity $(\mathrm{pY} / \mathrm{pS} \approx 1.5)$ also in the more complex digest sample. Turning to the size dependent phosphospecific enrichment (Figures $8 \mathrm{C}$ and $8 \mathrm{D}$ ) we observed clear differences between the materials.

Whereas the benchmark material MIP-B showed the low est $\mathrm{pY} / \mathrm{Y}$ ratio and only a minor increase of the ratio with peptide size, both the mesoporous materials MIP-M and MIP-HE showed a clear trend of increasing enrichment efficiency with increasing size of the peptide. This we attribute to the larger average pore diameter of these materials and a relative increase in the number of sites associated with such pores. In addition to size exclusion effects, it is important to consider the surface chemistry of the materials. The silica template defines not only the average size and distribution of pores in the polymer replica but also the surface chemistry of these pores. Hence, as we have previously shown by the Engelhardt test, $\underline{18}$ surface hydrophilicity is affected by the type of silica surface modification, e.g. TMS endcapped silica leads to a more hydrophobic material than a material synthesized using a rehydroxylated silica template. The acetamide endcapped silicas used in the current study may have resulted in a more hydrophilic surface compared to that present in the benchmark material. Such material will display a lower degree of non-specific peptide binding.

\section{Conclusions}

In conclusion, we have shown that silica templated MIP synthesis and surface imprinting are useful approaches to bias the phosphopeptide preferences to larger peptide sizes (> $2 \mathrm{kDa}$ ) as well as to suppress non-specific binding of nonphosphorylated peptides. Further optimization of the synthesis parameters is in progress to adapt the materials to middle-down and top-down phosphoproteomics workflows.

\section{Associated content}

\section{Supporting information}

Binding isotherms, SEM images and optical micrographs, nitrogen sorption, TGA and elemental analysis, ATR-FTIR and MALDI spectra, MALDI peak intensity analysis.

\section{Acknowledgements}

This work was supported by the EU-funded Marie Curie ITN project PEPMIP (PITN-GA-2010-264699). Work in the ONJ laboratory is supported by a generous grant from the VILLUM Foundation to the VILLUM Center for Bioanalytical Sciences at SDU, Odense.

\section{Notes and references}

1 S. A. Johnson and T. Hunter, Nature Methods, 2005, 2, 17-24.

2 T. E. Thingholm, T. J. Jorgensen, O. N. Jensen and M. R. Larsen Nature Protoc., 2006, 1929-1935.

3 N. M. Riley and J. J. Coon, Analytical Chemistry, 2016, 88, 74 94.

4 S. J. Humphrey, S. B. Azimifar and M. Mann, Nat Biotech, 2015, 33, 990-995.

5 K. Engholm-Keller and M. R. Larsen, PROTEOMICS, 2013, 13 910-931.

6 O. Pagel, S. Loroch, A. Sickmann and R. P. Zahedi, Expert Review of Proteomics, 2015, 12, 235-253.

7 C. J. Tape, J. D. Worboys, J. Sinclair, R. Gourlay, J. Vogt, K. M. McMahon, M. Trost, D. A. Lauffenburger, D. J. Lamont and C. Jørgensen, Analytical Chemistry, 2014, 86, 10296-10302.

8 B. A. Garcia, Journal of the American Society for Mass Spectrometry, 2010, 21, 193-202.

9 M. Emgenbroich, C. Borrelli, S. Shinde, I. Lazraq, F. Vilela, A. J. Hall, J. Oxelbark, E. De Lorenzi, J. Courtois, A. Simanova, J. Verhage, K. Irgum, K. Karim and B. Sellergren, Chem. Eur. J., 2008, 14, 9516-9529.

10 J. Chen, S. Shinde, M.-H. Koch, M. Eisenacher, S. Galozzi, T. Lerari, K. Barkovits, P. Subedi, R. Krüger, K. Kuhlmann, B. Sellergren, S. Helling and K. Marcus, Scientific Reports, 2015, 5 11438.

11 Y. Chen, D. Li, Z. Bie, X. He and Z. Liu, Analytical Chemistry, 2016, 88, 1447-1454.

12 L. Xu, Y. Hu, F. Shen, Q. Li and X. Ren, Journal of Chromatog raphy $A, 2013,1293,85-91$.

13 J. Haginaka, H. Tabo and H. Matsunaga, Analytica Chimica Acta, 2012, 748, 1-8.

14 Q. Li, F. Shen, X. Zhang, Y. Hu, Q. Zhang, L. Xu and X. Ren, Analytica Chimica Acta, 2013, 795, 82-87.

15 B. Sellergren and A. J. Hall, in Molecularly imprinted polymers. Man-made mimics of antibodies and their applications in analytical chemistry., ed. B. Sellergren, Elesevier Science B.V. Amsterdam, 2001, vol. 23, pp. 21-57.

16 C. Sulitzky, B. Rückert, A. J. Hall, F. Lanza, K. Unger and B. Sellergren, Macromolecules, 2002, 35, 79-91.

17 M. R. Halhalli, C. S. A. Aureliano, E. Schillinger, C. Sulitzky, M. M. Titirici and B. Sellergren, Polymer Chemistry, 2012, 3, 1033 1042.

18 M. R. Halhalli, E. Schillinger, C. S. A. Aureliano and B. Sellergren, Chemistry of Materials, 2012, 24, 2909-2919.

19 M. M. Titirici, A. J. Hall and B. Sellergren, Chemistry of Materials, 2003, 15, 822-824.

20 E. Yilmaz, O. Ramström, P. Möller, D. Sanchez and K. Mosbach, J. Mat. Chem., 2002, 12, 1577-1581.

21 J. Hall Andrew, P. Manesiotis, M. Emgenbroich, M. Quaglia, E. De Lorenzi and B. Sellergren, Journal of organic chemistry, 2005, 70, 1732-1736.

22 S. Kjellström and O. N. Jensen, Analytical Chemistry, 2004, 76, 5109-5117.

23 K. A. Connors, Binding constants. The measurement of molecular complex stability, John Wiley \& Sons, New York, 1987.

24 K. D. Shimizu, in Molecularly Imprinted Materials: Science and Technology, 2005, pp. 419-434.

25 M. R. Larsen, T. E. Thingholm, O. N. Jensen, P. Roepstorff and T. J. D. Jørgensen, Molecular \& Cellular Proteomics, 2005, 4, 873-886

26 O. Haglund, Qualitative Comparison of Normalization Approaches in MALDI-MS, Datavetenskap och kommunikation, Kungliga Tekniska högskolan, 2008. 


\title{
Supporting Information
}

\section{Hierarchically templated beads with tailored pore structure for phosphopeptide capture and phosphoproteomics}

\author{
Celina Wierzbicka, $\uparrow$ Silje B. Torsetnes, $₫$ Ole N. Jensen, $₫$ Sudhirkumar Shinde $\uparrow$ \\ and Börje Sellergren*† \\ $\dagger$ Department of Biomedical Science, Faculty of Health and Society, Malmö University, 20506 Malmö, Sweden \\ † Department of Biochemistry and Molecular Biology and VILLUM Center for Bioanalytical Sciences, University \\ of Southern Denmark, DK-5230 Odense M, Denmark
}

\section{Table of contents}

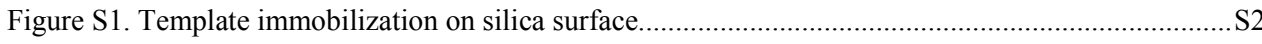

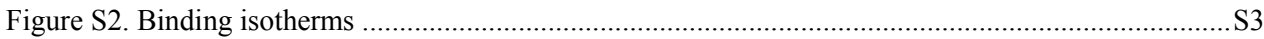

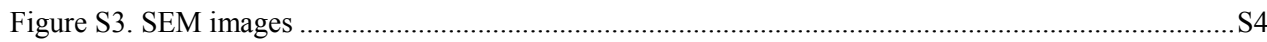

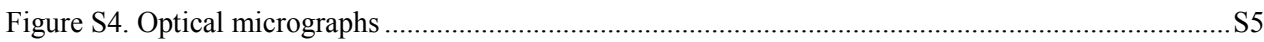

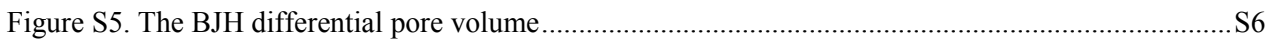

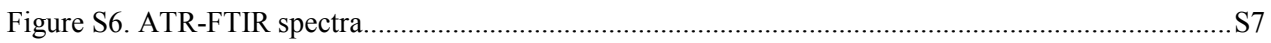

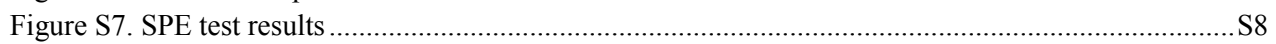

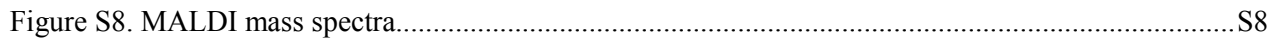

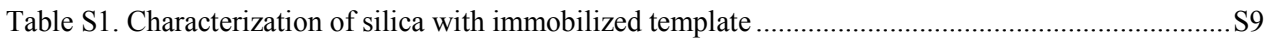

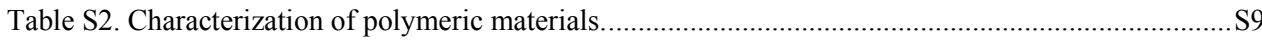

Table S3. Elemental composition of imprinted and non-imprinted polymers.......................................S10

Table S4. Binding constants $\left(\mathrm{K}_{\mathrm{a}}\right)$ maximum binding capacity $\left(\mathrm{B}_{\max }\right)$ and imprinting efficiency (IE)......S10 Table S5. Peptides found in the sample before enrichment and in combined flow-through and washing

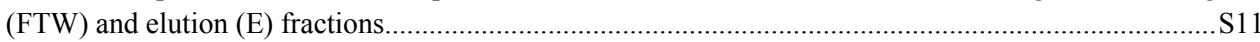

Table S6. Peak intensity analysis for samples before and after MIP enrichment. ...................................S12 


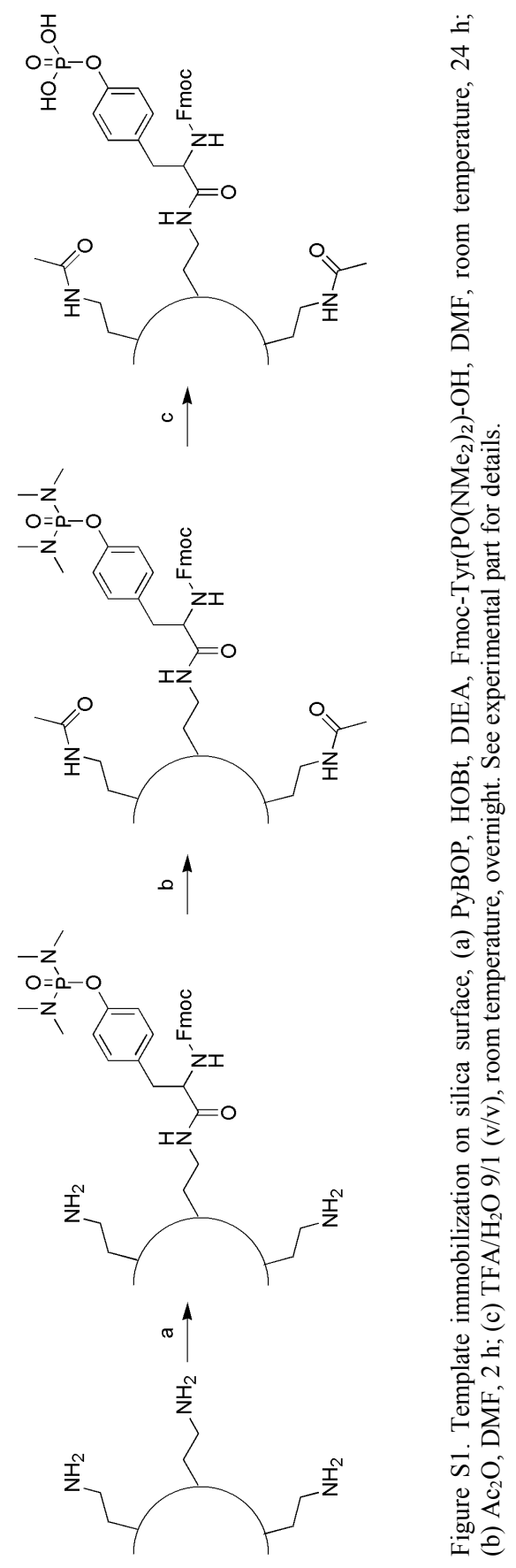



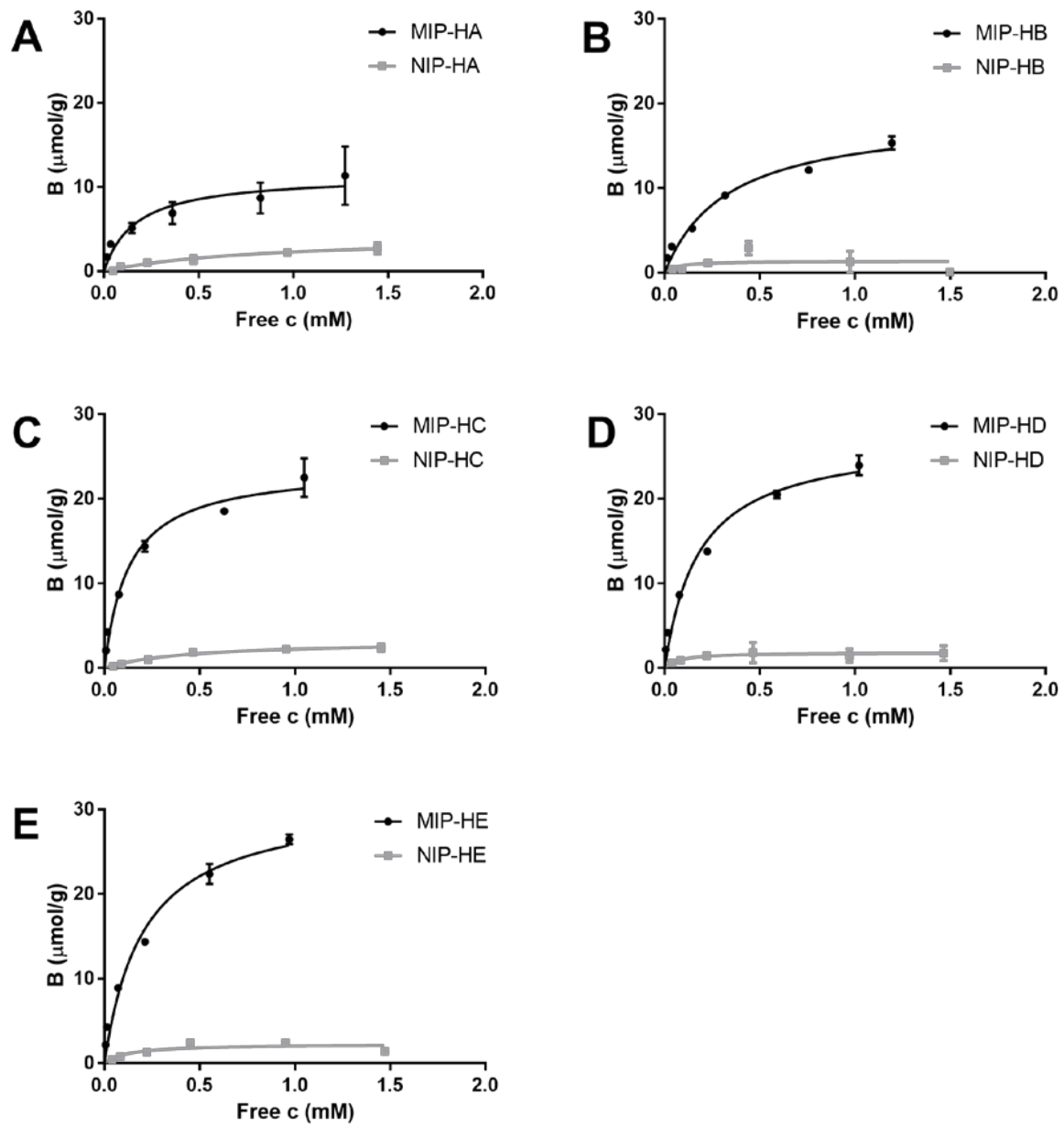

Figure S2. Binding isotherms of Fmoc-pTyr-OH (concentration range $0.05 \mathrm{mM}-1.5 \mathrm{mM}$ ) for surface imprinted polymers and corresponding non-imprinted polymers. (A) MIP-HA/NIP-HA, (B) MIP-HB/NIP-HB, (C) MIP-HC/NIP-HC, (D) MIP-HD/NIP-HD, (E) MIP-HE/NIP-HE. Points show an average of three replicas with the error bars representing standard deviation. 


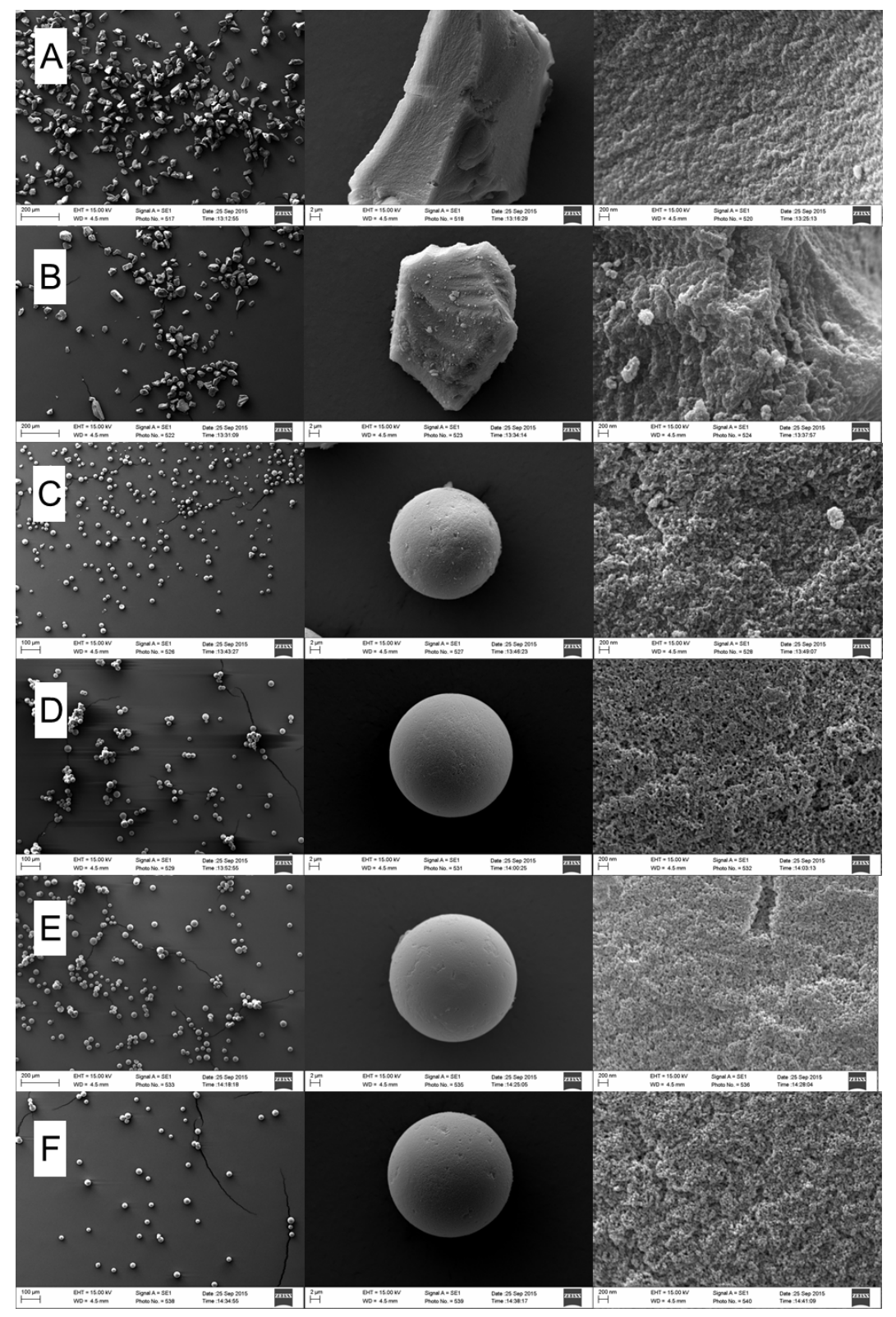

Figure S3. SEM images of (A) MIP-B, (B) NIP-B, (C) MIP-M, (D) NIP-M, (E) MIP-HE, and (F) NIP-HE at different magnifications. 


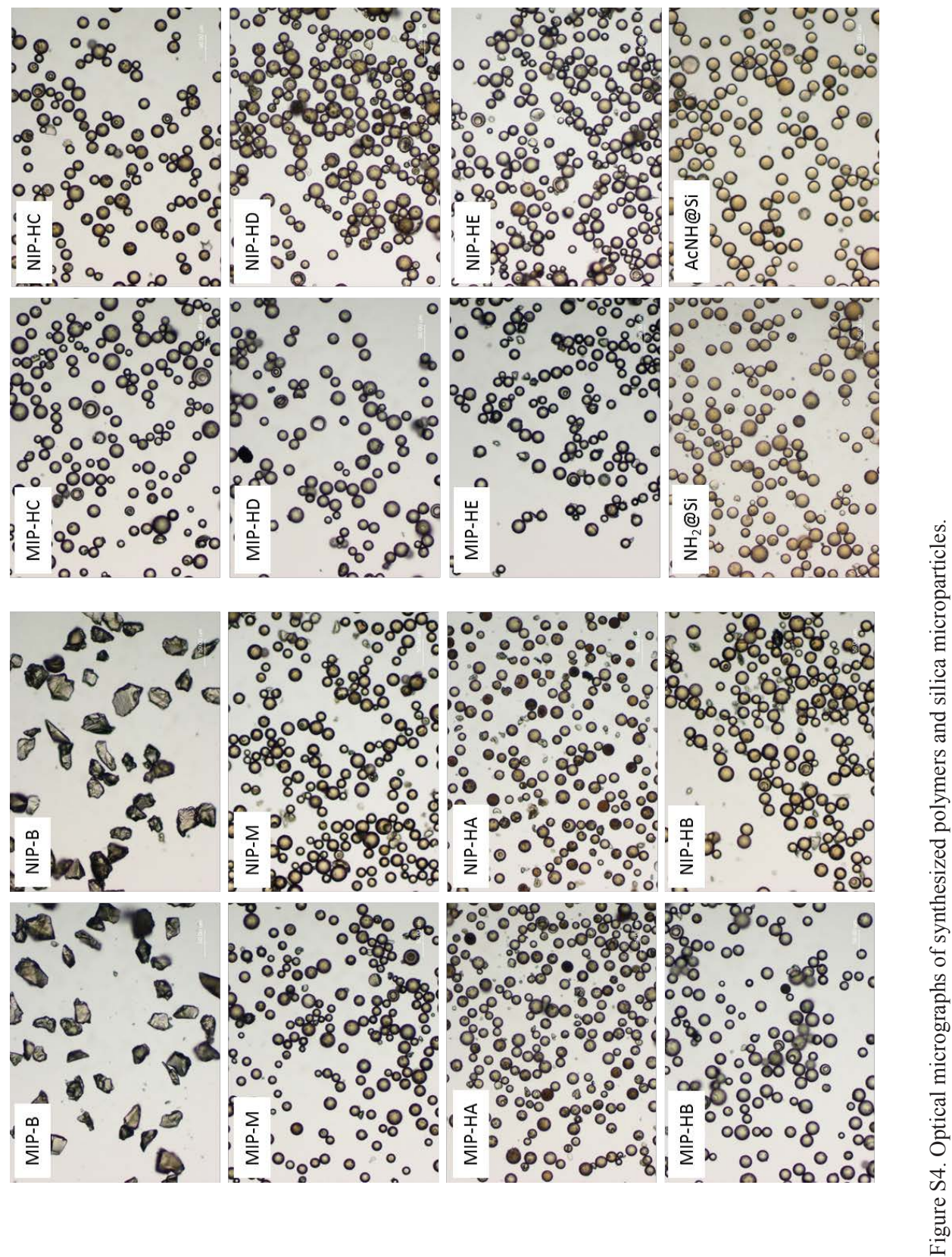


A

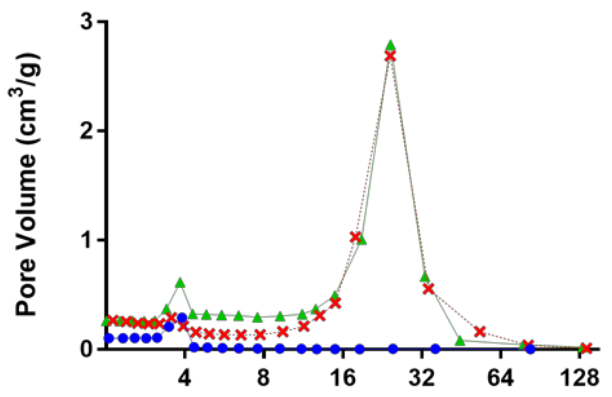

Pore Width (nm)
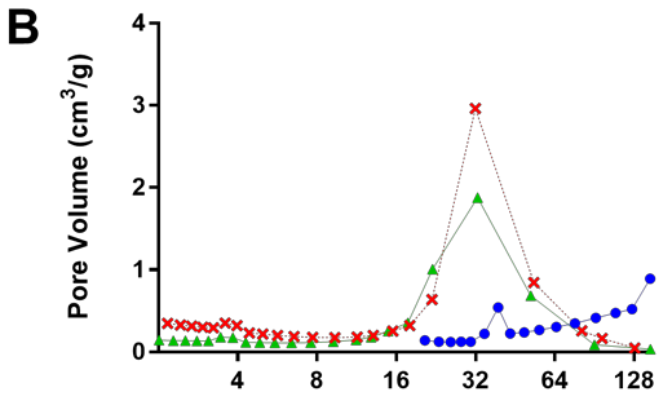

Pore Width (nm)
-- MIP-B

×- MIP-M

$\_$MIP-HE
- NIP-B

×- NIP-M

$\_$NIP-HE

Figure S5. The BJH differential pore volume $(\mathrm{dV} / \mathrm{d} \log (\mathrm{w}))$ distribution plots against pore width for (A) MIP-B, MIP-M, MIP-HE and (B) NIP-B, NIP-M, NIP-HE. 

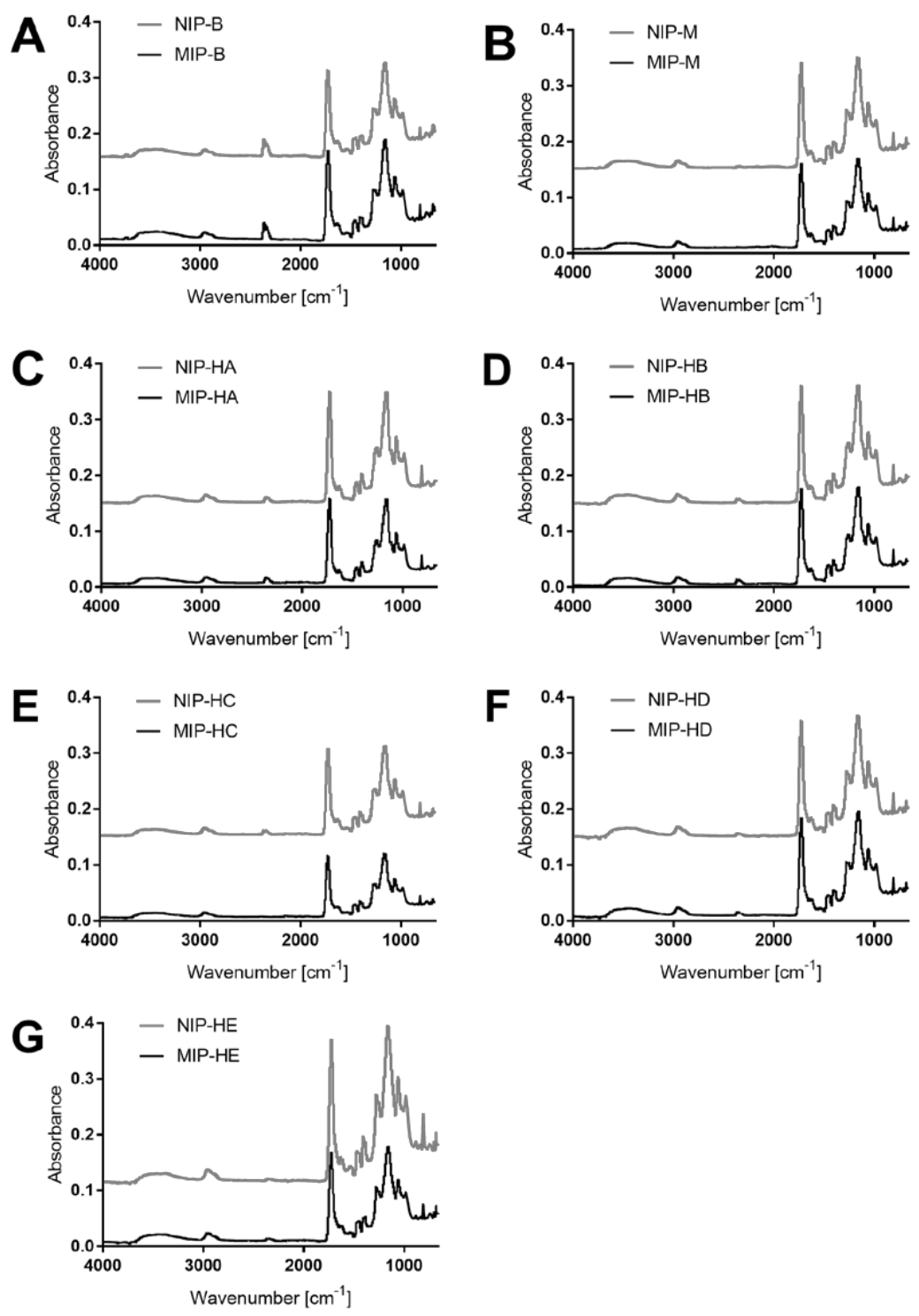

Figure S6. ATR-FTIR spectra of imprinted and non-imprinted polymers (A) MIP-B/NIP-B, (B) $\mathrm{MIP}-\mathrm{M} / \mathrm{NIP}-\mathrm{M}$, (C) MIP-HA/NIP-HA, (D) MIP-HB/NIP-HB, (E) MIP-HC/NIP-HC, (F) MIPHD/NIP-HD, (G) MIP-HE/NIP-HE. 

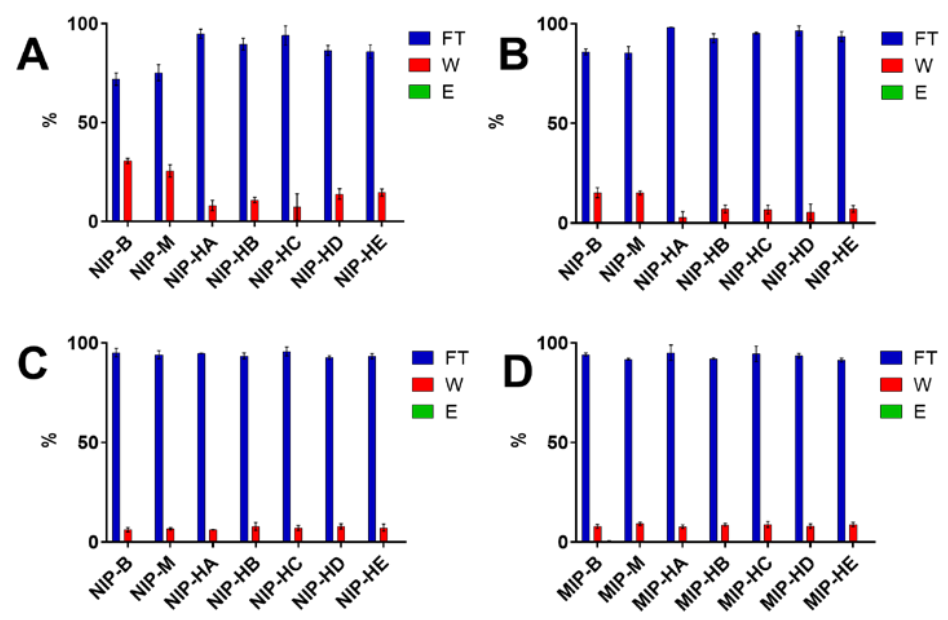

Figure S7. Results of SPE test with Fmoc-pTyr-OH (A), and Fmoc-pSer-OH (B) and Fmoc-Tyr-OH (C, D) showing \% of each analyte in flow-through (FT), washing (W) and elution (E) fractions. The following conditions were applied: loading $95 \% \mathrm{ACN}+0.1 \% \mathrm{FA}$, washing $80 \% \mathrm{ACN}+0.1 \% \mathrm{FA}$, elution $80 \% \mathrm{MeOH}$ $+1 \%$ TFA. The bars show the average of three replicas and the error bars represent standard deviation.

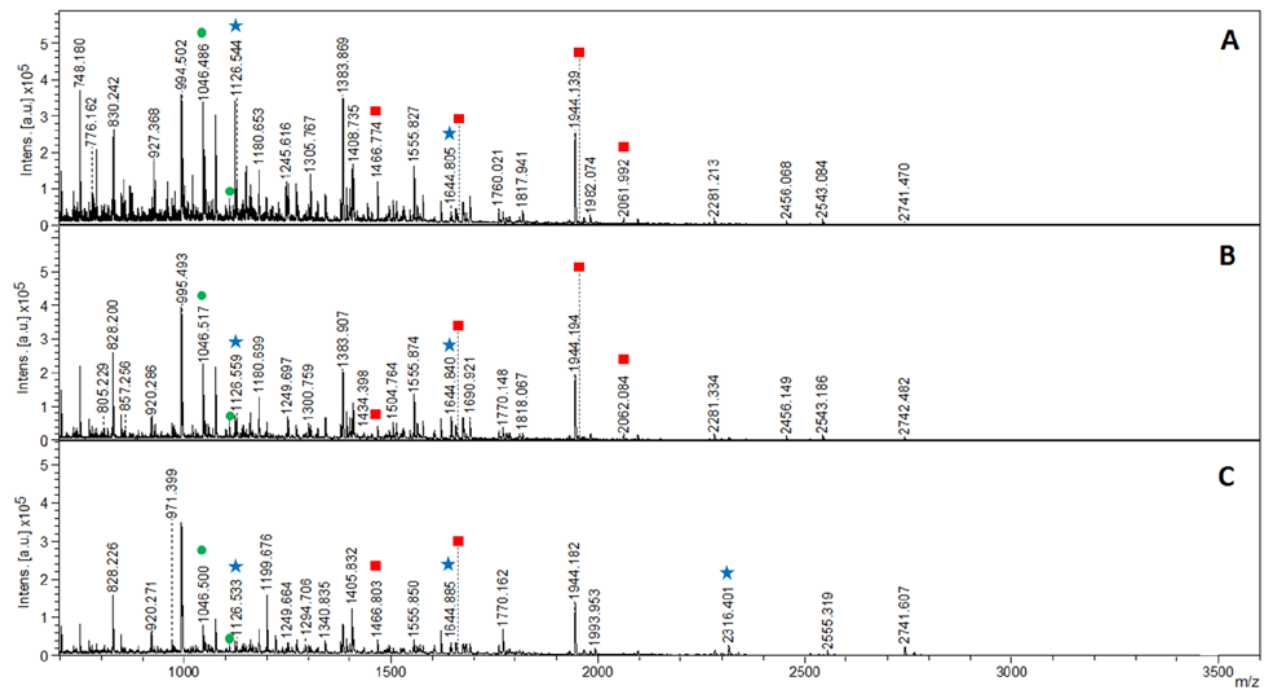

Figure S8. MALDI mass spectra obtained for combined flow-through and washing fraction (FTW) from (A) MIP-B, (B) MIP-M and (C) MIP-HE. Marked are spiked phosphotyrosine peptides (asterisk), phosphoserine peptides (square) and spiked phosphoserine and nonphosphorylated peptides (circle). 
Table S1. Characterization of silica with immobilized template.

\begin{tabular}{|c|c|c|c|c|c|}
\hline \multirow{2}{*}{ Sample } & \multicolumn{2}{|c|}{ Nominal template coverage } & \multicolumn{2}{|c|}{ Real template coverage $^{a}$} & \multirow{2}{*}{$\begin{array}{c}\text { Mass loss } \\
(\mathbf{( \% )})^{\mathbf{b}}\end{array}$} \\
\hline & $\left(\mu \mathrm{mol} / \mathrm{m}^{2}\right)$ & $(\mu \mathrm{mol} / \mathrm{g})$ & $\left(\mu \mathrm{mol} / \mathrm{m}^{2}\right)$ & $(\mu \mathrm{mol} / \mathrm{g})$ & \\
\hline Fmoc-pTyr@Si-A & 0.44 & 20 & 0.23 & 10 & 3.1 \\
\hline Fmoc-pTyr@Si-B & 0.60 & 2 & 0.40 & 18 & 3.5 \\
\hline Fmoc-pTyr@Si-C & 0.76 & 34 & 0.73 & 33 & 3.8 \\
\hline Fmoc-pTyr@Si-D & 0.90 & 40 & 0.86 & 39 & 4.1 \\
\hline Fmoc-pTyr@Si-E & 1.20 & 54 & 1.22 & 55 & 4.5 \\
\hline
\end{tabular}

${ }^{a}$ Calculated by Fmoc-cleavage test; ${ }^{\mathrm{b}}$ Determined by thermogravimetric analysis.

Table S2. Characterization of polymeric materials. ${ }^{a}$

\begin{tabular}{|c|c|c|}
\hline Sample & Silica used for polymerization & Mass loss (\%) $^{\mathbf{a}}$ \\
\hline MIP-B & - & 94.3 \\
\hline NIP-B & - & 94.4 \\
\hline MIP-M & AcNH@Si & 93.9 \\
\hline NIP-M & AcNH@Si & 93.1 \\
\hline MIP-HA & Fmoc-pTyr@Si-A & 94.9 \\
\hline NIP-HA & AcNH@Si & 94.7 \\
\hline MIP-HB & Fmoc-pTyr@Si-B & 94.2 \\
\hline NIP-HB & AcNH@Si & 94.9 \\
\hline MIP-HC & Fmoc-pTyr@Si-C & 93.2 \\
\hline NIP-HC & AcNH@Si & 94.4 \\
\hline MIP-HD & Fmoc-pTyr@Si-D & 93.5 \\
\hline NIP-HD & AcNH@Si & 95.6 \\
\hline MIP-HE & Fmoc-pTyr@Si-E & 95.2 \\
\hline NIP-HE & AcNH@Si & 97.3 \\
\hline
\end{tabular}

${ }^{a}$ The mass loss was determined by thermogravimetric analysis (TGA). The mass loss of the composites before etching was roughly $30 \%$. 
Table S3. Elemental composition of imprinted and non-imprinted polymers. ${ }^{a}$

\begin{tabular}{|c|c|c|c|c|c|c|}
\hline \multirow{2}{*}{ Polymer } & \multicolumn{3}{|c|}{ Theoretical } & \multicolumn{3}{c|}{ Experimental } \\
\cline { 2 - 7 } & $\mathbf{\% C}$ & $\mathbf{\% H}$ & $\mathbf{\% N}$ & $\mathbf{\%} \mathbf{C}$ & $\mathbf{\% ~ H}$ & $\mathbf{\% ~ N}$ \\
\hline MIP-B & 56.30 & 5.91 & 1.06 & 56.36 & 5.80 & 0.98 \\
\hline NIP-B & 56.30 & 5.91 & 1.06 & 55.88 & 6.94 & 0.96 \\
\hline MIP-M & 56.30 & 5.91 & 1.06 & 56.28 & 6.89 & 0.99 \\
\hline NIP-M & 56.30 & 5.91 & 1.06 & 55.78 & 6.28 & 0.92 \\
\hline MIP-HA & 56.42 & 6.09 & 0.62 & 56.24 & 6.94 & 0.50 \\
\hline NIP-HA & 56.42 & 6.09 & 0.62 & 56.08 & 6.82 & 0.49 \\
\hline MIP-HB & 56.39 & 6.04 & 0.74 & 56.16 & 6.13 & 0.65 \\
\hline NIP-HB & 56.39 & 6.04 & 0.74 & 56.05 & 5.81 & 0.69 \\
\hline MIP-HC & 56.33 & 5.95 & 0.95 & 56.22 & 6.88 & 0.92 \\
\hline NIP-HC & 56.33 & 5.95 & 0.95 & 56.08 & 6.80 & 0.82 \\
\hline MIP-HD & 56.31 & 5.92 & 1.03 & 56.14 & 5.75 & 0.96 \\
\hline NIP-HD & 56.31 & 5.92 & 1.03 & 55.78 & 5.77 & 0.96 \\
\hline MIP-HE & 56.25 & 5.84 & 1.24 & 56.13 & 5.69 & 1.16 \\
\hline NIP-HE & 56.25 & 5.84 & 1.24 & 56.20 & 5.53 & 1.14 \\
\hline
\end{tabular}

${ }^{a}$ The theoretical nitrogen content for polymers prepared in absence of urea monomer 1 was $0.47 \%$.

Table S4. Binding constants $\left(\mathrm{K}_{\mathrm{a}}\right)$, maximum binding capacity $\left(\mathrm{B}_{\max }\right)$ and imprinting efficiency (IE) for MIPs and NIPs.

\begin{tabular}{|c|c|c|c|}
\hline Polymer & $\left.\mathbf{K}_{\mathbf{a}} \mathbf{\times} \mathbf{1 0}^{\mathbf{3}} \mathbf{( M}^{\mathbf{- 1}}\right)$ & $\mathbf{B}_{\max }(\boldsymbol{\mu} \mathbf{m o l} / \mathbf{g})$ & $\mathbf{I E} \mathbf{( \% )}$ \\
\hline MIP-B & $16.5 \pm 2.6$ & $25.0 \pm 1.0$ & 23 \\
\hline MIP-M & $16.7 \pm 2.3$ & $36.9 \pm 1.3$ & 33 \\
\hline MIP-HA & $5.9 \pm 2.6$ & $11.4 \pm 1.4$ & 36 \\
\hline MIP-HB & $3.0 \pm 0.9$ & $18.7 \pm 2.0$ & 33 \\
\hline MIP-HC & $7.8 \pm 1.9$ & $23.8 \pm 1.6$ & 23 \\
\hline MIP-HD & $5.5 \pm 1.4$ & $27.3 \pm 2.2$ & 22 \\
\hline MIP-HE & $4.8 \pm 1.3$ & $31.2 \pm 2.8$ & 18 \\
\hline NIP-B & $2.1 \pm 0.5$ & $7.8 \pm 0.7$ & - \\
\hline NIP-M & $1.8 \pm 0.5$ & $6.5 \pm 0.7$ & - \\
\hline NIP-HA & $1.2 \pm 0.3$ & $4.2 \pm 0.6$ & - \\
\hline NIP-HB & $17.4 \pm 49$ & $1.4 \pm 0.8$ & - \\
\hline NIP-HC & $2.2 \pm 0.5$ & $3.2 \pm 0.2$ & - \\
\hline NIP-HD & $13.7 \pm 4.7$ & $1.8 \pm 0.1$ & - \\
\hline NIP-HE & $8.2 \pm 6.9$ & $2.3 \pm 0.5$ & \\
\hline
\end{tabular}




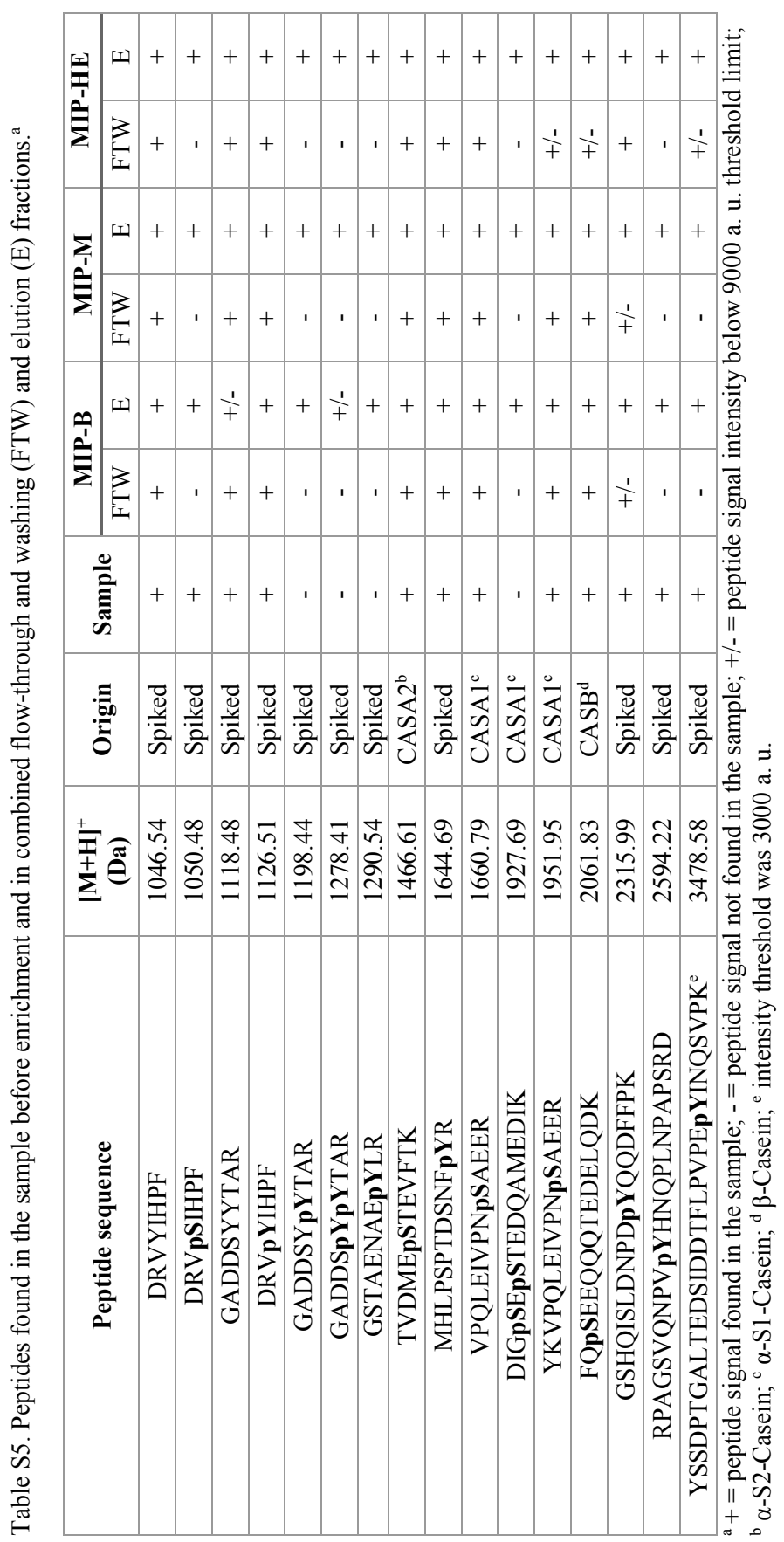




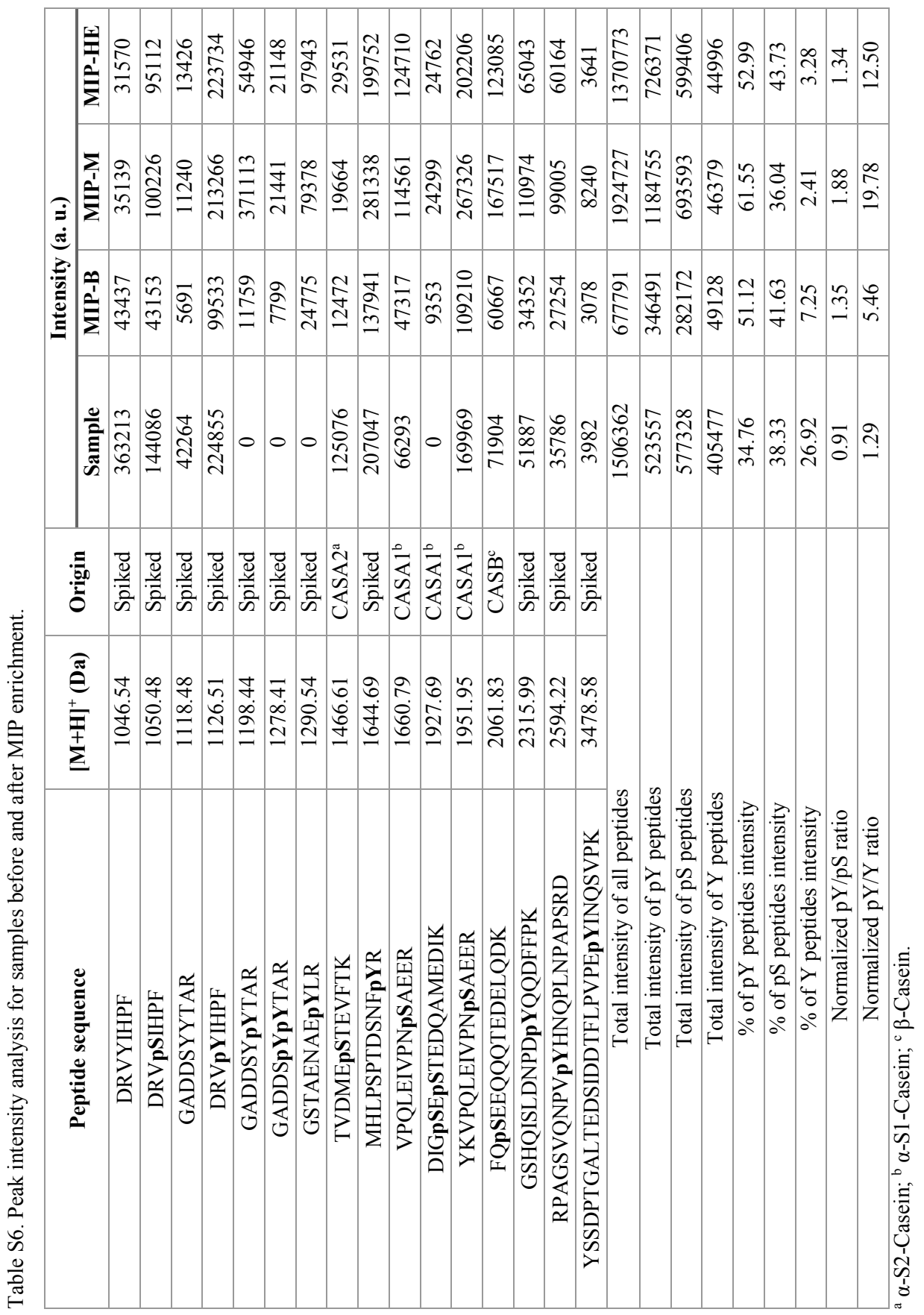





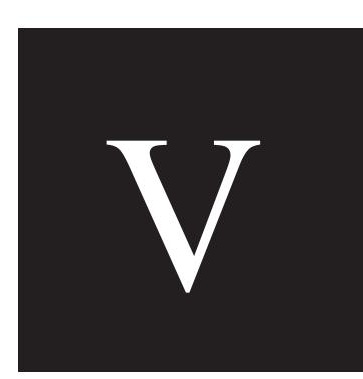





\section{Journal of \\ Materials Chemistry B}

\section{PAPER}

CrossMark

CrossMark
\&lickfor updates

Cite this: J. Mater. Chem. B, 2017 5,953

Received 2nd November 2016 Accepted 4th January 2017

DOI: $10.1039 / \mathrm{c} 6 \mathrm{tb} 02864 \mathrm{k}$

www.rsc.org/MaterialsB
View Article Online

View Journal | View Issue

\section{Cationic pTyr/pSer imprinted polymers based on a bis-imidazolium host monomer: phosphopeptide recognition in aqueous buffers demonstrated by $\mu$-liquid chromatography and monolithic columns $\uparrow$}

Celina Wierzbicka, ${ }^{\mathrm{a}}$ Mingquan Liu, ${ }^{\mathrm{b}}$ David Bauer, ${ }^{\mathrm{a}}$ Knut Irgum ${ }^{\star \mathrm{b}}$ and Börje Sellergren*a

We report on the design and characterization of imprinted cationic host polymers for selective trapping of phosphoserine and phosphotyrosine peptides. A series of imidazolium host monomers were synthesized and characterized with respect to binding affinity and stoichiometry of interaction with salts of phenylphosphonic acid. The strongest binders were subsequently used for the preparation of imprinted polymers in the form of crushed monoliths, using Fmoc-phosphotyrosine-ethyl ester or Fmoc-phosphoserine-ethyl ester as templates in combination with a hydrophilic crosslinking monomer. The polymers were compared with respect to binding and its dependence on solvent, and whether charged or uncharged host monomers were used. The recipes were subsequently implemented in the capillary monolith format for evaluation by micro-liquid chromatography in both buffered and organic media. Results from both tested formats reveal that the cationic host polymers displayed enhanced recognition in polar and buffered media, in contrast to neutral urea-based hosts which showed best results in acetonitrile rich mobile phases.

\section{Introduction}

Host-guest chemistry directed toward anion recognition has made significant progress during the last years. ${ }^{1-4}$ These efforts have resulted in low molecular weight hosts capable of selective complexation of oxyanions in water. ${ }^{1}$ It is difficult to engineer such hosts for the recognition of guests of higher complexity or of larger size. In this context the concept of molecularly imprinted polymers (MIPs) has been very successful. ${ }^{5-10}$ Formation of MIPs relies on a proper choice of monomers capable of interacting with complementary functional groups of a template molecule. Upon polymerization, the functional group arrangement is carried into the polymer while the template molecule can be removed e.g. by a simple solvent extraction step. Properly implemented,

${ }^{a}$ Department of Biomedical Sciences, Faculty of Health and Society, Malmo University, Malmö, Sweden. E-mail: borje.sellergren@mah.se

${ }^{b}$ Department of Chemistry, Umeå University, 90187 Umeå, Sweden.

E-mail: knut.irgum@chem.umu.se

† Electronic supplementary information (ESI) available: Titration data containing ${ }^{1} \mathrm{H}$-NMR CIS curves and Jobs plots for host-monomer guest interactions. Binding curves, ATR-FTIR spectra for the imprinted and nonimprinted polymers. Field effect scanning electron microscopy (FESEM) images for the TRIM monolith substrate, the NIP monolith, and the pS and pY monolithic MIPs at five different magnifications ranging from 520 to $125000 \times$. See DOI: $10.1039 /$ c6tb02864k this leaves behind binding sites in the resulting polymer that are capable of rebinding the template with high fidelity. This "top down" approach to receptor design can be used to construct hosts for rather complex guests without prior knowledge of their structure. The main downside is that it requires preparative quantities of templates.

A number of imprinting strategies targeting small anions have been reported in the literature. ${ }^{11,12}$ Design of such polymers drawing inspiration from anion recognition by low molecular weight receptors has been especially rewarding. These can be divided into charged hosts where recognition is driven by ion pairing (e.g. Brönsted acid-base interactions) ${ }^{13-15}$ and neutral hosts binding the anions primarily by hydrogen bonding. ${ }^{16-20}$ These categories of hosts typically display different solvent dependencies, i.e., the ionic interactions which operate over a longer range are less susceptible to the presence of water than hydrogen bonding receptors where water can dramatically alter or even suppress binding. ${ }^{1}$

We have recently reported on a range of imprinted anion receptors for carboxylates, ${ }^{16,17,21}$ phosphates ${ }^{18}$ and sulfates ${ }^{22}$ featuring 1,3-diaryl ureas (Fig. 1A) as the common host monomer. We have used this concept to construct receptors for structural features characterizing protein post-translational modifications (phosphorylation, sulfation, and glycosylation), 

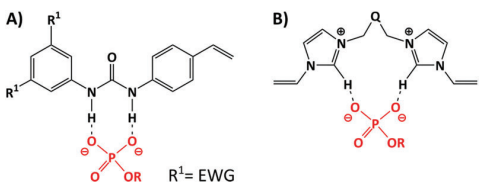

Fig. 1 Monomers and binding ability. Theoretical hydrogen bonding interactions with the target phosphate group and (a) 1,3-diarylurea host monomers or (b) bis-imidazolium host monomers.

the former mainly compatible with less competitive organic solven systems. Imprinted receptors for phosphorylated peptides have been particularly powerful in extracting very low levels of phosphorylated biomarkers from tryptic digests. ${ }^{23}$ In order to extend the solvent compatibility of such receptors to water and thereby be able to target proteins in their natural environment we decided to assess the use of monomers based on water compatible host motifs.

The use of imidazolium derivatives as anion receptors has in this context been extensively reported in the literature.,24 The success of these receptors is to a large degree ascribed to the ability of the imidazolium group to engage in strong $[\mathrm{C}-\mathrm{H}]^{+}$ ionic hydrogen bonding interactions which prevail also in polar protic media. The recognition of phosphate guests in water (e.g., ATP, DNA) has been amply demonstrated. ${ }^{4}$ For example, Kim et al. reported a novel water-soluble imidazolium anthracene derivative, acting as a potential fluorescent chemosensor for GTP in $100 \%$ aqueous solution $(\mathrm{pH}=7.4) .^{25}$

We have here evaluated mono- and bis-imidazolium monomers (Fig. 1B) as cationic host monomers predesigned to bind divalent oxyanions by combined ionic and hydrogen bonding, possibly aided by $\pi-\pi$ stacking interactions. We report on their interactions with salts of phenylphosphonic acid in protic media and on polymers prepared by stoichiometric imprinting using the most potent monomers. Finally their potential use as receptors for selective enrichment of phosphopeptides from aqueous media has been demonstrated.

\section{Experimental}

Trimethylolpropane trimethacrylate (TRIM), 4-(2-hydroxyethyl)1-piperazineethanesulfonic acid (HEPES), tetrabutylammonium hydroxide (TBAOH; $1 \mathrm{M}$ in methanol), methanol (MeOH), phosphorus (V) oxychloride $\left(\mathrm{POCl}_{3}\right)$, dry dichloromethane (DCM) magnesium sulfate, acrylamide (AAm) and phenylphosphonic acid (PPA) were purchased from Sigma-Aldrich (Steinheim, Germany). Pentaerythritol triacrylate (PETA) was from Polysciences (Warrington, PA, USA) and 1-vinylimidazole was from Alfa Aesar (Karlsruhe, Germany). $N, N^{\prime}$-Azo-bis(2,4-dimethyl) valeronitrile (ABDV) from Wako Chemicals $\mathrm{GmbH}$ (Neuss, Germany); DMSO- $\mathrm{d}_{6}$, methanol- $\mathrm{d}_{4}\left(\mathrm{CD}_{3} \mathrm{OD}\right)$, sodium hydrogen carbonate $\left(\mathrm{NaHCO}_{3}\right)$, acetone and ethyl acetate were obtained from VWR (Radnor, PA, USA). Trifluoroacetic acid (TFA), 2,2,4 trimethylpentane, $\mathrm{N}$-ethyldiisopropylamine (DIPEA), $\mathrm{N}$-(9-fluorenylmethoxycarbonyloxy)succinimide (Fmoc-OSu), and diethyl ether were from Merck (Darmstadt, Germany) and benzoin methyl ether (BME), 1,2,2,6,6-pentamethylpiperidine (PMP) and 3-[(methacryloyl)oxypropyl]trimethoxysilane ( $\gamma$-MAPS) were obtained from Fluka (Buchs, Switzerland). The acetonitrile (ACN) was from J. T. Baker (Phillipsburg, NJ, USA). Sulfur and dry toluene were from Acros Organics (NJ, USA).

The test probes Fmoc-SerOH, Fmoc-TyrOH, Fmoc-pSerOH and Fmoc-pTyrOH [Fmoc $=N$-(9-fluorenylmethoxy)carbonyl $]$ and L-tyrosine ethyl ester hydrochloride and L-serine ethyl ester hydrochloride were purchased from Bachem $\mathrm{GmbH}$ (Bubendorf, Switzerland) and the angiotensin peptides and their phosphorylated counterparts [DRVSIHPF, DRVYIHPF, DRVPSIHPF, and DRVPYIHPF] were purchased from LifeTein, LLC (Hillsborough, NJ, USA). The functional monomers $N$-3,5-bis(trifluoromethyl)phenyl- $N^{\prime}$-4-vinylphenylurea (FM1), ${ }^{16}$ 3-benzyl-1-vinyl- $1 H$-imidazolium bromide (FM2) ${ }^{26}$ and 1,1' ${ }^{\prime}$ [2,6-pyridindiylbis(methylene)] bis[3-vinyl]-1 $H$-imidazolium dibromide $(\mathrm{FM} 3)^{27}$ were synthesized as reported before. The reagent $N$-(3,5-bis(trifluoromethyl)phenyl)2-chloroacetamide was synthesized as reported elsewhere. ${ }^{34}$ The templates Fmoc-pTyrOEt, Fmoc-pSerOEt and the monomer 1-[(3,5-Bis-trifluoromethyl-phenylcarbamoyl)-methyl]-3-vinyl-1 $\mathrm{H}_{\text {- }}$ imidazolium chloride (FM4) were synthesised as described in the ESI. $\dagger$

The mono- and ditetrabutylammonium salts of PPA (PPA.TBA and PPA.2TBA) were prepared as follows: PPA ( $0.2 \mathrm{~g} ; 1.26 \mathrm{mmol})$ was dissolved in methanol $(2 \mathrm{~mL})$ followed by addition of 1 or 2 equivalents of TBAOH ( $1 \mathrm{M}$ in methanol), respectively. Next the solvents were removed on a rotary evaporator and the residues dried in vacuo overnight.

\section{Apparatus and methods}

All NMR spectra were recorded at $25^{\circ} \mathrm{C}$ using an Agilent (Varian) Mercury $400 \mathrm{MHz}$ instrument. Purification of templates was performed on preparative HPLC Waters 600 HPLC instrument (Waters, Milford MA, USA) equipped with in-line degasser, a Waters 2487 dual absorbance detector, a Waters 2700 sample manager and a Waters Fraction collector II. A Waters Alliance 2695 analytical HPLC equipped with Photodiode Array Detector 2996 was used for quantification of FmocpTyrOH in binding isotherm experiments. A micro-HPLC system (Shimadzu, Kyoto, Japan) consisting of an LC-10 ADVP pump and an SPD-10 AVP UV-detector fitted with a $35 \mathrm{~nL}$ capillary cell from LC Packings (Amsterdam, The Netherlands) was used in the chromatographic evaluation of capillary monoliths. Infrared spectra were recorded using a Thermo Nicolet Nexus 6700 instrument (Thermo Scientific, Waltham, MA, USA). Mass spectra were recorded on Waters ZQ 2000 LCMS System in positive ion mode.

\section{Preparation of molecularly imprinted polymers in the bulk format}

The compositions of the bulk imprinted and nonimprinted polymers are given in Table 1 . The polymers were prepared by dissolving template $(0.5 \mathrm{mmol}$; $\mathrm{T})$, functional monomer $(0.5$ or $1 \mathrm{mmol}$; FM), acrylamide ( $1 \mathrm{mmol}$ ), and PETA (3.96 g; $13.3 \mathrm{mmol})$ in porogen $(5.6 \mathrm{~mL})$. The initiator $\operatorname{ABDV}(1 \% \mathrm{w} / \mathrm{w}$ of total monomer mass) was added to the solution. The solution was 
Table 1 Composition of imprinted (P1-P5) and nonimprinted (PN1-PN5) polymers

\begin{tabular}{|c|c|c|c|c|c|}
\hline Polymer & Funct. mon. (FM) & Template $(\mathrm{T})$ & Molar ratio T/FM/PETA & Porogen $^{a}$ & Swelling $^{b}\left(\mathrm{~mL} \mathrm{~mL}^{-1}\right)$ \\
\hline P1 & FM1 & Fmoc-pTyrOEt-2PMP & $1 / 2 / 26$ & $\mathrm{ACN}$ & 1.6 \\
\hline PN1 & FM1 & - & $-/ 2 / 26$ & $\mathrm{ACN}$ & 1.3 \\
\hline P2 & FM2 & Fmoc-pTyrOEt-2TBA & $1 / 2 / 26$ & MeOH/Tol. & 1.3 \\
\hline PN2 & FM2 & - & $-/ 2 / 26$ & $\mathrm{MeOH} / \mathrm{Tol}$. & 1.4 \\
\hline P3 & FM3 & Fmoc-pTyrOEt-2TBA & $1 / 1 / 26$ & $\mathrm{MeOH}$ & 1.1 \\
\hline PN3 & FM3 & - & $-/ 1 / 26$ & $\mathrm{MeOH}$ & 1.2 \\
\hline P4 & FM3 & Fmoc-pTyrOEt-2TBA & $1 / 1 / 26$ & MeOH/Tol. & 1.4 \\
\hline PN4 & FM3 & - & $-/ 1 / 26$ & $\mathrm{MeOH} / \mathrm{Tol}$. & 1.3 \\
\hline P5 & FM4 & Fmoc-pTyrOEt-2TBA & $1 / 2 / 26$ & $\mathrm{MeOH} / \mathrm{Tol}$. & 1.3 \\
\hline PN5 & FM4 & - & $-/ 2 / 26$ & $\mathrm{MeOH} / \mathrm{Tol}$. & 1.4 \\
\hline
\end{tabular}

${ }^{a}$ Porogens were pure acetonitrile (ACN) or methanol (MeOH), or a 1:1 (v/v) mixture of methanol and toluene. ${ }^{b}$ Swelling factor measured as the bed volume of swollen polymer after sedimentation in methanol divided by the bed volume of dry polymer.

transferred to a glass ampoule, cooled to $0{ }^{\circ} \mathrm{C}$, and purged with a flow of dry nitrogen for $10 \mathrm{~min}$. The tubes were then flamesealed while the contents were still being cooled, and the polymerization initiated by placing the tubes in a water bath heated to $50^{\circ} \mathrm{C}$. After $24 \mathrm{~h}$ the tubes were broken and the polymers crushed using the minimal force required. The recovered polymers were thereafter washed with $\mathrm{MeOH} / 0.1 \mathrm{M} \mathrm{HCl}(1: 1 \mathrm{v} / \mathrm{v})$, extracted in a Soxhlet apparatus with methanol for $24 \mathrm{~h}$, and dried under vacuum. The dried polymers were finally subjected to a grinding and dry sieving step whereby the fraction between 25 and $36 \mu \mathrm{m}$ was used to evaluate the binding properties. Nonimprinted polymers were prepared as described above, but with omission of the template molecule from the pre-polymerization solution.

\section{${ }^{1} \mathrm{H}$ NMR spectroscopic titrations and estimation of binding affinities and stoichiometries}

The complex stoichiometry was first assessed using the Job method of continuous variation. Stock solutions of the host monomer and guest $\left(10 \mathrm{mM}\right.$ and $25 \mathrm{mM}$ in DMSO- $\mathrm{d}_{6}$ or $\mathrm{CD}_{3} \mathrm{OD}$, respectively) were combined in NMR tubes, thereby resulting in the following molar ratios: $0: 10,2: 8,3: 7,4: 6,5: 5,6: 4,7: 3$, $8: 2,10: 0$. Total concentration of host and guest was $2 \mathrm{mM}$. ${ }^{1} \mathrm{H}$ NMR spectra were thereafter recorded and the proton signals, which could be monitored for eight of the mixing ratios, were used for the evaluation of the complex stoichiometry from plots of the product of the mole fraction of host $\left(f_{\mathrm{M}}\right)$ and the complexation induced shift (CIS) versus $f_{\mathrm{M}}$.

${ }^{1} \mathrm{H}$ NMR spectroscopic titrations were performed in dry deuterated solvents. The dissociation $\left(K_{\mathrm{d}}\right)$ and association $\left(K_{\mathrm{a}}\right)$ constants for the interaction between the hosts and guests were determined by titrating an increasing amount of guest (PPA.TBA or PPA.2TBA) into a constant amount of functional monomer (FM1-FM4). The initial concentration of the functional monomer was $2 \mathrm{mM}$ and the amount of added guest was $0,0.25,0.5,0.75,1.0,1.5,2.0,4.0,6.0$, and 10.0 equivalents. The CISs of relevant protons were followed and titration curves were constructed by plotting CIS $v s$. free guest concentration $(c)$. The raw titration data were fitted to a $1: 1$ or to a cooperative binding site model $^{28}$ by nonlinear regression using the built-in functions of GraphPad Prism 7 (GraphPad Software, La Jolla, CA, USA), from which the association constants were calculated.
For a $1: 1$ stoichiometry of interaction a Langmuir mono-site model was used according to eqn (1):

$$
\mathrm{CIS}=\mathrm{CIS}_{\max } \cdot c /\left(K_{\mathrm{d}}+c\right)
$$

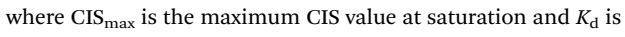
the dissociation constant.

In the case of the cooperative binding behavior the curves were fitted using the empirical Hill equation according to eqn (2):

$$
\mathrm{CIS}=\mathrm{CIS}_{\max } \cdot c^{h} /\left(K_{\mathrm{d}}{ }^{h}+c^{h}\right)
$$

where $h$ is the Hill slope and $K_{\mathrm{d}}$ is the dissociation constant. The association constants $K_{\mathrm{a}}$ were calculated as the inverse of the dissociation constants.

\section{Binding tests using imprinted and nonimprinted polymers}

Polymers (P1-P5 and $\mathrm{P}_{\mathrm{N}} 1-\mathrm{P}_{\mathrm{N}} 5 ; 2 \mathrm{mg}$ each) were separately mixed with $200 \mu \mathrm{L}$ of Fmoc-pTyrOH at 0.25, 0.5, 1.0, 1.3 and $2.0 \mathrm{mM}$ concentration in methanol and shaken vigorously for $2 \mathrm{~h}$. Next the samples were centrifuged and the supernatants were analyzed by HPLC to determine the concentration of unbound Fmoc-pTyrOH. The experiments were performed in two parallel replicas. The specific amount of solute bound by the polymer particles $(B)$ was determined by the following formula:

$$
B=\left(C_{0}-c\right) \nu / m
$$

where $C_{0}$ is the initial solute concentration, $c$ is the final free solute concentration in the supernatant, $v$ is the total volume of the adsorption mixture, and $m$ is the mass of polymer in each vial. Binding curves were constructed by plotting $B$ against free concentration $c$ and were subsequently fitted by non-linear regression in the Graphpad Prism 7 curve fitting software to a Langmuir mono-site model:

$$
B=B_{\max } \cdot c /\left(K_{\mathrm{d}}+c\right)
$$

where $B_{\max }$ is the maximum amount of solute bound by the polymer particles at saturation. The association constants $K_{\mathrm{a}}$ were calculated as the inverse of the dissociation constants $\left(K_{\mathrm{d}}\right)$. 
Preparation of molecularly imprinted and non-imprinted monolithic capillary columns

Capillary pre-treatment procedure. UV-transparent fused silica capillaries $(250 \mu \mathrm{m}$ i.d. $\times 360 \mu \mathrm{m}$ o.d.) obtained from Polymicro Technologies (Phoenix, AZ, USA) were treated as described elsewhere, ${ }^{29}$ with the procedure being selected on the basis of a previous study. ${ }^{30}$ Briefly, the capillaries were washed with acetone and deionized water, then $1 \mathrm{M} \mathrm{NaOH}$ was flushed through the capillary for approx. $5 \mathrm{~min}$, where after the capillary was sealed in the filled state. It was heated at $100{ }^{\circ} \mathrm{C}$ for $2 \mathrm{~h}$, then cooled to room temperature and washed first with deionized water and then acetone ( $15 \mathrm{~min}$ each), and finally dried by a flow of dry nitrogen for at least $1 \mathrm{~h}$. A silanization reaction to introduce methacrylic anchoring groups on the surface was carried out by filling the capillary with a degassed mixture of $10 \% \gamma$-MAPS in toluene, sealing it in the filled state and keeping it at room temperature for $2 \mathrm{~h}$. Finally, the capillary was washed with toluene and dried with a flow of dry nitrogen for at least $1 \mathrm{~h}$.

Capillary monolithic core supports synthesis. Monolith substrates were prepared following literature procedure ${ }^{31}$ from a precursor solution consisting of $40 \%(\mathrm{w} / \mathrm{w})$ TRIM in a mixture of 2,2,4-trimethylpentane/toluene $4: 1(\mathrm{w} / \mathrm{w})$ as porogen, with BME added at $1 \%$ of the TRIM monomer weight as photopolymerization initiator. The $\gamma$-MAPS activated capillary was cut into $70 \mathrm{~mm}$ long pieces that were filled with the monolith precursor solution by piercing both ends through the septa of two GC vials which had been partially filled with the monolith precursor solution and applying pressure in one of the vials using a syringe. When the capillary was filled, the pressure was released and both ends were carefully kept below the surfaces of the respective vials. The capillary/vial assembly was then subjected to photopolymerization in a UV-Spectrolinker XL-1500 from Spectronics Corporation (Westbury, NY, USA) at $365 \mathrm{~nm}$ with irradiation intensity in the polymerization zone at $3.2 \mathrm{~mW} \mathrm{~cm}^{-2}$, as determined by an International Light Model IL1400 radiometer (Newburyport, MA, USA) fitted with a model XRL140B probe. After the poly merization was completed for $1 \mathrm{~h}$, one millimeter was cut from each end of the capillaries, which were thereafter flushed with methanol for at least $1 \mathrm{~h}$ at $4 \mu \mathrm{L} \mathrm{min}{ }^{-1}$, making a note of the back pressure of each capillary.

Grafting of the imprinted and non-imprinted polymer to capillary monolithic core supports. The MIP prepolymerization cocktail was prepared in the manner optimized in our previous work. $^{22}$ The templates Fmoc-pSerOEt (3.4 mg; $7.8 \mu \mathrm{mol}$ ) targeting phosphorylated serine (pS MIP) or Fmoc-pTyrOEt (4.0 mg; $7.8 \mu \mathrm{mol}$ ) targeting phosphorylated tyrosine (pY MIP) were separately mixed with two equivalents of the strong base TBAOH to form in situ the corresponding bis-TBA phosphate salts. Two cocktails were then prepared by mixing the above-mentioned individual templates with monomer FM3 (3.6 mg; $7.8 \mu \mathrm{mol}$ ), acrylamide (0.9 mg; $12.7 \mu \mathrm{mol}$ ), and PETA (59 mg; $197.8 \mu \mathrm{mol}$ ) in dry toluene $(478 \mu \mathrm{L})$ and dry methanol $(478 \mu \mathrm{L})$ to make up the MIP grafting solutions. BME $(1 \% \mathrm{w} / \mathrm{w}$ with respect to the combined monomer weight) was added as the initiator, and the grafting solutions were finally given a 5 min purge with nitrogen to remove dissolved oxygen. The nonimprinted polymer (NIP) was prepared in the same way, but with the template bisTBA salt omitted from the grafting mixture. At least ten column volumes of these grafting solutions were introduced into each TRIM core monolith capillary using syringe pump. Both capillary ends were then sealed with GC rubber septa and frozen at $-70{ }^{\circ} \mathrm{C}$ by clamping between two blocks of solid carbon dioxide for $1 \mathrm{~h}$. The capillary was thereafter rapidly transferred to the surface of a KP 282 cooling-plate (FRYKA-Kältetechnik GmbH, Esslingen, Germany) set at $-15{ }^{\circ} \mathrm{C}$ and the photopolymerization was carried out under a JD-230 Gel Curing UV Lamp (Yayuo Jiadi Electrical Factory, Zhejiang, China) with four $9 \mathrm{~W}$ fluorescent tubes having emission maximum around $370 \mathrm{~nm}$ to establish the imprinted polymer layer. Prior to use, the UV lamp had been warmed up around $3 \mathrm{~h}$ to ascertain constant temperature and intensity during the course of the $60 \mathrm{~min}$ photo-polymerization period. The light intensity in the polymerization zone was determined to be $2.8 \mathrm{~mW} \mathrm{~cm}^{-2}$, as described above. After the polymerization was completed, a $1 \mathrm{~mm}$ piece was trimmed from each capillary end, and the finished NIP and MIP capillaries were thereafter individually flushed by methanol containing $0.1 \%$ TFA

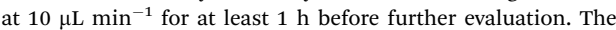
back pressure was measured again during the washing step, and columns that did not show an increase in the back pressure of $0.4 \pm 0.1 \mathrm{MPa}$ compared to the back-pressures before grafting were discarded.

Field emission scanning electron microscopy (FESEM). Samples with fresh rupture surfaces prepared by snapping in liquid nitrogen were positioned on adhesive carbon foils attached to standard aluminum sample stubs and mechanically secured to the holders by using conductive glue (Ted Pella Inc., Redding, CA, USA). All samples were thereafter coated with a sequence of $10 \mathrm{~nm}$ of carbon by evaporation in an Edwards E14 vacuum coating unit integrating an automatic tilt and rotate device (Edwards High Vacuum Ltd, Crawley, UK) and $5 \mathrm{~nm}$ of iridium in a Quorum Q150TS sputter coater (Quorum Technologies, Ringmer, UK). The coated samples were analyzed in a Zeiss Merlin field emission scanning electron microscope (Carl Zeiss Microscopy $\mathrm{GmbH}$, Oberkochen, Germany) operated at $4 \mathrm{kV}$. Images were captured at standardized magnifications from randomly chosen areas.

\section{Results and discussion}

\section{Monomer synthesis and characterization}

The imidazolium based receptors interact with oxyanions through combined $[\mathrm{C}-\mathrm{H}]^{+}$anion hydrogen bonding and ionic attraction, the relative importance of which depends on the basicity of the guest and the polarity of the medium. ${ }^{4}$ Given the enhanced water compatibility of such receptors our goal was to find out whether polymerizable hosts can be used in imprinting of phosphorylated amino acids and how they compare with the previously reported neutral urea-based receptors. ${ }^{18}$

As a first step in our evaluation of imidazolium based hosts we thus decided to compare the urea host monomer FM1 with the mono- and bis-imidazolium monomers FM2-FM4 shown in Fig. 2. 


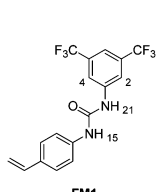

FM1

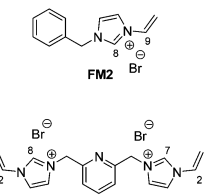

FM3

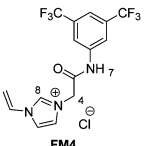

Fig. 2 Functional monomers used to prepare phosphotyrosine and phosphoserine imprinted polymers.

The monomers FM2-FM4 were synthesized as we have reported previously in one (FM1-FM3) or two (FM4) steps by nucleophilic substitution of corresponding alkylhalides with 1-vinyl-imidazole. Tetrabutylammonium hydrogenphenylphosphonate (PPA.TBA) and bis-tetrabutylammonium phenylphosphonate (PPA.2TBA) were chosen as mono- and di-anionic guests respectively, mimicking the phenylphosphate substituent of the template, Fmoc-pTyrOEt. The receptor monomer solutions ( $2 \mathrm{mM}$ in DMSO- $\mathrm{d}_{6}$ or $\mathrm{CD}_{3} \mathrm{OD}$ ) were titrated with a standard solution of the anion guest up to a ten-fold molar excess. Table 2 shows the maximum complexation induced NMR shifts (CIS) of the protons used to calculate the given association constants $\left(K_{\mathrm{a}}\right)$ and the complex stoichiometries, the latter determined by Jobs method of continuous variation (Fig. S1-S6, ESI $\dagger)^{28}$

The titrations performed in DMSO- $\mathrm{d}_{6}$ were accompanied by pronounced downfield shifts of the urea protons (FM1) or imidazolium (FM2-FM4) ring protons, indicative of hydrogen bonding dominating in the former case (FM1) or contributing in the latter (FM2-FM4) to the host guest interactions. These signals were absent when performing the titrations in $\mathrm{CD}_{3} \mathrm{OD}$ which indicates enhanced exchange of these protons or host deprotonation in this solvent. The reported CIS values refer in this case to the FM1 aryl or the FM2-FM4 vinyl protons. The signals that could be monitored throughout the titration were used to calculate free and bound concentrations and the association constants from the resulting binding curve fitted to a $1: 1$ or a cooperative binding model using the Langmuir (1) or Hill (2) equations, respectively.
Considering first the relative complex stabilities involving the monofunctional monomers FM1 and FM2, the monotetrabutylammonium salt (PPA.TBA) was used as a monoanion guest in order to promote formation of $1: 1$ complexes. We were interested to see how protic versus nonprotic solvents of different polarity influenced the interactions. After having confirmed the $1: 1$ stoichiometry from the Job's plots in DMSO, the 1:1 binding model was used in order to determine the respective association constants. As seen in Table 2 the urea monomer FM1 formed the more stable complexes $\left(K_{\mathrm{a}}=7350 \mathrm{M}^{-1}\right.$ for FM1 versus $K_{\mathrm{a}}=82 \mathrm{M}^{-1}$ for FM2) in DMSO- $\mathrm{d}_{6}$, whereas no interactions were observed for any of the monofunctional host monomers when probing binding in the protic solvent $\mathrm{CD}_{3} \mathrm{OD}$. This speaks in favor of hydrogen bonding as the dominating interaction and agrees with previous literature reports on urea and imidazolium receptors. ${ }^{2}$

A different behavior was observed for receptor FM3 which features two cationic sites and, like FM1, two hydrogen bond donor sites. Relative to FM1, also this monomer interacted more weakly with the monoanion guest (PPA.TBA) in DMSO- $\mathrm{d}_{6}$ $\left(K_{\mathrm{a}}=266 \mathrm{M}^{-1}\right)$ whereas, in contrast to FM2, binding of the guest could in this case be detected in $\mathrm{CD}_{3} \mathrm{OD}(\mathrm{CIS}=0.015 \mathrm{ppm})$. This agrees with the presence of a strong electrostatic contribution to the binding. Being designed to complex the dianion in a presumed 1:1 stoichiometry we tested their ability to complex PPA.2TBA. The divalent anion interacted strongly with FM3, as viewed by the steep CIS plots (Fig. S4, ESI $\dagger$ ). The sigmoidal shape of the curve and the Jobs plots reveal that the binding was cooperative with an apparent association constant of $K_{\mathrm{a}}=1680 \mathrm{M}^{-1}$ and a preferred $1: 2$ host-guest stoichiometry. Apparantly, binding of the first guest equivalent induces a host conformation complementary to a second guest equivalent. This unusual stoichiometry has also been observed for bis-imidazolium hosts interacting with singly charged phosphate ions and has either been attributed to binding-induced conformational changes $^{32}$ in the host or left without explanation. ${ }^{33}$ Attempts to gain more detailed structural information from 2-dimensional NMR or crystal structures proved fruitless. Nevertheless, given the lack of interaction between the mono-imidazolium monomer FM2 and the phosphonate guest in methanol, the structure of the termolecular complex between FM3 and PPA.2TBA must

Table 2 Association constants, stoichiometries, complexation induced shifts and Hill slopes for complexes formed between functional monomers FM1-FM4 and tetrabutylammonium salts of phenylphosphonic acid (PPA) guests in DMSO- $\mathrm{d}_{6}$ or $\mathrm{CD}_{3} \mathrm{OD}$

\begin{tabular}{|c|c|c|c|c|c|c|c|}
\hline Host & Guest & Solvent & Proton & $K_{\mathrm{a}}^{a}\left(\mathrm{M}^{-1}\right)$ & Cplx. (H: G) & $\mathrm{CIS}^{a}(\mathrm{ppm})$ & $h^{a}$ \\
\hline FM1 & PPA.TBA & $\mathrm{d}_{6}$-DMSO & $\mathrm{NH}(15,21)$ & $7350 \pm 320$ & $1: 1$ & 2.90 & 1.0 \\
\hline FM1 & PPA.TBA & $\mathrm{CD}_{3} \mathrm{OD}$ & $\mathrm{CH}(2,4)$ & $\mathrm{n} / \mathrm{a}^{b}$ & $\mathrm{n} / \mathrm{a}^{b}$ & $\mathrm{n} / \mathrm{a}^{b}$ & $\mathrm{n} / \mathrm{a}$ \\
\hline FM2 & PPA.TBA & $\mathrm{d}_{6}$-DMSO & CH (8) & $82 \pm 5$ & $1: 1$ & 1.07 & 1.0 \\
\hline FM2 & PPA.TBA & $\mathrm{CD}_{3} \mathrm{OD}$ & $\mathrm{CH}(9)$ & $\mathrm{n} / \mathrm{a}^{b}$ & $\mathrm{n} / \mathrm{a}^{b}$ & $\mathrm{n} / \mathrm{a}^{b}$ & $\mathrm{n} / \mathrm{a}^{b}$ \\
\hline FM3 & PPA.TBA & $\mathrm{d}_{6}$-DMSO & $\mathrm{CH}(7,8)$ & $266 \pm 17$ & $1: 1$ & 0.23 & 1.0 \\
\hline FM3 & PPA.TBA & $\mathrm{CD}_{3} \mathrm{OD}$ & $\mathrm{CH}(2,22)$ & $\mathrm{n} / \mathrm{a}^{c}$ & $1: 1$ & $0.015^{d}$ & $\mathrm{n} / \mathrm{a}$ \\
\hline FM3 & PPA.2TBA & $\mathrm{CD}_{3} \mathrm{OD}$ & $\mathrm{CH}(2,22)$ & $1680 \pm 121$ & $1: 2$ & 0.15 & 1.9 \\
\hline FM4 & PPA.TBA & $\mathrm{d}_{6}$-DMSO & $\mathrm{CH}(8)$ & $332 \pm 16$ & $1: 1 / 1: 2$ & 0.82 & 1.1 \\
\hline
\end{tabular}

${ }^{a}$ Association constants $\left(K_{\mathrm{a}}\right)$, complexation induced shifts (CIS) and Hill slope $(h)$ based on the shift values of the resonance signals indicated.

Association constants $\left(K_{\mathrm{a}}\right)$, complexation induced shifts (CIS) and Hill slope $(h)$ based on the shift values of the resonance signals indicated.
${ }^{b}$ Titration and Job's experiment did not result in any observable CIS. ${ }^{c}$ Determination of $K_{\mathrm{a}}$ was not possible due to lack of curvature. ${ }^{d}$ The value represents CIS of sample with 10 equivalents of guest. 
involve both imidazolium groups simultaneously coordinating the two phosphonate guests. Assuming both imidazolium moieties in an anti conformation with respect to the pyridine ring plane, it is likely that binding of the first guest equivalent is a slow process due to the rearrangements involved. This may however open up a tight site allowing a second guest molecule to bind from the back side of the pyridine moiety.

Further studies are under way to elucidate the nature of these interactions.

\section{Polymer preparation and characterization}

Having established the potency of the bis-imidazolium tweezer monomer FM3 to complex phosphonates in methanol we turned our attention to the polymer preparation. We wanted first to see whether the binding behavior in solution would be reflected in the ability of the corresponding MIPs to recognize and bind phosphorylated amino acid guests. Hence a series of polymers were prepared using Fmoc-pTyrOEt as template according to the description in Table 1.

The polymers were prepared using the functional monomers in a $2: 1(\mathrm{P} 1, \mathrm{P} 2, \mathrm{P} 5)$ or $1: 1(\mathrm{P} 3, \mathrm{P} 4)$ stoichiometric ratios to template (Table 1). With P3 and P4 we wanted to investigate the influence of porogen polarity on polymer properties. Nonimprinted polymers were prepared identically to the imprinted polymers but omitting the template. Acrylamide was added as a supplementary monomer to provide additional hydrogen bond stabilization and pentaerytritoltriacrylate (PETA) was used as crosslinking monomer in the indicated solvents. Conventional azo-initiated thermal polymerization at $50{ }^{\circ} \mathrm{C}$ subsequently afforded the imprinted and nonimprinted polymers. The polymers were crushed and sieved to a $25-36 \mu \mathrm{m}$ particle size fraction obtained after crushing and sieving the polymers were subjected to template removal by washing with acidic methanol, followed by extraction with methanol using a Soxhlet apparatus. The polymers were characterized by IR-spectroscopy (Fig. S8, ESI $\dagger$ ) and swelling measurements (see Table 1) which confirmed their identity and verified that they were comparable, in terms of morphology and composition.

\section{Template rebinding tests}

Simple binding tests were conducted in order to compare the polymers with respect to their ability to recognize and bind the template in the protic solvent methanol. Fig. 3 shows the binding constants and capacity estimated by non-linear curve fitting of the data in Fig. S7 (ESI $\dagger$ ) assuming a Langmuir monosite binding model. The ranking of the polymers in terms of binding constants agrees overall with the relative host affinities for PPA obtained from the NMR titrations in solution. Thus P1 prepared using the neutral urea host failed as expected to bind the template in $\mathrm{MeOH}$. On the contrary, P2 and P5 prepared from the cationic host FM2 and the hybrid design FM5 both showed imprinting and enhanced binding capacity in methanol. All imidazolium-based imprinted polymers displayed capacities approaching the nominal capacity expected based on the amount of added template (dashed line in Fig. 3) indicating that the imprinting was nearly stoichiometric.

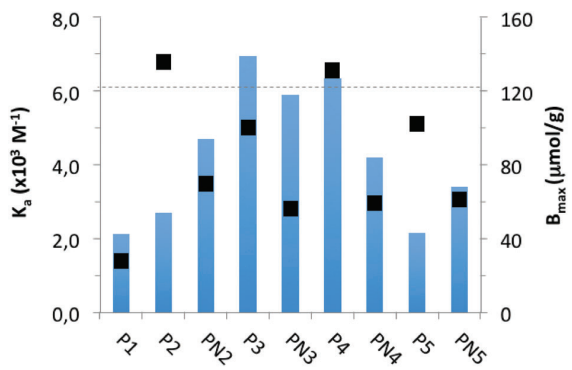

Fig. 3 Association constants ( $K_{\mathrm{a}}$; blue bars) and binding capacities ( $B_{\max }$, black squares) for Fmoc-pTyrOH interacting with imprinted (P1-P5) and nonimprinted (PN2-PN5) polymers in methanol. The binding parameters were obtained by fitting of the binding data in Fig. S7 (ESI†) to a Langmuir monosite binding model. The dashed line represents a $B_{\max }$ corresponding to the nominal capacity of the materials assuming quantitative template incorporation

Also in agreement with the solution binding data, the bisimidazolium tweezers of MIPs P3 and P4 displayed the highest affinity for the template with P4 being superior to P3 presumably since it was prepared in a less competitive solvent system.

\section{Microliquid chromatography ( $\mu$-LC)}

Microliquid chromatography using the capillary column format is an attractive technique for separation problems requiring low sample loads and mass spectrometry interfacing. These needs apply in the proteomics area where sample volumes are strongly limited but where the demand for detection sensitivity and selectivity is high. In order to shrink the imprinted polymers to match the $\mu$-LC format we made use of our previously reported technique based on grafting of imprinted polymer layers onto flow-through poly-TRIM monoliths utilizing unreacted surface double bonds as anchor points. Thus, imprinted and nonimprinted capillaries for both phosphotyrosine and phosphoserine using the FM3 bis-imidazolium based host monomer were prepared for use in the $\mu$-LC-mode. The morphological structure investigated by field emission scanning electron microscopy (FESEM, Fig. 4 and Fig. S9, ESI $\dagger$ ) showed the high porosity and good homogeneity, which is essential to ensure fast mass transport and low back-pressure - factors advantageous to the enhancement of separation performance. As is seen, the three-dimensional skeletal structure was retained after the photo-grafting step and a significant loss of pores could not be seen up to the maximum magnification of $125 \mathrm{k}$.

Fig. 5 shows the elution profiles of a mixture of two nonphosphorylated Fmoc amino acids and their two phosphorylated counterparts injected on the nonimprinted (NIP), pS-imprinted (pS-MIP) and pY-imprinted (pY-MIP) capillary monoliths using as eluent high (95\% ACN) and low organic $(10 \% \mathrm{ACN})$ mobile phases. It is obvious that the NIP had no recognition capability for any of these four amino acids and exhibited minimal nonspecific interactions, since all the amino acids eluted very close to the void volume with both the organic rich and the mainly aqueous mobile phases. On the contrary, the phosphorylated 


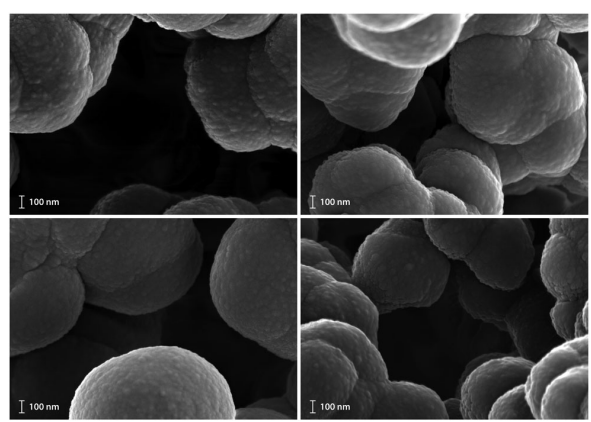

Fig. 4 Scanning electron micrographs of TRIM capillary (upper left) and grafted nonimprinted polymer (NIP) (upper right), pS-imprinted (pS-MIP) (lower left) and pY-imprinted (pY-MIP) capillary monolith (lower right).

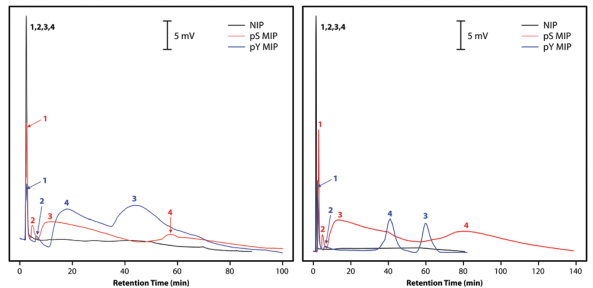

Fig $5 \mu-L C$ chromatograms acquired after injection of amino acids mixture on NIP and MIP capillary monoliths. Amino acids peaks: Fmoc$\mathrm{SerOH}$ (1); Fmoc-TyrOH (2); Fmoc-pTyrOH (3); Fmoc-pSerOH (4). $\mu$-LC conditions: mobile phase, left: $\mathrm{ACN} / \mathrm{H}_{2} \mathrm{O}(0.1 \%$ TFA) (95/5), right: $\mathrm{ACN} /$ HEPES buffer (100 mM, pH 7.4) (10/90); flow rate, $4 \mu \mathrm{L} \mathrm{min}^{-1}$; monitoring, $\mathrm{UV}$ at $254 \mathrm{~nm}$; injection volume, $35 \mathrm{~nL}$.

Fmoc amino acids (Fmoc-pTyrOH and Fmoc-pSerOH) had high retention on the imprinted monoliths. The selectivity also matched the imprinted epitope, i.e., Fmoc-pSerOH had higher retention than Fmoc-pTyrOH on the $\mathrm{pS}$ MIP and vice versa. Some retention was also seen for the unphosphorylated Fmoc amino acids on both the imprinted monoliths, albeit substantially lower than the retention shown by their phosphorylated counterparts. It is thereby evident that the capillary monoliths imprinted by surface grafting retained a strong and specific retention for the phosphorylated amino acids under these radically different solvent conditions.

Likewise, when a mixture of four model human Angiotensin II peptide homologues consisting of two nonphosphorylated (DRVSIHPF and DRVYIHPF) and the corresponding phosphory-

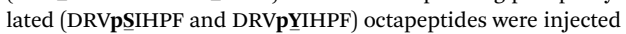
(Fig. 6) the chromatographic behavior showed similarly strong selectivites and absence of non-specific interactions.

Again, distinct high affinities were observed for the phosphorylated peptides on the pS and pY imprinted capillary monoliths compared to their NIP counterparts. Accordingly, the

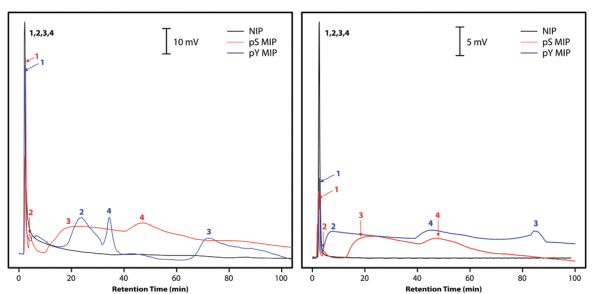

Fig. $6 \mu$-LC chromatograms acquired after injection of a mixture of human Angiotensin II octapeptides on NIP and MIP capillary monoliths. Peptides peaks: DRVSIHPF (1); DRVYIHPF (2); DRVpYIHPF (3); DRVpSIHPF (4). $\mu$-LC conditions: mobile phase, left: $\mathrm{ACN} / \mathrm{H}_{2} \mathrm{O}(0.1 \%$ TFA) $(95 / 5)$, right: ACN/HEPES buffer (100 mM, pH 7.4) (10/90); flow rate, $4 \mu \mathrm{L} \mathrm{min}{ }^{-1}$. monitoring, UV at $210 \mathrm{~nm}$; injection volume, $35 \mathrm{~nL}$.

$\mathrm{pS} / \mathrm{pY}$ imprinted monolith displayed corresponding preference for the $\mathrm{pS} / \mathrm{pY}$ peptide, respectively. It is particularly noteworthy that both the relative retentivity and resolution prevailed in buffered media with the pY-MIP showing somewhat higher selectivity and better discrimination performance compared to the pS-MIP. These results prove the successful application of epitope imprinting using single amino acid as a template to create PTM specific sites also for oligopeptides, even when the phosphorylation sites are located well away from the terminals.

\section{Conclusions}

Imprinted receptors for phosphorylated proteins have been proven to be particularly powerful in extracting very low levels of phosphorylated biomarkers from tryptic digests. ${ }^{23}$ In order to extend the solvent compatibility of such receptors to water and thereby be able to target proteins in their natural environment we have shown that a bis-imidazolium monomer as cationic host predesigned to bind divalent oxyanions by combined ionic and hydrogen bonding interactions can in principle be used for this purpose. These receptors can be used for selective enrichments and display a remarkable crossreactivity with phosphorylated peptides in buffered media. The programmable selectivity allows a completely inversed elution order of a phosphoserine and a phosphotyrosine model peptides, having an otherwise identical amino acid sequence, with the exception of the phosphosite.

\section{Acknowledgements}

This work was supported by the EU-funded Marie Curie ITN project PEPMIP (PITN-GA-2010-264699). We also appreciate the technical training of Dr. Cheng Choo Lee from the Umeå Core Facility Electron Microscopy in obtaining the FESEM images.

\section{References}

1 M. J. Langton, C. J. Serpell and P. D. Beer, Angew. Chem., Int. Ed., 2016, 55, 1974-1987. 
2 A. E. Hargrove, S. Nieto, T. Zhang, J. L. Sessler and E. V. Anslyn, Chem. Rev., 2011, 111, 6603-6782.

3 N. Busschaert, C. Caltagirone, W. Van Rossom and P. A. Gale, Chem. Rev., 2015, 115, 8038-8155.

4 Z. Xu, S. K. Kim and J. Yoon, Chem. Soc. Rev., 2010, 39 1457-1466.

5 M. J. Whitcombe, N. Kirsch and I. A. Nicholls, J. Mol. Recognit., 2014, 27, 297-401.

6 B. Sellergren and A. J. Hall, in Supramolecular Chemistry: from Molecules to Nanomaterials, ed. J. W. Steed and P. A. Gale, John Wiley \& Sons Ltd, Chichester, UK, 2012, pp. 3255-3282.

7 K. Haupt and C. Ayela, Molecular Imprinting, Springer, 2012

8 R. Schirhagl, Anal. Chem., 2013, 86, 250-261.

9 G. Vasapollo, R. D. Sole, L. Mergola, M. R. Lazzoi, A. Scardino, S. Scorrano and G. Mele, Int. J. Mol. Sci., 2011, 12, 5908 .

10 W. J. Cheong, S. H. Yang and F. Ali, J. Sep. Sci., 2013, 36, 609-628.

11 X. Wu, Microchim. Acta, 2012, 176, 23-47.

12 J. Q. Fu, L. X. Chen, J. H. Li and Z. Z. Zhang, J. Mater. Chem A, 2015, 3, 13598-13627.

13 J. V. Beach and K. J. Shea, J. Am. Chem. Soc., 1994, 116 , 379-380.

14 G. Wulff, T. Gross and R. Schönfeld, Angew. Chem., Int. Ed. Engl., 1997, 36, 1962-9164.

15 A. Cutivet, C. Schembri, J. Kovensky and K. Haupt, J. Am Chem. Soc., 2009, 131, 14699-14702.

16 A. J. Hall, P. Manesiotis, M. Emgenbroich, M. Quaglia, E. De Lorenzi and B. Sellergren, J. Org. Chem., 2005, 70, 1732-1736.

17 L. Urraca Javier, J. Hall Andrew, C. Moreno-Bondi Maria and B. Sellergren, Angew. Chem., Int. Ed. Engl., 2006, 45, 5158-5161.

18 M. Emgenbroich, C. Borrelli, S. Shinde, I. Lazraq, F. Vilela A. J. Hall, J. Oxelbark, E. De Lorenzi, J. Courtois, A. Simanova, J. Verhage, K. Irgum, K. Karim and B. Sellergren, Chem. - Eur. J., 2008, 14, 9516-9529.
19 A. Kugimiya and H. Takei, Anal. Chim. Acta, 2006, 564, 179-183.

20 A. Kugimiya and H. Takei, Anal. Lett., 2008, 41, 302-311.

21 S. Shinde, Z. El-Schich, A. Malakpour, W. Wan, N. Dizeyi, R. Mohammadi, K. Rurack, A. Gjörloff Wingren and B. Sellergren, J. Am. Chem. Soc., 2015, 137, 13908-13912.

22 S. Shinde, A. Bunschoten, J. A. W. Kruijtzer, R. M. J. Liskamp and B. Sellergren, Angew. Chem., Int. Ed., 2012, 51, 8326-8329.

23 J. Chen, S. Shinde, M.-H. Koch, M. Eisenacher, S. Galozzi, T. Lerari, K. Barkovits, P. Subedi, R. Krüger, K. Kuhlmann, B. Sellergren, S. Helling and K. Marcus, Sci. Rep., 2015, $5,11438$.

24 S. K. Kim, N. J. Singh, S. J. Kim, H. G. Kim, J. K. Kim, J. W. Lee K. S. Kim and J. Yoon, Org. Lett., 2003, 5, 2083-2086.

25 J. Y. Kwon, N. J. Singh, H. N. Kim, S. K. Kim, K. S. Kim and J. Yoon, J. Am. Chem. Soc., 2004, 126, 8892-8893.

26 S. Ambrosini, M. Serra, S. Shinde, B. Sellergren and E. De Lorenzi, J. Chromatogr. A, 2011, 1218, 6961-6969.

27 P. Narayanaswamy, S. Shinde, R. Sulc, R. Kraut, G. Staples, C. H. Thiam, R. Grimm, B. Sellergren, F. Torta and M. R. Wenk, Anal. Chem., 2014, 86, 3043-3047.

28 K. A. Connors, Binding constants. The measurement of molecular complex stability, John Wiley \& Sons, New York, 1987.

29 I. Gusev, X. Huang and C. Horvath, J. Chromatogr. A, 1999, 855, 273-290.

30 J. Courtois, M. Szumski, E. Byström, A. Iwasiewicz, A. Shchukarev and K. Irgum, J. Sep. Sci., 2006, 29, 14-24.

31 J. Courtois, G. Fischer, S. Schauff, K. Albert and K. Irgum, Anal. Chem., 2006, 78, 580-584.

32 K. Ghosh and D. Kar, Beilstein J. Org. Chem., 2011, 7, 254-264.

33 S. K. Kim, D. Seo, S. J. Han, G. Son, I.-J. Lee, C. Lee, K. D. Lee and J. Yoon, Tetrahedron, 2008, 64, 6402-6405.

34 T. R. K. Reddy, C. Li, X. Guo, P. M. Fischer and L. V. Dekker, Bioorg. Med. Chem., 2014, 22, 5378-5391. 


\section{Malmö University Health and Society Doctoral Dissertations}

Ross, M. W. Typing, doing and being. A study of men who have sex with men and sexuality on the Internet. 2006:1

Stoltz, P. Searching for meaning of support in nursing. A study on support in family care of frail aged persons with examples from palliative care at home. 2006:2

Gudmundsson, P. Detection of myocardial ischemia using real-time myocardial contrasts echocardiograpy. 2006:3

Holmberg, L. Communication in palliative home care, grief and bereavement. A mother's experiences. 2007:1

$\mathrm{Ny}, \mathrm{P}$. Swedish maternal health care in a multiethnic society - including the fathers. 2007:2

Schölin, T. Etnisk mångfald som organisationsidé. Chefs- och personalpraktiker i äldreomsorgen. 2008:1

Svensson, O. Interactions of mucins with biopolymers and drug delivery particles. 2008:2

Holst, M. Self-care behaviour and daily life experiences in patients with chronic heart failure. 2008:3

Bahtsevani, C. In search of evidence-based practices. Exploring factors influencing evidence-based practice and implementation of clinical practice guidelines. 2008:4

Andersson, L. Endocytosis by human dendritic cells. 2009:1 .

Svendsen, I. E. In vitro and in vivo studies of salivary films at solid/liquid interfaces. 2009:2.

Persson, K. Oral health in an outpatient psychiatric population. Oral status, life satisfaction and support. 2009:3.

Hellman, P. Human dendritic cells. A study of early events during pathogen recognition and antigen endocytosis. 2009:4.

Baghir-Zada, R. Illegal aliens and health (care) wants. The cases of Sweden and the Netherlands. 2009:5.

Stjernswärd, S. Designing online support for families living with depression. 2009:6.

Carlsson, A. Child injuries at home - prevention, precautions and intervention with focus on scalds. 2010:1. 
Carlson, E. Sjuksköterskan som handledare. Innehåll i och förutsättningar för sjuksköterskors handledande funktion i verksamhetsförlagd utbildning en etnografisk studie. 2010:2.

Sinkiewicz, G. Lactobacillus reuteri in health and disease. 2010:3.

Tuvesson, H. Psychiatric nursing staff and the workplace. Perceptions of the ward atmosphere, psychosocial work environment, and stress. 2011:1.

Ingvarsdotter, K. Mental ill health and diversity. Researching human suffering and resilience in a multicultural context. 2011:2.

Hamit-Eminovski, J. Interactions of biopolymers and metal complexes at biological interfaces. 2011:3.

Mellgren, C. What's neighbourhood got to do with it? The influence of neighbourhood context on crime and reactions to crime. 2011:4.

Annersten Gershater, M. Prevention of foot ulcers in patients with diabetes mellitus. Nursing in outpatient settings. 2011:5.

Pooremamali P. Culture, occupation and occupational therapy in a mental care context- the challenge of meeting the needs of Middle Eastern immigrants. 2012:1

Gustafsson A. Aspects on sepsis: treatment and markers. 2012:2

Lavant, E. Multiplex HLA-DR-DQ genotyping. For genetic epidemiology and clinical risk assessment. 2012:3

Wangel, A-M. Mental ill-health in childbearing women. Markers and risk factors. 2012:4

Scaramuzzino, R. Equal opportunities? - A cross-national comparison of immigrant organisations in Sweden and Italy. 2012:5

Ivert, A-K. Adolescent mental health and utilisation of psychiatric care - The role of parental country of birth and neighbourhood of residence 2013:1

Znamenskaya, Y. Effect of hydration on thermodynamic, rheological and structural properties of mucin. 2013:2

Andersson, F. The female offender. Patterning of antisocial and criminal activity over the life-course. 2013:3

Lindroth, M. Utsatthet och sexuell hälsa - en studie om unga på statliga ungdomshem. 2013:4

Hulusjö, A. The multiplicities of prostitution experience - narratives about power and resistance. 2013:5 
Falk, M. Direct electron transfer based biofuel cells. Operation in vitro and in vivo. 2014:1

Finnbogadóttir, H. Exposure to domestic violence during pregnancy. Impact on outcome, midwives' awareness, women's experience and prevalence in the south of Sweden. 2014:2

Fagerström, A. Effects of surfactant adjuvants on barrier properties of plant leaf cuticle. 2014:3

Lamberg, P. Design and characterization of direct electron transfer based biofuel cells including tests in cell cultures. 2014:4

Richert, T. Överdoser, försörjningsstrategier och riskhantering - livsvillkor för personer som injicerar narkotika. 2014:5

Örmon, K. Experiences of abuse during the life course. - Disclosure and the care provided among women in a general psychiatric context. 2014:6

Sjöblom, I. Planerade hemförlossningar i Norden - kvinnors och barnmorskors perspektiv. 2014:7

Albèr, C. Humectants and Skin - Effects of hydration from molecule to man. 2015:1

Kisch M., A. Allogeneic stem cell transplantation. - Patients' and sibling donors' perspectives. 2015:2

Weiber, I. Children in families where the mother has an intellectual or developmental disability - incidence, support and first person perspectives. 2015:3

Schlyter, M. Myocardial infarction, Personality factors, Coping strategies, Depression and Secondary prevention 2016:1

Carlström, C. BDSM - Paradoxernas praktiker. 2016:2

El-Schich, Z. Novel imaging technology and tools for biomarker detection in cancer. 2016:3

Boonsatean, W. Living with type 2 diabetes in Thai population: Experiences and socioeconomic characteristics. 2016:4

Vejzovic, V. Going through a colonoscopy and living with inflammatory bowel disease: Children's and parents' experiences and evaluation of the bowel cleansing quality prior to colonoscopy. 2016:5

Isma, G.E. Overweight and obesity in young children: Preventive work in child health care with focus on nurses' perceptions and parental risk factors. 2016:6 
Brännvall, M. Frigörelse med förhinder - Om polisanmälan när kvinnor tar sig ur mäns våld i nära relationer. 2016:7

Pankratov, D. Self-charging biosupercapacitors. 2016:8

Guidi, P. Social work assessment of families with children at risk: Similarities and differences in Italian and Swedish public social services. 2016:9

Jakobsson, J. The process of recovery after colorectal cancer surgery: Patients' experiences and factors of influence. 2017:1

Gerell, M. Neighborhoods without community. Collective efficacy and crime in Malmö, Sweden. 2017:2

Wierzbicka, C. New fractionation tools targeting elusive post-translational modifications. 2017:3

The publications are available on-line.

See www.mah.se/muep 

ISBN 978-9I-7 IO4-728-I(print)

ISBN 978-9I-7IO4-729-8 (pdf)

ISSN $1653-5383$

MALMÖ UNIVERSITY 20506 MALMÖ, SWEDEN WWW.MAH.SE 